A11202 4612288

MATL INST OF STANDAADS \& TECH A.I.C.

\title{
Smoke Control at Veterans Administration Hospitals
}

\section{Reference}

NBS

PUBLICATIONS

John H. Klote

U.S. DEPARTMENT OF COMMERCE

National Bureau of Standards

National Engineering Laboratory

Center for Fire Research

Gaithersburg, MD 20899

January 1986

Sponsored by:

Veterans Administration

QC $\quad$ ice of Construction Research $\mathbf{0 8 H}$

100 shington, DC 20420

456 



\section{SMOKE CONTROL AT VETERANS} ADMINISTRATION HOSPITALS

John H. Klote

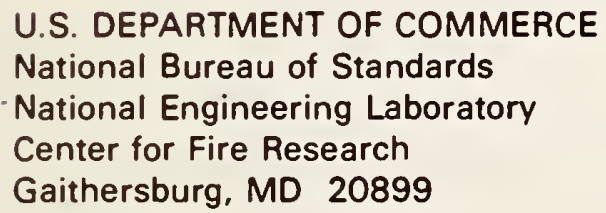

January 1986

Sponsored by:

Veterans Administration

Office of Construction Research $\mathrm{O} 8 \mathrm{H}$

Washington, DC 20420

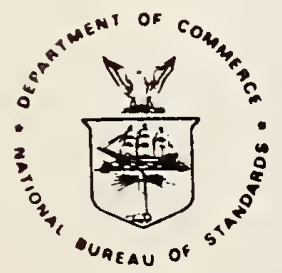





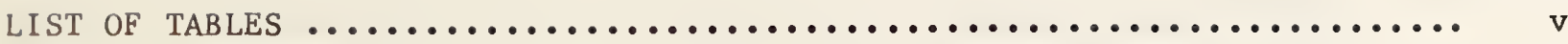

LIST OF FIGURES $\ldots \ldots \ldots \ldots \ldots \ldots \ldots \ldots \ldots \ldots \ldots \ldots \ldots \ldots \ldots \ldots \ldots \ldots \ldots \ldots \ldots \ldots$ viii

Abstract $\ldots \ldots \ldots \ldots \ldots \ldots \ldots \ldots \ldots \ldots \ldots \ldots \ldots \ldots \ldots \ldots \ldots \ldots \ldots \ldots \ldots \ldots \ldots \ldots \ldots \ldots$

1. INTRODUCTION $\ldots \ldots \ldots \ldots \ldots \ldots \ldots \ldots \ldots \ldots \ldots \ldots \ldots \ldots \ldots \ldots \ldots \ldots \ldots \ldots \ldots \ldots \ldots$

2. SMOKE MANAGEMENT $\ldots \ldots \ldots \ldots \ldots \ldots \ldots \ldots \ldots \ldots \ldots \ldots \ldots \ldots \ldots \ldots \ldots \ldots \ldots \ldots \ldots \ldots . \ldots \ldots$

3. PRINCIPLES OF SMOKE CONTROL ........................... 3

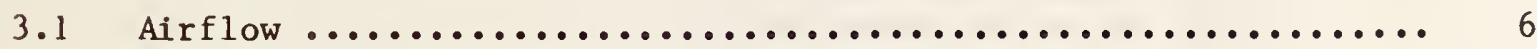

3.2 Pressurization $\ldots \ldots \ldots \ldots \ldots \ldots \ldots \ldots \ldots \ldots \ldots \ldots \ldots \ldots \ldots \ldots \ldots . \ldots \ldots$

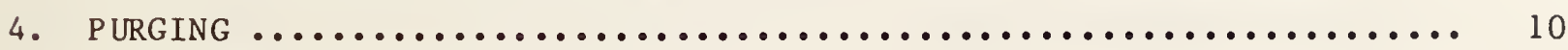

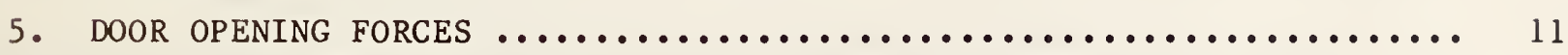

6. BUILDING AIR FLOW ANALYSIS ............................ 12

7. FLOW AREAS AND EFFECTIVE FLOW AREAS ..................... 13

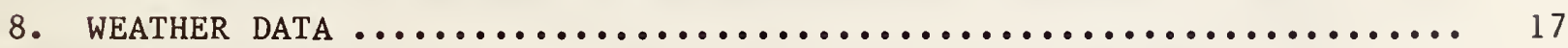

9. SYSTEM PERFORMANCE ................................... 19

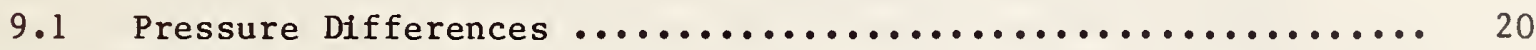

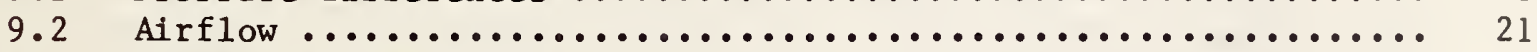

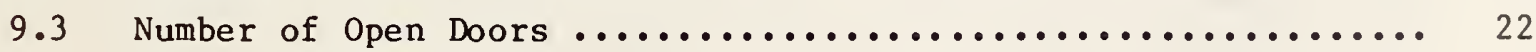

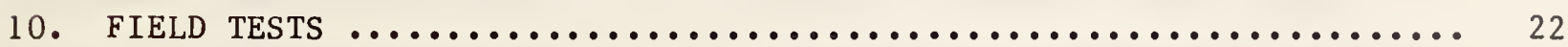

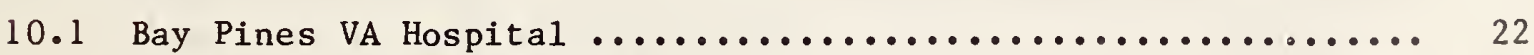

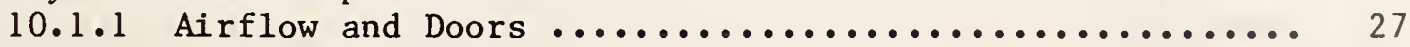

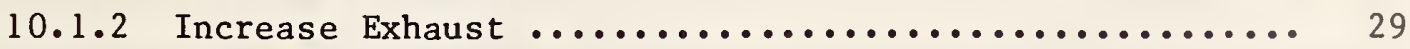

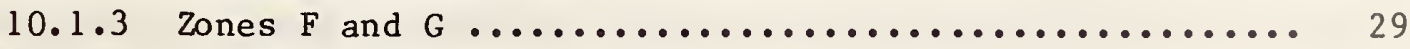

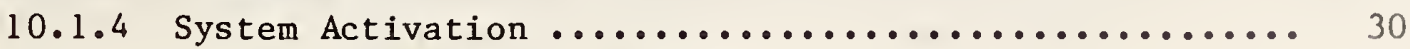

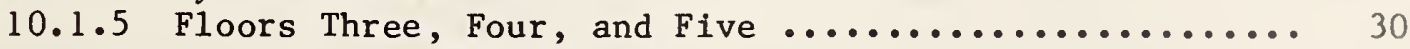

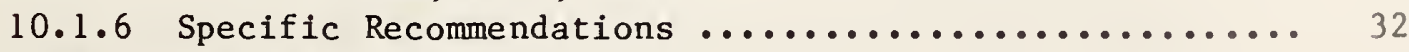

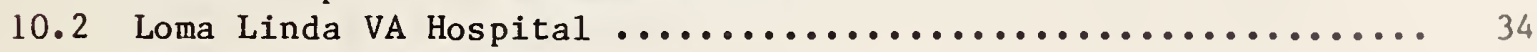

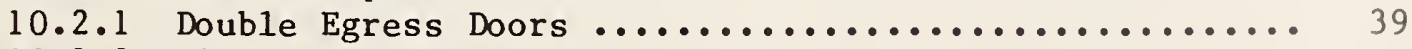

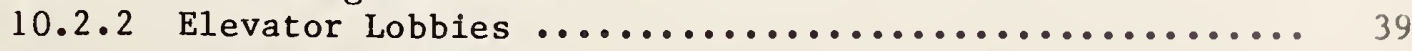

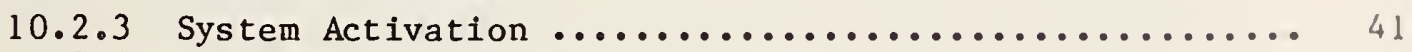

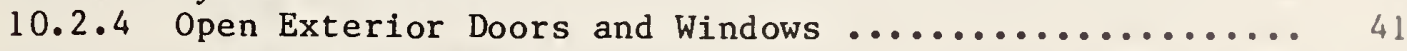

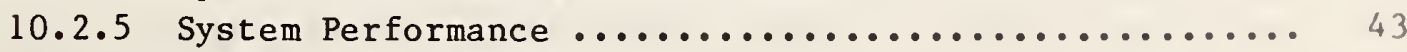

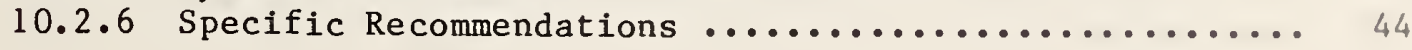


10.3 San Diego VA Hospita1 ......................... 44

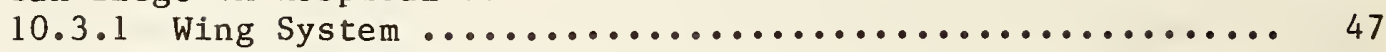

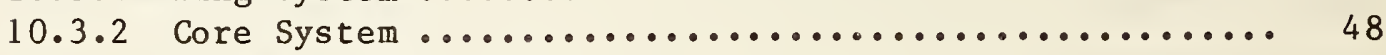

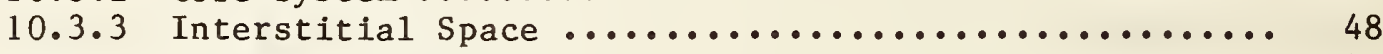

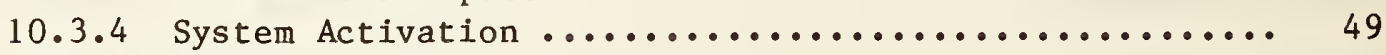

10.4 Martinsburg VA Hos pital ......................... 49

10.5 Richmond VA Hospita1 .......................... 50

11. SMOKE CONTROL SYSTEMS ............................. 52

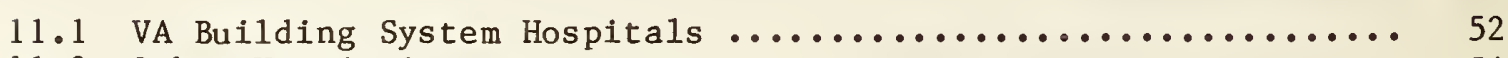

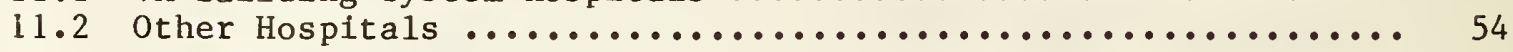

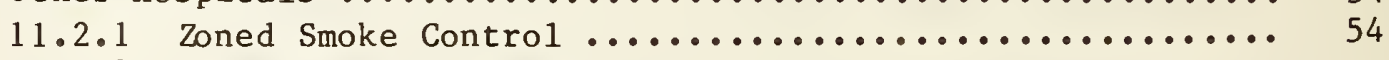

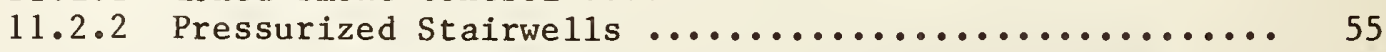

11.2 .3 Elevator Smoke Control $\ldots \ldots \ldots \ldots \ldots \ldots \ldots \ldots \ldots \ldots \ldots \ldots . \ldots \ldots$

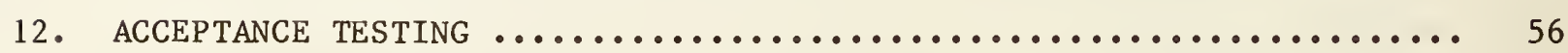

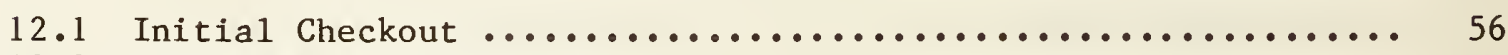

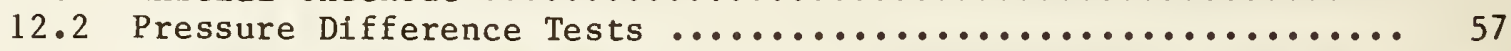

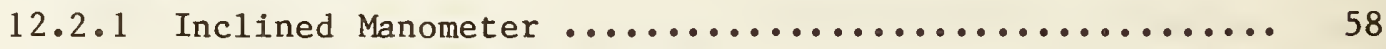

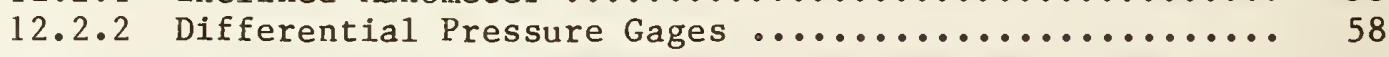

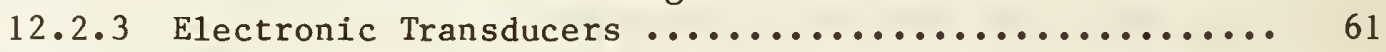

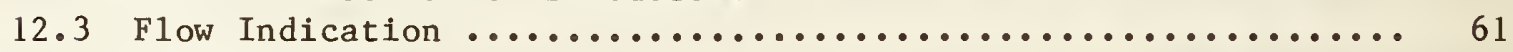

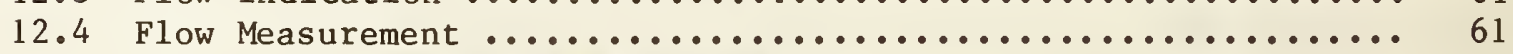

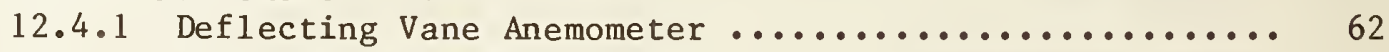

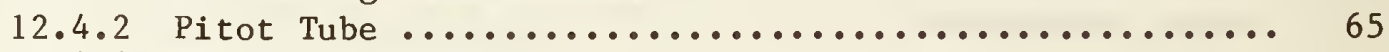

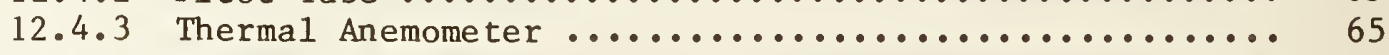

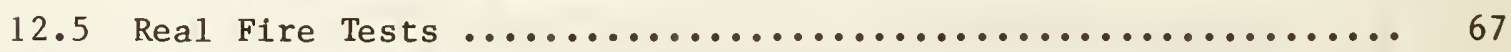

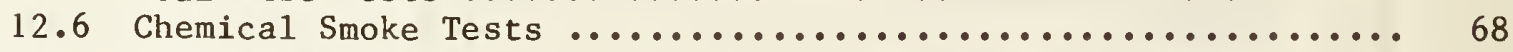

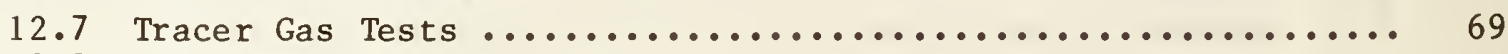

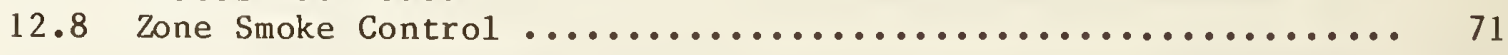

13. SUMMARY AND RECOMMENDATIONS .......................... 71

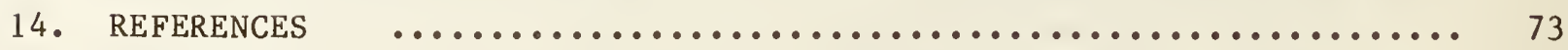

APPENDIX A. Typical Leakage Areas for Walls and Floors of Commercial

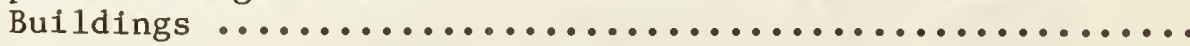


Table 1. Smoke control test of VA Bay Pines Hospital, first floor,

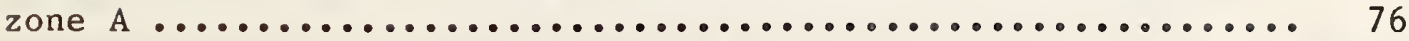

Table 2. Smoke control test of VA Bay Pines Hospital, first floor,

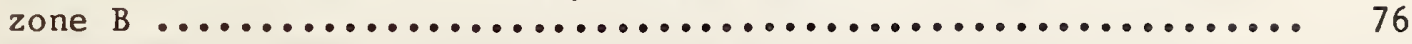

Table 3. Smoke control test of VA Bay Pines Hospital, first floor,

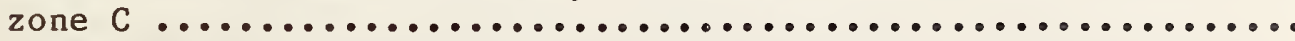

Table 4. Smoke control test of VA Bay Pines Hospital, first floor,

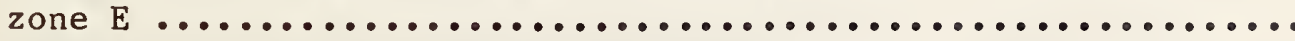

Table 5. Smoke control test of VA Bay Pines Hospital, first floor,

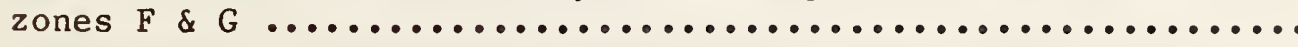

Table 6. Smoke control test of VA Bay Pines Hospital, first floor, zone $\mathrm{H}$

Table 7. Smoke control test of VA Bay Pines Hospital, first floor, zone J ......................................

Table 8. Smoke control test of VA Bay Pines Hospital, third floor,

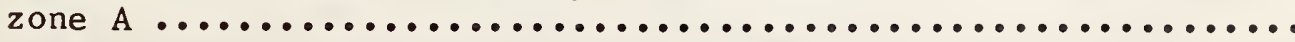

Table 9. Smoke control test of VA Bay Pines Hospital, third floor, zone $B$

Table 10. Smoke control test of VA Bay Pines Hospital, third floor, zone $\mathrm{C}$

Table 11. Smoke control test of VA Bay Pines Hospital, third floor, zone D

Table 12. Smoke control test of VA Bay Pines Hospital, fourth floor, zone A

Table 13. Smoke control test of VA Bay Pines Hospital, fourth floor, zone B

Table 14. Smoke control test of VA Bay Pines Hospita1, fourth floor,

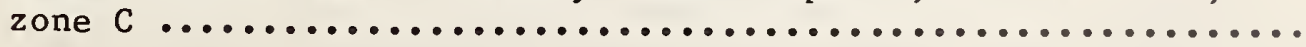

Table 15. Smoke control test of VA Bay Pines Hospital, fourth floor,

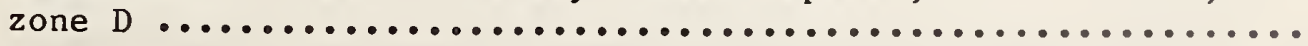

Table 16. Smoke control test of VA Bay Pines Hospital, fifth floor, zone A 
Table 17. Smoke control test of VA Bay Pines Hospital, fifth floor,

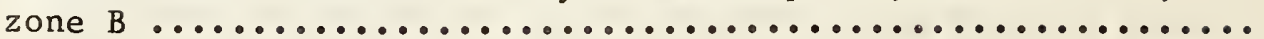

Table 18. Smoke control test of VA Bay Pines Hospital, fifth floor,

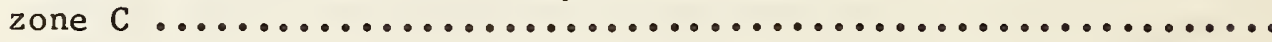

Table 19. Smoke control test of VA Bay Pines Hospital, fifth floor,

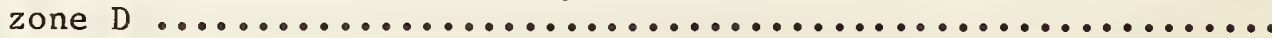

Table 20. Smoke control test of Loma Linda VA Hospital, first floor,

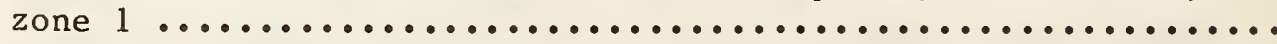

Table 21. Smoke control test of Loma Linda VA Hospital, first floor, zone 3

Table 22. Smoke control test of Loma Linda VA Hospital, first floor, zone 5

Table 23. Smoke control test of Loma Linda VA Hospital, second floor,

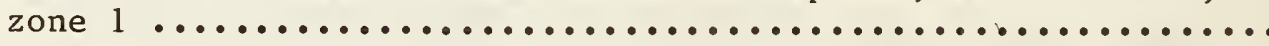

Table 24. Smoke control test of Loma Linda VA Hospital, second floor,

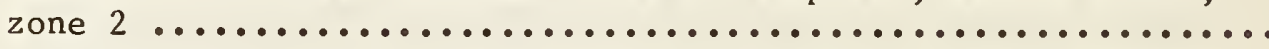

Table 25. Smoke control test of Loma Linda VA Hospital, second floor,

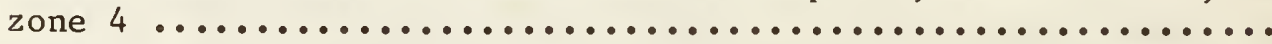

Table 26. Smoke control test of Loma Linda VA Hospital, second floor,

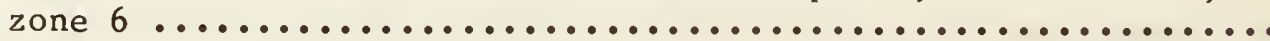

Table 27. Smoke control test of Loma Linda VA Hospital, second floor,

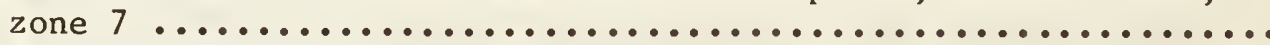

Table 28. Smoke control test of Loma Linda VA Hospital, second floor,

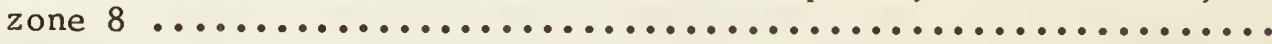

Table 29. Smoke control test of Loma Linda VA Hospital, third floor,

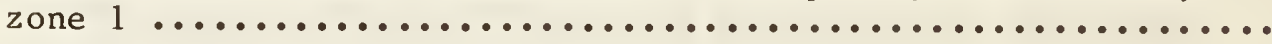

Table 30. Smoke control test of Loma Linda VA Hospital, third floor,

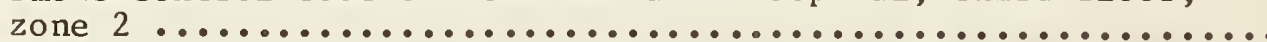

Table 31. Smoke control test of Loma Linda VA Hospital, third floor,

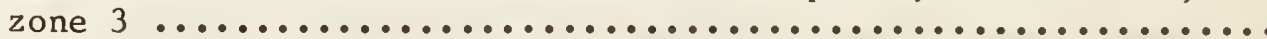

Table 32. Smoke control test of Loma Linda VA Hospital, third floor,

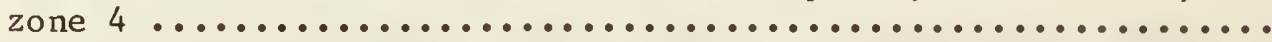

Table 33. Smoke control test of Loma Linda VA Hospital, third floor,

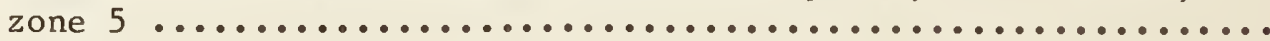


$\underline{\text { Page }}$

Table 34. Smoke control test of Loma Linda VA Hospital, third floor,

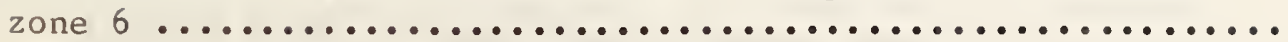

Table 35. Smoke control test of Loma Linda VA Hospital, third floor,

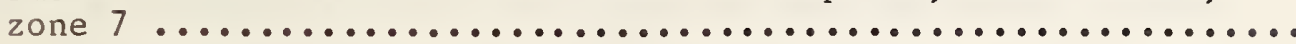

Table 36. Smoke control test of Loma Linda VA Hospital, third floor, zone 8

Table 37. Smoke control test of Loma Linda VA Hospital, fourth floor,

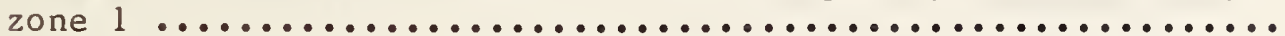

Table 38. Smoke control test of Loma Linda VA Hospital, fourth floor,

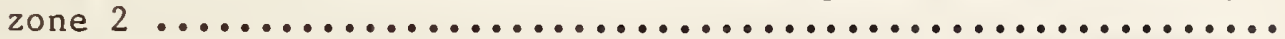

Table 39. Smoke control test of Loma Linda VA Hospital, fourth floor,

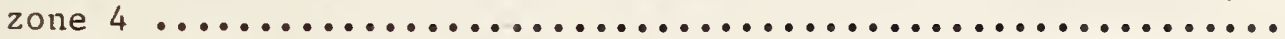

Table 40. Smoke control test of Loma Linda VA Hospital, fourth floor,

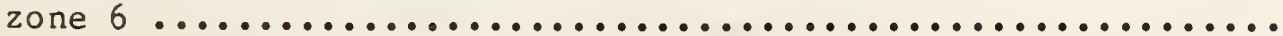

Table 41. Smoke control test of Loma Linda VA Hospital, fourth floor, zone 7

Table 42. Smoke control test of San Diego VA Hospital, third floor,

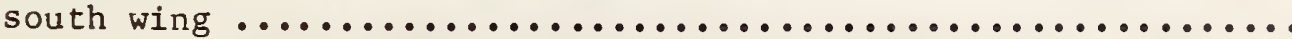

Table 43. Smoke control test of San Diego VA Hospital, third floor,

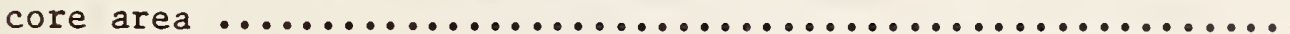

Table 44. Smoke control test of Martinsburg VA Hospital, sixth floor, zone 2

Table 45. Smoke control test of Richmond VA Hospital, fourth floor..... 


\section{LIST OF FIGURES}

Page

Figure 1. Pressure difference across a barrier of a smoke control system preventing smoke infiltration to the high pressure side of the barrier

Figure 2. Smoke backflow against low air velocity through an open doorway

Figure 3. No smoke backflow with high air velocity through an open doorway

Figure 4. Leakage paths in parallel

Figure 5. Leakage paths in series

Figure 6. Combination of leakage paths in parallel and series

Figure 7. Bay Pines VA Hospital first floor plan

Figure 8. Bay Pines VA Hospital second floor plan

Figure 9. Bay Pines VA Hospital typical plans for floors 3, 4, and 5 ..

Figure 10. Operations of double egress doors in smoke control system ...

Figure 11. Loma Linda VA Hospital first floor plan ............... 35

Figure 12. Loma Linda VA Hospital second floor plan .............. 36

Figure 13. Loma Linda VA Hospital third floor plan .............. 37

Figure 14. Loma Linda VA Hospital fourth floor plan ............. 38

Figure 15. Loma Linda VA Hospital third floor, zone 7 plan ........ 40

Figure 16. Data from open door study at Loma Linda VA Hospital ....... 42

Figure 17. San Diego VA Hospital typical floor plan .............. 46

Figure 18. Martinsburg VA Hospital sixth floor plan .............. 51

Figure 19. Richmond VA Hospital fourth floor plan ............... 51

Figure 20. Set-up for measuring pressure difference across a door ..... 59

Figure 21. Inclined manometer with liquid reservoir ............. 59

Figure 22. Magnetically coupled differential pressure gage ......... 60

Figure 23. Flow measurement traverse for corridors and open doorways ... 63 


\section{LIST OF FIGURES (continued)}

Page

Figure 24. Deflecting vane anemometer: (a) principle of operation, and (b) the instrument in use 64

Figure 25. Pitot-static tube 66 



\section{Abstract}

The Veterans Administration (VA) has sponsored a project at the Center for Fire Research of the National Bureau of Standards to study smoke control In VA hospitals and evaluate design system approaches and methods of acceptance testing. This report presents general background information that is belleved to be of interest to those tasked with design, construction and acceptance testing of smoke control systems. The performance requirements of smoke control systems for VA hospitals are discussed. The results of field tests at five VA hospitals is presented and discussed. Based on the information gained from the field tests and the background information, different approaches to smoke control at VA hospitals and methods of acceptance testing are evaluated. General recommendations concerning smoke control at VA hospitals are made.

Key words: acceptability, acceptance tests, air movement, doors, field tests, hospitals, pressurization, smoke control.

\section{INTRODUCTION}

In bullding fire situations, smoke flows through numerous leakage paths to locations remote from the fire, resulting in a hazard to human life and destruction of property. These leakage paths can be open doors, cracks around closed doors, stairwells, elevator shafts and other cracks or openings in construction. As a solution to the smoke problem, the concept of smoke control has developed. Smoke control makes use of fans to produce pressure differences and air flows that can control smoke movement.

This paper is the final report of a project sponsored by the U.S. Veterans Administration (VA) to study smoke control in VA hospitals and evaluate design system approaches and methods of acceptance testing. Two previous reports presented the field tests of the smoke control systems at the Bay Pines VA Hospital [1] and the San Diego VA Hospital [2]. As a convenfence 
to the reader the results of these tests plus those of three other hospitals are presented in this report. Because smoke control is a new field, background information about smoke management, the principles of smoke control, purging, door opening forces, building flow analysis, flow areas and weather data is provided in the belief that this will be of help to many readers. Based on this information and that gained from field tests, different smoke contro1 approaches and methods of acceptance testing are evaluated.

In this paper the term "smoke" is used in accordance with the ASTM and NFPA definition which states that smoke consists of the airborne solid and liquid particulates and gases evolved when a material undergoes pyrolysis or combustion $[3,4]$.

\section{SMOKE MANAGEMENT}

The term "smoke management", as used in this report, includes all methods that can be used singly or in combination to modify smoke movement for the benefit of occupants and fire fighters and for the reduction of property damage. The use of barriers, smoke vents, and smoke shafts are traditional methods of smoke mangement.

The effectiveness of a barrier in limiting smoke movement depends on the leakage paths in the barrier and on the pressure difference across the barrier. Holes where pipes penetrate walls or floors, cracks where walls meet floors, and cracks around doors are a few possible leakage paths. The pressure difference across these barriers depends on stack effect, buoyancy, wind and the HVAC system. The effectiveness of barriers in a traditional smoke management system are limited to the extent to which the barriers are free of leakage paths.

The effectiveness of smoke vents and smoke shafts depends on their proximity to the fire, the buoyancy of the smoke, and the presence of other driving forces. Smoke vents and smoke shafts are limited to the extent that the smoke must be sufficiently buoyant to overcome any other driving forces that might be present. When smoke is cooled due to sprinklers the effectiveness of smoke vents and smoke shafts is greatly reduced. 
Elevator shafts in buildings have been used as smoke shafts. Unfortunately, this prevents their use for fire evacuation and these shafts frequently distribute smoke to floors far from the fire. Specially designed smoke shafts, which have essentially no leakage on floors other than the fire floor, can be used to prevent the smoke shaft from distributing smoke to nonfire floors.

In the last few decades, fans have been employed with the intent of overcoming the limitations of the traditional systems. The systems with fans are called smoke control systems and they rely on pressure differences and airflows to limit smoke movement as discussed in the next section.

\section{PRINCIPLES OF SMOKE CONTROL}

Smoke control uses the barriers (walls, floors, doors, etc.) used in traditional smoke management in conjunction with airflows and pressure differences generated by mechanical fans.

Figure 1 illustrates a pressure difference across a barrier acting to control smoke movement. Within the barrier is a door. The high pressure side of the door can be either a refuge area or an escape route. The low pressure side is exposed to smoke from a fire. Airflow through the cracks around the door and through other construction cracks prevents smoke infiltration through those cracks to the high pressure side.

When the door in the barrier is opened, airflow through the open door results. When the air velocity is low, smoke can flow against the airflow into the refuge area or escape route, as shown in figure 2. This smoke backflow can be prevented if the air velocity is sufficiently large, as shown in figure 3. The magnitude of the velocity necessary to prevent backflow depends on the energy release rate of the fire, as discussed in section 3.1 .

The two basic principles of smoke control can be stated as follows:

- Airflow by itself can control smoke movement if the average alr velocity is of sufficient magnitude. 


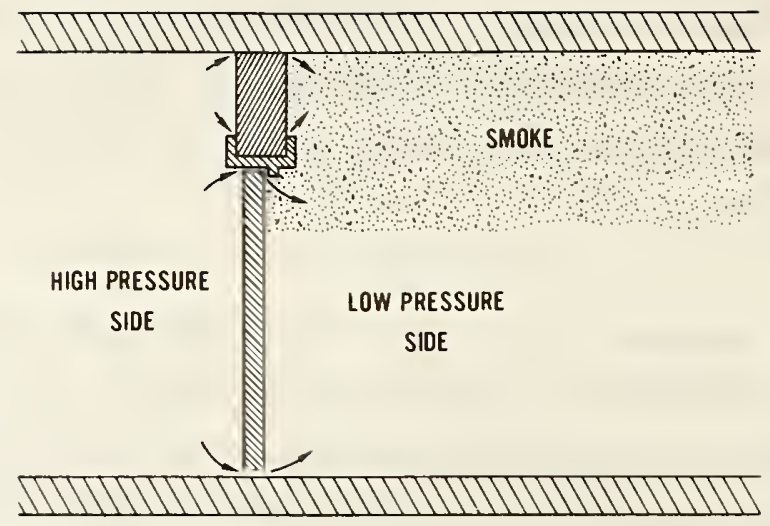

Figure 1. Pressure difference across a barrier of a smoke control system preventing smoke infiltration to the high pressure side of the barrier
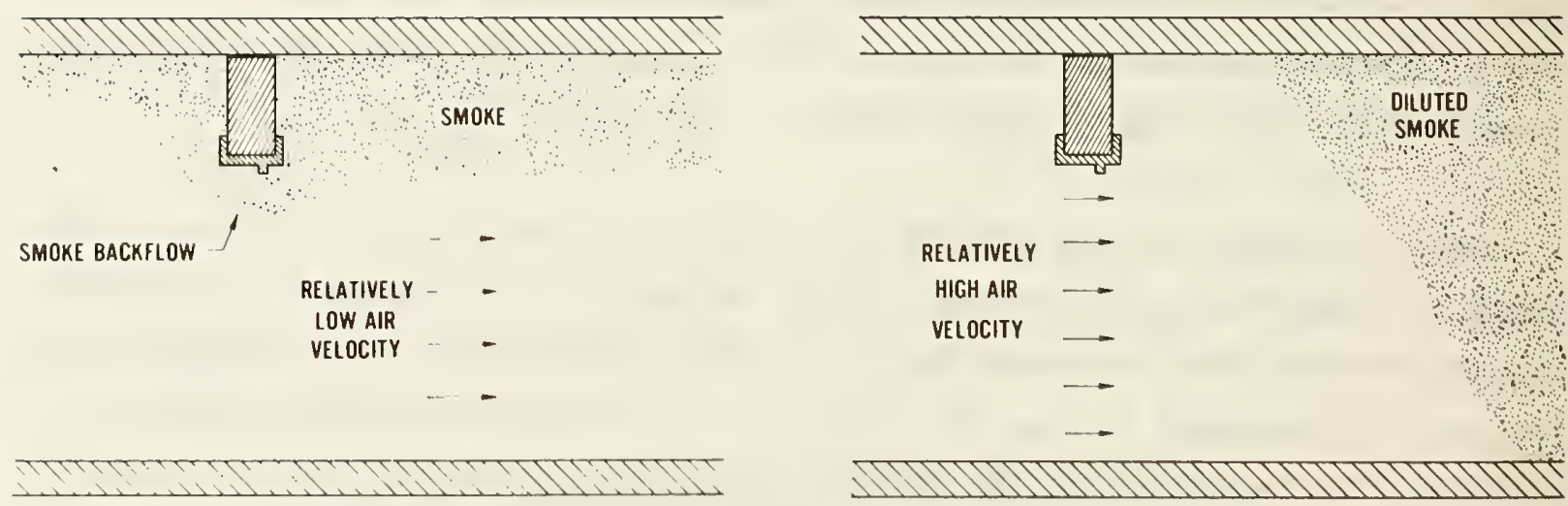

Figure 2. Smoke backflow against low air velocity through an open doorway

Figure 3. No smoke backflow with high air velocity through an open doorway 
- Air pressure differences across barriers can act to control smoke movement.

The use of air pressure differences across barriers to control smoke is frequently referred to as pressurization. Pressurization results in airflows in the small gaps around closed doors and in construction cracks, thereby preventing smoke backflows through these openings. Therefore, in a strict physical sense, the second principle is a special case of the first principle. However, considering the two principles as separate is advantageous for smoke control design. For a barrier with one or more large openings, air velocity is the appropriate physical quantity for both design considerations and for acceptance testing. However, when there are only small cracks, such as around closed doors, designing to and measuring air velocities is impractical. In this case, the appropriate physical quantity is pressure difference. Consideration of the two principles as separate has the added advantage that it emphasizes the different considerations that need to be given for open and closed doors. The principle that smoke can be controlled by pressurization has been demonstrated in full scale fire tests in New York City [5], Atlanta, Georgia [6] and Hamburg, Germany [7]. In each of these tests, pressurization across a barrier controlled smoke produced by an intense and flaming fire.

Because smoke control relies on air velocities and pressure differences produced by fans, it has the following three advantages in comparison to the traditional methods of smoke management:

- Smoke control is less dependent on tight barriers. Allowance can be made in the design for reasonable leakage through barriers.

- Stack effect, buoyancy, and wind are less likely to overcome smoke control than passive smoke management. In the absence of smoke contro1, these driving forces cause smoke movement to the extent that leakage paths allow. However, pressure differences and airflows of a smoke control system act to oppose these driving forces. 
- Smoke control can be designed to prevent smoke flow through an open doorway in a barrier by the use of airflow. Doors in barriers are opened during evacuation and are sometimes accidentally left open or propped open throughout fires. In the absence of smoke control, smoke flow through these doors is common.

Smoke control systems should be designed so that a path exists for smoke movement to the outside.

The smoke control designer should be cautioned that dilution of smoke in the fire space is not a means of achieving smoke control, i.e., smoke control as defined above cannot be achieved by simply supplying and exhausting large quantities of air from the space or zone in which the fire is located. This supplying and exhausting of air is sometimes referred to as purging the smoke. Because of the large quantities of smoke produced in a fire, purging cannot assure breathable air in the fire space. In addition, purging in itself cannot control smoke movement because it does not provide the needed airflows at open doors and the pressure differences across barriers. However, for spaces separated from the fire space by smoke barriers, purging can significantly limit the level of smoke.

\subsection{Airflow}

Theoretically, alrflow can be used to stop smoke movement through any space. However, the two places where air velocity is most commonly used to control smoke movement are open doorways and corridors. The problem of preventing smoke movement through doorways is currently being researched. As far back as 1970, Thomas [8] has developed an empirical relation for the critical velocity to prevent smoke from flowing upstream in a corridor:

$$
\mathrm{v}_{\mathrm{k}}=\mathrm{K}\left(\frac{\mathrm{gE}}{\mathrm{W \rho cT}}\right)^{1 / 3}
$$

where: $\quad V_{k}=$ critical air velocity to prevent smoke backflow

$\mathrm{E}=$ energy release rate into corridor

$W=$ corridor width

$\rho=$ density of upstream air 


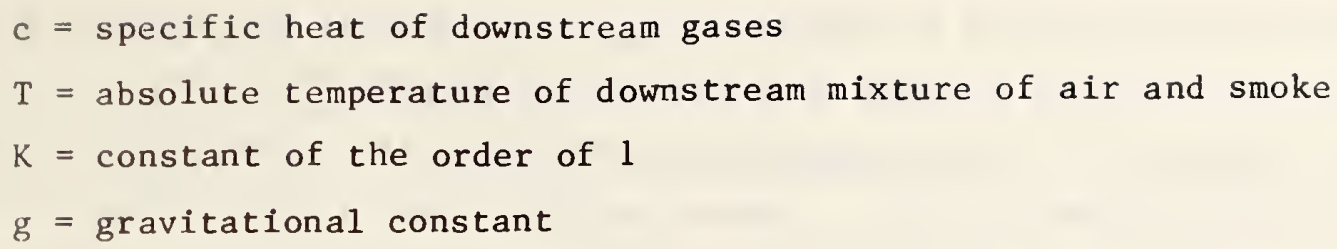

The downstream properties are considered to be taken at a point sufficiently far downstream of the fire for the properties to be uniform across the cross section. The critical air velocity can be evaluated at $\rho=0.0811 \mathrm{~b} / \mathrm{ft}^{3}\left(1.3 \mathrm{~kg} / \mathrm{m}^{3}\right), \quad c=0.24 \mathrm{Btu} / 1 \mathrm{~b}^{\circ} \mathrm{F} \quad\left(1.005 \mathrm{~kJ} / \mathrm{kg}^{\circ} \mathrm{C}\right) \quad \mathrm{T}=81^{\circ} \mathrm{F}$ $\left(27^{\circ} \mathrm{C}\right)$, and $\mathrm{K}=1$.

$$
v_{k}=k_{v}\left(\frac{E}{W}\right)^{1 / 3}
$$

where: $\quad v_{k}=$ critical air velocity to prevent smoke backflow, $f p m(m / s)$

$\mathrm{E}=$ energy release rate into corridor, $\mathrm{Btu} / \mathrm{hr}(\mathrm{W})$

$\mathrm{W}=$ corridor width, $\mathrm{ft}(\mathrm{m})$

$\mathrm{K}_{\mathrm{v}}=$ coefficient, $5.68(0.0292)$

This relation can be used when the fire is located in the corridor or when the smoke enters the corridor through an open door, air transfer grille, or other opening. The critical velocities calculated from the above relation are approximate because only an approximate value of $\mathrm{K}$ was used. However, critical velocities calculated from this relation are indicative of the kind of air velocities required to prevent smoke backflow from fires of different sizes.

For an energy release rate of $0.512 \times 10^{6} \mathrm{Btu} / \mathrm{hr}(150 \mathrm{~kW})$ into a corridor $4.00 \mathrm{ft}(1.22 \mathrm{~m})$ wide, the above relation yields a critical velocity of $286 \mathrm{fpm}(1.45 \mathrm{~m} / \mathrm{s})$. However, for a larger energy release rate of $7.2 \times 10^{6}$ $\mathrm{Btu} / \mathrm{hr}(2.1 \mathrm{MW})$, the relation yields a critical velocity of $690 \mathrm{fpm}(3.50 \mathrm{~m} / \mathrm{s})$ for a corridor of the same width.

In general, a requirement for a high air velocity results in a smoke control system that is expensive and difficult to design. The use of airflow is most important in preventing smoke backflow through an open doorway that serves as a boundary of a smoke control system. Thomas [8] indicated that 
equation (1) can be used to obtain a rough estimate of the airflow needed to prevent smoke backflow through a door. Many designers feel that it is prohibitively expensive to design systems to maintain air velocities in doorways greater than $300 \mathrm{fpm}(1.5 \mathrm{~m} / \mathrm{s})$. Later in this paper a discussion is provided of what constitutes an appropriate design air velocity in a smoke control system.

Equation (1) is not appropriate for sprinklered fires having small temperature differences between the upstream air and downstream gases. Shaw and Whyte [9] provide an analysis with experimental verification of a method to determine the velocity needed through an open doorway to prevent backflow of contaminated air. This analysis is specifically for small temperature differences and includes the effects of natural convection. If this method is used for a sprinklered fire where the temperature difference is only $3.6^{\circ} \mathrm{F}$ $\left(2^{\circ} \mathrm{C}\right)$, then an average velocity of $50 \mathrm{fpm}(0.25 \mathrm{~m} / \mathrm{s})$ would be the minimum velocity needed through a doorway to prevent smoke backflow. This temperature difference is small, and it is possible that larger values may be appropriate in many situations. Further research is needed in this area.

Even though airflow can be used to control smoke movement, it is not the primary method because the quantities of air required are so large. The primary means is by air pressure differences across partitions, doors, and other building components.

\subsection{Pressurization}

The airflow rate through a construction crack, door gap, or other flow path is proportional to the pressure difference across that path raised to the power n. For a flow path of fixed geometry, $n$ is theoretically in the range of 0.5 to 1. However, for all flow paths except extremely narrow cracks, using $\mathrm{n}=0.5$ is reasonable and the flow can be expressed as:

$$
Q=C A \sqrt{\frac{2 \Delta P}{\rho}}
$$

where: $Q=$ volumetric airflow rate

$C=$ flow coefficient 

$A=f l o w$ area (also called leakage area)
$\Delta \mathrm{P}=$ pressure difference across the flow path
$\rho=$ density of air entering the flow path

The flow coefficient depends on the geometry of the flow path as well as on turbulence and friction. In the present context, the flow coefficient is generally in the range of 0.6 to 0.7 . For $\rho=0.0751 \mathrm{~b} / \mathrm{ft}^{3}\left(1.2 \mathrm{~kg} / \mathrm{m}^{3}\right)$ and $C=0.65$, the flow equation above can be expressed as:

$$
Q=K_{f} A \sqrt{\Delta P}
$$

where: $Q=$ volumetric flow rate, $\mathrm{cfm}\left(\mathrm{m}^{3} / \mathrm{s}\right)$

$$
\begin{aligned}
A & =\text { flow area, } \mathrm{ft}^{2}\left(\mathrm{~m}^{2}\right) \\
\Delta \mathrm{P} & =\text { pressure difference across flow path, in } \mathrm{H}_{2} \mathrm{O}(\mathrm{Pa}) \\
\mathrm{K}_{\mathrm{f}} & =\text { coefficient, } 2610(0.839)
\end{aligned}
$$

The flow area is frequently the same as the cross sectional area of the flow path; an exception being the flow area of an open stairwell doorway as discussed later. A closed door with a crack area of $0.11 \mathrm{ft}^{2}\left(0.01 \mathrm{~m}^{2}\right)$ and with a pressure difference of 0.01 in $\mathrm{H}_{2} \mathrm{O}(2.5 \mathrm{~Pa})$ would have an air leakage rate of approximately $29 \mathrm{cfm}\left(0.013 \mathrm{~m}^{3} / \mathrm{s}\right)$. If the pressure difference across the door were increased to 0.30 in $\mathrm{H}_{2} \mathrm{O}(75 \mathrm{~Pa})$, then the flow would be $157 \mathrm{cfm}$ $\left(0.073 \mathrm{~m}^{3} / \mathrm{s}\right)$.

Frequently in field tests of smoke control systems, pressure differences across partitions or closed doors have fluctuated by as much as 0.02 in $\mathrm{H}_{2} \mathrm{O}$ ( $5 \mathrm{~Pa}$ ). These fluctuations have generally been attributed to the wind, although they could have been due to the HVAC system or some other source. Pressure fluctuations and the resulting smoke movement are a current topic of research. To control smoke movement, the pressure differences produced by $a$ smoke control system must be sufficiently large that they are not overcome by pressure fluctuations, stack effect, smoke buoyancy, and the forces of the wind. However, the pressure difference produced by a smoke control system should not be so large that door opening problems result (see section 5 ). 
In general the systems discussed in this paper are based on the two basic principles of smoke control. However, it is not always possible to maintain sufficiently large airflows through open doors to prevent smoke from infiltrating a space that is intended to be protected. Ideally such occurrences of open doors will only happen for short periods of time during evacuation. Smoke that has entered such a space can be purged, i.e., diluted by supplying outside air to the space.

Consider the case where a compartment is isolated from a fire by smoke barriers and self closing doors, so that no smoke enters the compartment when the doors are closed. However, when one or more of the doors is open, there is insufficient airflow to prevent smoke backflow into the compartment from the fire space. In order to facilitate analysis, it is considered that smoke is of uniform concentration throughout the compartment. When all the doors are closed, the concentration of contaminant in the compartment can be expressed as:

$$
\frac{C}{C_{0}}=e^{-a t}
$$

where: $\quad C_{0}=$ initial concentration of contaminant

$\mathrm{C}=$ concentration of contaminant at time, $t$

$a=$ purging rate in number of air changes per minute

$t=$ time after doors closed in minutes

$\mathrm{e}=$ constant (approximately 2.718)

The concentrations $\mathrm{C}_{\mathrm{O}}$ and $\mathrm{C}$ must both be in the same units, and they can be any units appropriate for the particular contaminant being considered. McGuire, Tamura, and Wilson [10] evaluated the maximum levels of smoke obscuration from a number of tests and a number of proposed criteria for tolerable levels of smoke obscuration. Based on this evaluation, they state that the maximum levels of smoke obscuration are greater by a factor of 100 than those relating to the limit of tolerance. Thus, they indicate that an area can be considered "reasonably safe" with respect to smoke obscuration if its atmosphere will not be contaminated to an extent greater than $1 \%$ by the atmosphere 
prevalling in the immediate fire area. It is obvious that such dilution would also reduce the concentrations of toxic smoke components. Toxicity is a more complicated problem, and no parallel statement has been made regarding the dilution needed to obtain a safe atmosphere with respect to toxic gases.

Equation (3) can be solved for the purging rate.

$$
a=\frac{1}{t} \log _{e} \frac{C_{0}}{C}
$$

For example, if when doors are open, the contaminant in a compartment is $20 \%$ of the burn room concentration, and at six minutes after the door is closed, the contaminant concentration is $1 \%$ of the burn room, then equation (4) indicates the compartment must be purged at a rate of one air change every two minutes.

In reality, it is impossible to assure that the concentration of the contaminant is uniform throughout the compartment. Because of buoyancy, it is likely that higher concentrations of contaminant would tend to be near the celling. Therefore, an exhaust inlet located near the ceiling and a supply outlet located near the floor would probably purge the smoke even faster than the above calculations indicate. Caution should be exercised in the location of the supply and exhaust points to prevent the supply air from blowing into the exhaust inlet and thus short circuiting the purging operation.

\section{DOOR OPENING FORCES}

The door opening forces resulting from the pressure differences produced by a smoke control system must be considered in any design. Unreasonably high door opening forces can result in occupants having difficulty or being unable to open doors to refuge areas or escape routes. This problem is discussed in more detail later in this paper.

The force required to open a door is the sum of the forces to overcome the pressure difference across the door and to overcome the door closer. This can be expressed as: 


$$
F=F_{d c}+\frac{K_{d} W A \Delta P}{2(W-d)}
$$

where: $\quad F=$ the total door opening force, $1 \mathrm{~b}(\mathrm{~N})$

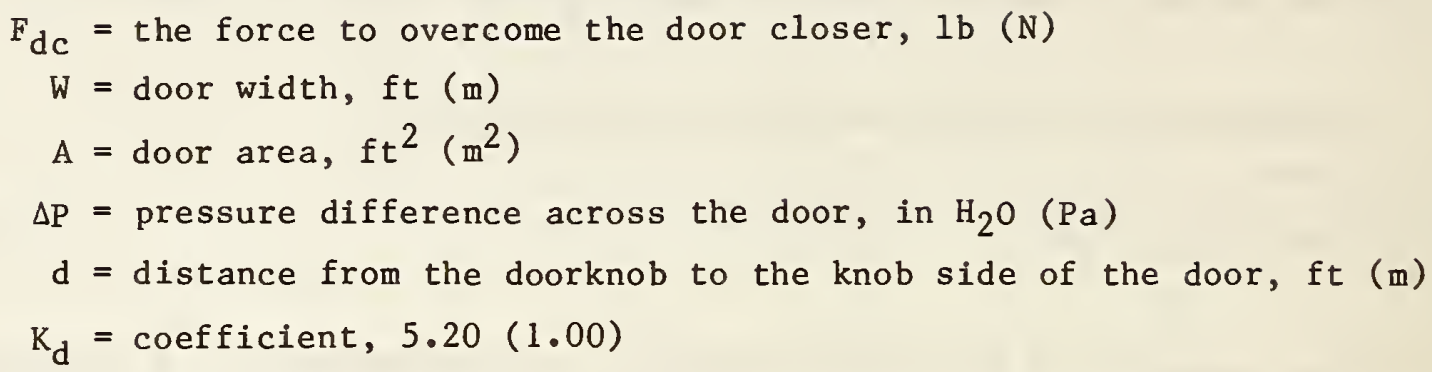

This relation assumes that the door-opening force is applied at the knob. The force to overcome the door closer is usually greater than $31 \mathrm{~b}$ $(13 \mathrm{~N})$ and, in some cases, can be as large as $201 \mathrm{~b}(90 \mathrm{~N})$. For a door that is $7 \mathrm{ft}(2.13 \mathrm{~m}) \mathrm{high}$ and $36 \mathrm{in}(0.91 \mathrm{~m})$ wide, subject to a pressure difference of 0.25 in $\mathrm{H}_{2} \mathrm{O}(62 \mathrm{~Pa})$, the total door opening force is $251 \mathrm{~b}(110 \mathrm{~N})$, if the force to overcome the door closer is $101 \mathrm{~b}(44 \mathrm{~N})$.

\section{BUILDING AIR FLOW ANALYSIS}

The performance of a smoke control system depends on the total airflow in the building in which the system is located. Therefore, analysis of a smoke control system includes a total building airflow analysis.

There are many situations where the building is complicated or where there are several driving forces, so that hand calculation is not practical. These cases can be more readily analyzed with the aid of a digital computer.

Several general purpose computer programs have been developed to simulate smoke movement in buildings. A specialized computer program to perform steady state analysis of smoke control systems has been developed by NBS and is discussed in detail in the American Society of Heating, Refrigerating and AirConditioning Engineers manual [11] on smoke control design. 
In the design of smoke control systems, airflow paths must be identified and evaluated. Some leakage paths are obvious, such as cracks around closed doors, open doors, elevator doors, windows, and air transfer grilles. Construction cracks in building walls are less obvious but no less important.

The flow area of most large openings, such as open windows, can be calculated easily. However, flow areas of cracks are more difficult to evaluate. The area of these leakage paths is dependent on workmanship, i.e., how well a door is fitted or how well weather stripping is installed. A door that is 36 in by $7 \mathrm{ft}(0.9 \times 2.1 \mathrm{~m})$ with an average crack width of $1 / 8$ in $(3.2 \mathrm{~mm})$ has a leakage area of $0.21 \mathrm{ft}^{2}\left(0.020 \mathrm{~m}^{2}\right)$. However, if this door is installed with a $3 / 4$ in $(19 \mathrm{~mm})$ undercut, the leakage area is $0.32 \mathrm{ft}^{2}\left(0.030 \mathrm{~m}^{2}\right)$. This is a significant difference. The leakage area of elevator doors has been measured in the range of 0.55 to $0.70 \mathrm{ft}^{2}\left(0.051\right.$ to $\left.0.065 \mathrm{~m}^{2}\right)$ per door.

For open stairwell doorways, Cresci [12] found that complex flow patterns exist and that the resulting flow through open doorways was considerably below the flow calculated by using the geometric area of the doorway as the flow area in equation ( $2 a)$. Based on this research, it is recommended that the flow area of an open stairwell doorway be half that of the geometric area (door height times width) of the doorway. An alternate approach for open stairwell doorways is to use the geometric area as the flow area and use a reduced flow coefficient. Because it does not allow the direct use of equation ( $2 a)$, this alternate approach is not used in this paper.

Typical leakage areas for walls and floors of commercial buildings are tabulated in appendix A. These data are based on a relatively small number of tests performed by the National Research Council of Canada, as referenced in appendix A. It is believed that actual leakage areas are primarily dependent on workmanship rather than construction materials, and, in some cases, the flow areas in particular buildings may vary from the values listed. Considerable data concerning air leakage through building components is also provided in ASHRAE Handbook-1985 Fundamentals, chapter 22 [13]. 
The determination of the flow area of a vent is not always straightforward, because the vent surface is usually covered by a louver and screen. Thus the flow area is less than the vent area (vent height times width). Because the slats in louvers are frequently slanted, calculation of the flow area is further complicated. Manufacturers' data should be sought for specific information.

The concept of effective flow areas is quite useful for analysis of smoke control systems. The paths in the system can be in parallel with one another, in series, or a combination of parallel and series paths. The effective area of a system of flow areas is the area that results in the same flow as the system when it is subjected to the same pressure difference over the total system of flow paths. This concept is similar to an effective resistance of a system of electrical resistances.

Three parallel leakage areas from a pressurized space are illustrated in figure 4 .

The effective area, $A_{e}$, for this situation is

$$
A_{e}=A_{1}+A_{2}+A_{3}
$$

In figure 4, if $A_{1}$ is $1.08 \mathrm{ft}^{2}\left(0.10 \mathrm{~m}^{2}\right)$ and $A_{2}$ and $A_{3}$ are $0.54 \mathrm{ft}^{2}$ $\left(0.05 \mathrm{~m}^{2}\right)$ each, then the effective flow area, $A_{e}$, is $2.16 \mathrm{ft}^{2}\left(0.20 \mathrm{~m}^{2}\right)$.

In general, it can be stated that the effective area is the sum of the individual leakage paths.

$$
A_{e}=\sum_{i=1}^{n} A_{i}
$$

where $\mathrm{n}$ is the number of flow areas, $A_{i}$, in parallel.

Three leakage areas in series from a pressurized space are illustrated in figure 5 .

The effective area for the three flow paths in series in figure 5 is 


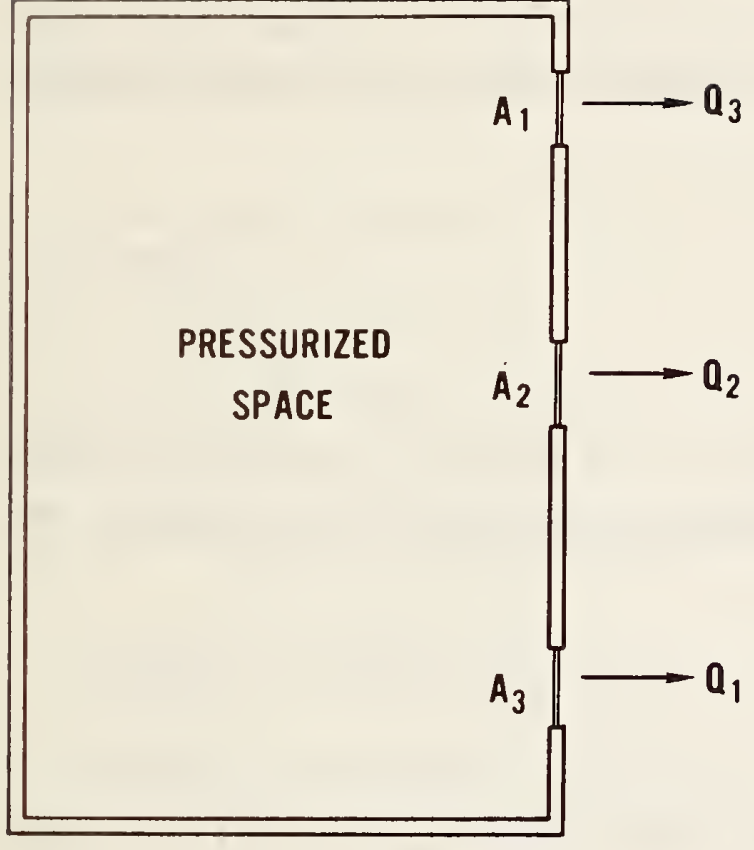

Figure 4. Leakage paths in parallel

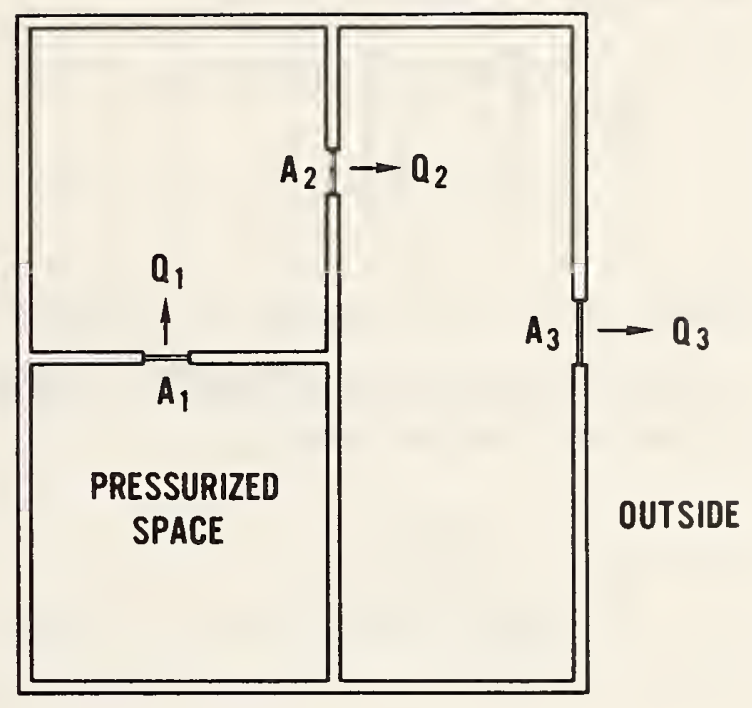

Figure 5. Leakage paths in series

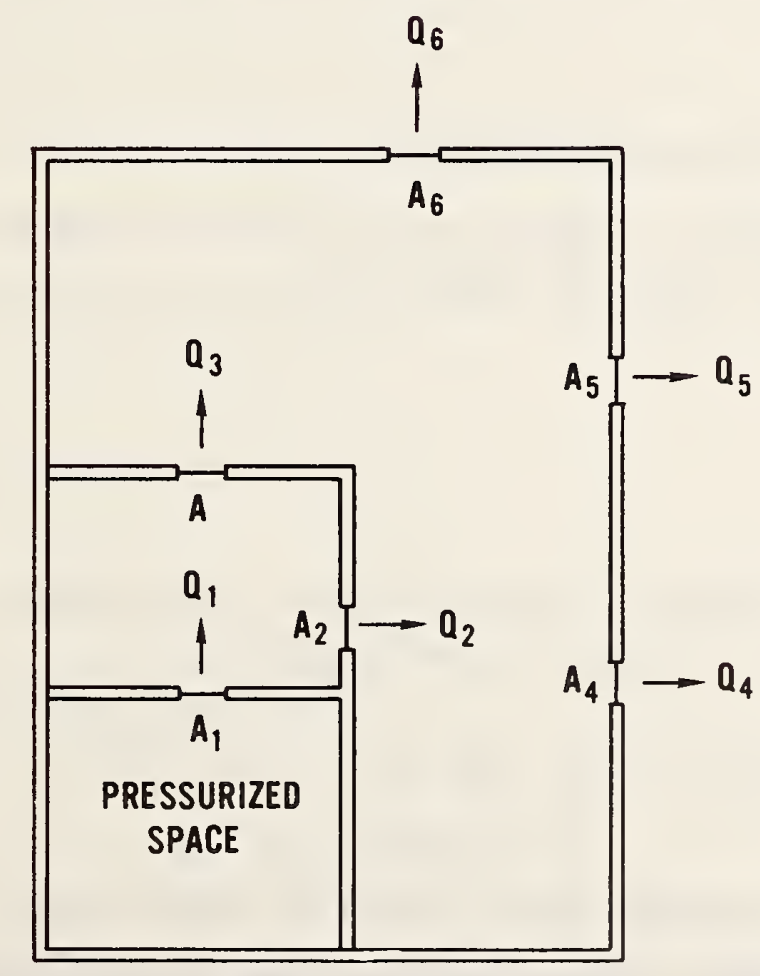

Figure 6. Combination of leakage paths in parallel and series 


$$
A_{e}=\left(\frac{1}{A_{1}^{2}}+\frac{1}{A_{2}^{2}}+\frac{1}{A_{3}^{2}}\right)^{-1 / 2}
$$

This same reasoning can be stated for any number of leakage areas in series as

$$
A_{e}=\left[\begin{array}{cc}
n & \frac{1}{2} \\
i=1 & A_{i}^{2}
\end{array}\right]^{-1 / 2}
$$

where $\mathrm{n}$ is the number of leakage areas, $A_{i}$, in series. In smoke control analysis, there are frequently only two paths in series. For this case, the effective leakage area is:

$$
A_{e}=\frac{A_{1} A_{2}}{\sqrt{A_{1}^{2}+A_{2}^{2}}}
$$

Example 1.

Calculate the effective leakage area of two equal flow paths of $0.2 \mathrm{ft}^{2}$ in series.

$$
\begin{aligned}
& \text { Let } A=A_{1}=A_{2}=0.22 \mathrm{ft}^{2}\left(0.02 \mathrm{~m}^{2}\right) \\
& A_{e}=\frac{A^{2}}{\sqrt{2 A^{2}}}=\frac{A}{\sqrt{2}}=0.15 \mathrm{ft}^{2}\left(0.014 \mathrm{~m}^{2}\right)
\end{aligned}
$$

Example 2.

Calculate the effective area of two flow paths in series, where $A_{1}=0.22 \mathrm{ft}^{2}\left(0.02 \mathrm{~m}^{2}\right)$ and $A_{2}=2.2 \mathrm{ft}^{2}\left(0.2 \mathrm{~m}^{2}\right)$.

$$
A_{e}=\frac{A_{1} A_{2}}{\sqrt{A_{1}+A_{2}}}=0.214 \mathrm{ft}^{2}\left(0.0199 \mathrm{~m}^{2}\right)
$$

This example illustrates that, when two areas are in series and one is much larger than the other, the effective area is approximately equal to the sma1ler area. 
The method of developing an effective area for a system of both paralle1 and series paths is to systematically combine groups of parallel paths and series paths. The system illustrated in figure 6 is analyzed as an example.

The figure shows that $A_{2}$ and $A_{3}$ are in parallel; therefore, their effective area is:

$$
\mathrm{A}_{23 \mathrm{e}}=\mathrm{A}_{2}+\mathrm{A}_{3}
$$

Areas $A_{4}, A_{5}$, and $A_{6}$ are also in parallel, so their effective area is:

$$
A_{456 e}=A_{4}+A_{5}+A_{6}
$$

These two effective areas are in series with $A_{1}$. Therefore, the effective flow area of the system is given by:

$$
A_{e}=\left[\frac{1}{A_{1}^{2}}+\frac{1}{A_{23 e}^{2}}+\frac{1}{A_{456 e}^{2}}\right]^{-1 / 2}
$$

Example 3 .

Calculate the effective area of the system in figure 2.8, if the leakage areas are $A_{1}=A_{2}=A_{3}=0.22 \mathrm{ft}^{2}\left(0.02 \mathrm{~m}^{2}\right)$ and $A_{4}=A_{5}=A_{6}=0.11 \mathrm{ft}^{2}$ $\left(0.01 \mathrm{~m}^{2}\right)$.

$$
\begin{aligned}
& A_{23 e}=0.44 \mathrm{ft}^{2}\left(0.04 \mathrm{~m}^{2}\right) \\
& A_{456 \mathrm{e}}=0.33 \mathrm{ft}^{2}\left(0.03 \mathrm{~m}^{2}\right) \\
& A_{e}=0.16 \mathrm{ft}^{2}\left(0.015 \mathrm{~m}^{2}\right)
\end{aligned}
$$

\section{WEATHER DATA}

The state-of-the-art of smoke control is such that little consideration has been given to the selection of weather data specifically for the design of smoke control systems. However, design temperatures for heating and cooling 
during winter and summer are recommended in the ASHRAE Handbook-1981 Fundamentals chapter 24 [13]. For example, this source provides 99 percent and 97.5 percent winter design temperatures. These values represent the temperatures that are equaled or exceeded in these portions of the heating season.*

A designer may wish to consider using these design temperatures for the design of smoke control systems. It should be remembered that in a normal winter, there would be approximately 22 hours at or below the 99 percent design value and approximately 54 hours at or below the 97.5 percent design value. Furthermore, extreme temperatures can be considerably lower than the winter design temperatures. For example, the ASHRAE 99 percent design temperature for Tallahasse, Florida is $27^{\circ} \mathrm{F}\left(-3^{\circ} \mathrm{C}\right)$, but the lowest listed there by the National Climatic Center [14] was $-2^{\circ} \mathrm{F}\left(-19^{\circ} \mathrm{C}\right)$ on February 13, 1899.

Temperatures are generally below the design values for short periods of time, and because of the thermal lag of building materials, these short intervals of low temperature usually do not result in problems with respect to heating systems. However, the same cannot necessarily be said of a smoke control system. There is no time lag for a smoke control system, i.e., a smoke control system is subjected to all the forces of stack effect that exist at the moment it is being operated. If the outside temperature is below the winter design temperature for which a smoke control system was designed, then problems from stack effect may result. A similar situation can result with respect to summer design temperatures and reverse stack effect.

Wind data is needed for a wind analysis of a smoke control system. At present, no formal method of such an analysis exists, and the approach most generally taken is to design the smoke control system so as to minimize any effects of wind. This approach is followed in this paper.

The development of temperature and wind data for design of smoke control systems is an area for future effort.

\footnotetext{
* The heating season usually consists of three winter months. A more exact definition of these temperatures is available in ASHRAE Handbook-1981 Fundamentals, chapter 24 [13].
} 


\section{SYSTEM PERFORMANCE}

The fire emergency procedure in hospitals throughout the United States including VA hospitals is essentially a plan of horizontal evacuation. Each floor of a hospital is divided into a number of zones, separated from one another by fire walls and fire doors. Generally, nurses are trained to evacuate any patients from the room of fire origin and then close the door. Then, if possible, the patients in the zone that includes the fire room are evacuated to other zones on that floor, otherwise patients seek refuge in their own rooms. Because of vertical smoke movement, horizontal evacuation may be necessary on floors other than the fire floor. The closed doors between the fire and the occupants tend to retard fire spread and smoke movement, ideally allowing sufficient time for fire fighters to extinguish the fire. There is the option for vertical evacuation from these other zones if such an extreme measure be deemed necessary.

This approach has the drawback that smoke movement through building cracks and gaps around doors is likely. The effectiveness of a barrier in limiting smoke movement depends on the leakage paths in the barrier and on the pressure difference across the barrier. The pressure difference depends on stack effect, buoyancy, wind and the heating, ventilation and air-conditioning (HVAC) system whether under normal operation or in the smoke control mode.

The concepts of zoned smoke control, as described in the ASHRAE smoke control manual [11] can be employed to provide pressure differences and airflows to limit the smoke movement to the zone in which the fire exists.

Because smoke control is a new field, consensus has not been reached as to what constitutes reasonable design parameters. The ASHRAE smoke control design manual lists the following areas for which design parameters must be established :

1. leakage areas

2. weather data

3. pressure differences

4. airflow

5. number of doors open in the smoke control system 
Leakage areas and weather data have previously been discussed and pressure differences, airflow and open doors have an important impact on design as we11 as acceptance testing.

\subsection{Pressure Differences}

It is appropriate to discuss both maximum and minimum allowable pressure differences across the boundaries of the smoke control zones. The maximum allowable pressure difference should be a value that does not result in an excessive door-opening force, but it is difficult to determine what constitutes excessive door-opening forces. Section 5-2.1.4.3 of the National Fire Protection Association (NFPA) Life Safety Code [15] states that the force required to open any door in a means of egress of a new building shall not exceed $30 \mathrm{lb}(133 \mathrm{~N})$. Because of the difficulty of evacuating a disabled patient and because exposure to smoke can adversely affect a person's physical ability, a lower value than $30 \mathrm{lb}$ (133 N) seems appropriate. For a dooropening force of $251 \mathrm{~b}(11 \mathrm{~N})$ and a force of $71 \mathrm{~b}(31 \mathrm{~N})$ to overcome the door closer, a door $44 \mathrm{in}(1.12 \mathrm{~m})$ wide and $7 \mathrm{ft}(2.13 \mathrm{~m})$ high would have a maximum allowable pressure difference of 0.25 in $\mathrm{H}_{2} \mathrm{O}(63 \mathrm{~Pa})$. For purposes of discussion, this will be used as the maximum allowable pressure difference in this paper.

In this paper, the criterion for a minimum allowable pressure difference is that no smoke leakage* shall occur from the smoke zone (one in which there is a fire) to an adjacent zone fire during evacuation. The smoke control system must produce sufficient pressure differences so that it is not overcome by the forces of wind, stack effect, or buoyancy of hot smoke.

Generally, new VA hospitals are sprinkled. The minimum pressure difference of 0.02 in $\mathrm{H}_{2} \mathrm{O}(5 \mathrm{~Pa})$ suggested in the ASHRAE manual (section 2.9.2) for sprinklered spaces is used in this paper as the minimum pressure difference to overcome the effects of buoyancy of smoke. Theoretically the smoke contro1 system should be able to produce at least this pressure under design conditions of wind and stack effect with a broken window in the fire compartment.

\footnotetext{
* It is obvious that a smoke control system can meet its objectives of reduced fire deaths, injuries, and property damage due to smoke, even if a small amount of smoke infiltrates the protected areas.
} 
Generally in VA hospitals, the doors (boundary doors) between smoke zones are located between corridors or between a corridor and a lobby . At locations where good housekeeping practices are observed, corridors and lobbies contain little, if any, material that would serve as fuel for a building fire. (This was the case for all the VA hospitals that were the subject of field tests for this study.) Thus, it seems that the probability of a fire in a corridor or lobby is considerably less than that of a fire in a room located off of a corridor. For a room fire, the resulting smoke temperature in the vicinity of the doors between smoke zones would depend on the size and growth rate of the fire and the location of the room of fire origin relative to the boundary doors. This temperature and the resulting buoyant pressure of smoke would increase as the fire grows and spreads. It is desired that the smoke control system maintain positive pressure differences until the fire zone and adjacent zones are evacuated. One approach to this would be to use the techniques of zone fire modeling and evacuation analysis to evaluate numerous fire scenarios to determine a minimum pressure difference for the unsprinkled condition. This is beyond the scope of this paper. An alternative is to determine a likely smoke temperature and from that the buoyancy pressure and based on these select a design value. It can be argued that for the majority of such room fires, the smoke temperature near the boundary doors does not exceed $750^{\circ} \mathrm{F}\left(400^{\circ} \mathrm{C}\right)$ during the time needed to evacuate the fire zone and adjacent zones. For this temperature, the pressure difference $5 \mathrm{ft}(1.53 \mathrm{~m})$ above the neutral plane would be 0.04 in $\mathrm{H}_{2} \mathrm{O}(10 \mathrm{~Pa})$ as calculated by eq. (2.2) of the ASHRAE smoke control manual. For this case a minimum design value for unsprinklered spaces of 0.06 in $\mathrm{H}_{2} \mathrm{O}(15 \mathrm{~Pa})$ would allow a margin of safety, and this value is used for discussion in this paper. If a system were to be designed to withstand an intense corridor fire in the vicinity of the doors between smoke zones, then a larger value of the minimum design pressure difference would be appropriate.

\subsection{Airflow}

As previously discussed, airflow through an open doorway can control smoke movement if the average velocity is of sufficient magnitude. In a sprinklered building, it might be considered that the smoke away from the immediate fire area would be cooled to near ambient temperature by the water 
spray from the sprinklers. In such a case the ASHRAE manual suggests a design velocity in the range of 50 to $250 \mathrm{fpm}(0.25$ to $1.25 \mathrm{~m} / \mathrm{s})$. For an intensive fire adjacent to the door, the ASHRAE manual suggests a design velocity of $800 \mathrm{fpm}(4 \mathrm{~m} / \mathrm{s})$.

\subsection{Number of Open Doors}

During a fire situation, the doors in boundaries of a smoke zone will be closed except for short intervals when a person is being evacuated or when a rescuer or fire fighter enters the smoke zone. Obviously, smoke infiltration into the protected zones is significantly less than for doors that are held open. For purposes of discussion in this paper, it will be considered that smoke leakage through such intermittently open doors is insignificant. However, the airflow produced by the smoke control system can be sufficient to hold doors open (section 11.1.1).

\section{FIELD TESTS}

\subsection{Bay Pines VA Hospital}

The Bay Pines VA Hospital consists of five stories, each with an interstitial space above for distribution of heating, ventilating, air conditioning, plumbing, and electrical systems. These utilities are systematically organized according to a standard plan, which is part of the VA hospital building system [16]. The interstitial space is approximately $7 \mathrm{ft}(2.1 \mathrm{~m})$ in height with its own gypsum floor. Each story of the hospital is divided into a number of service modules, each served by its own variable-volume HVAC system and each having its own supply and exhaust air-handling units utilizing a heat wheel between them for energy conservation. The hospital is sprinkled throughout.

The smoke control system is designed so that each HVAC zone (see figures 7-9) is a smoke control zone. During a fire situation, the HVAC system, controlled by a computer, is put in the following smoke control mode: 


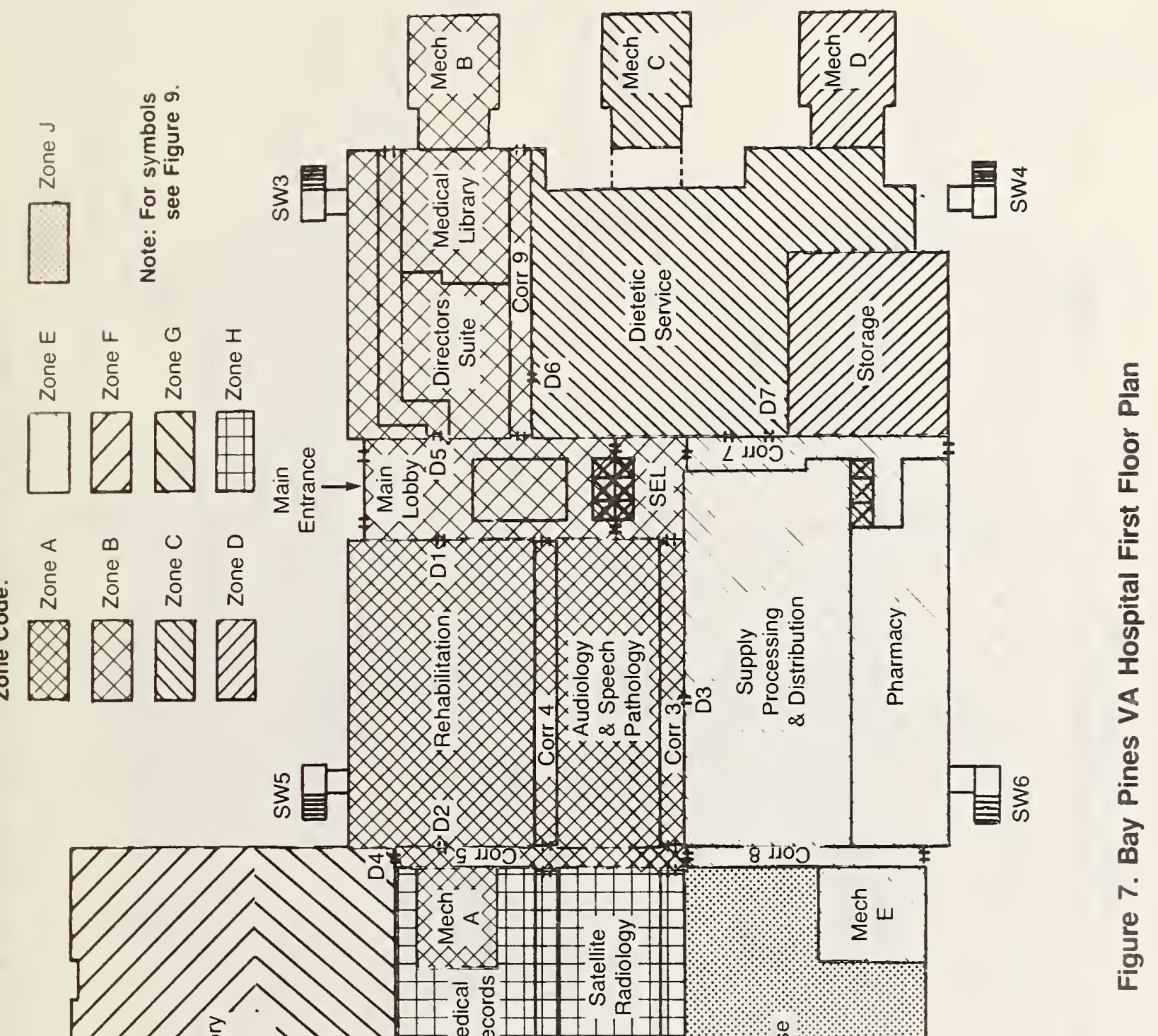




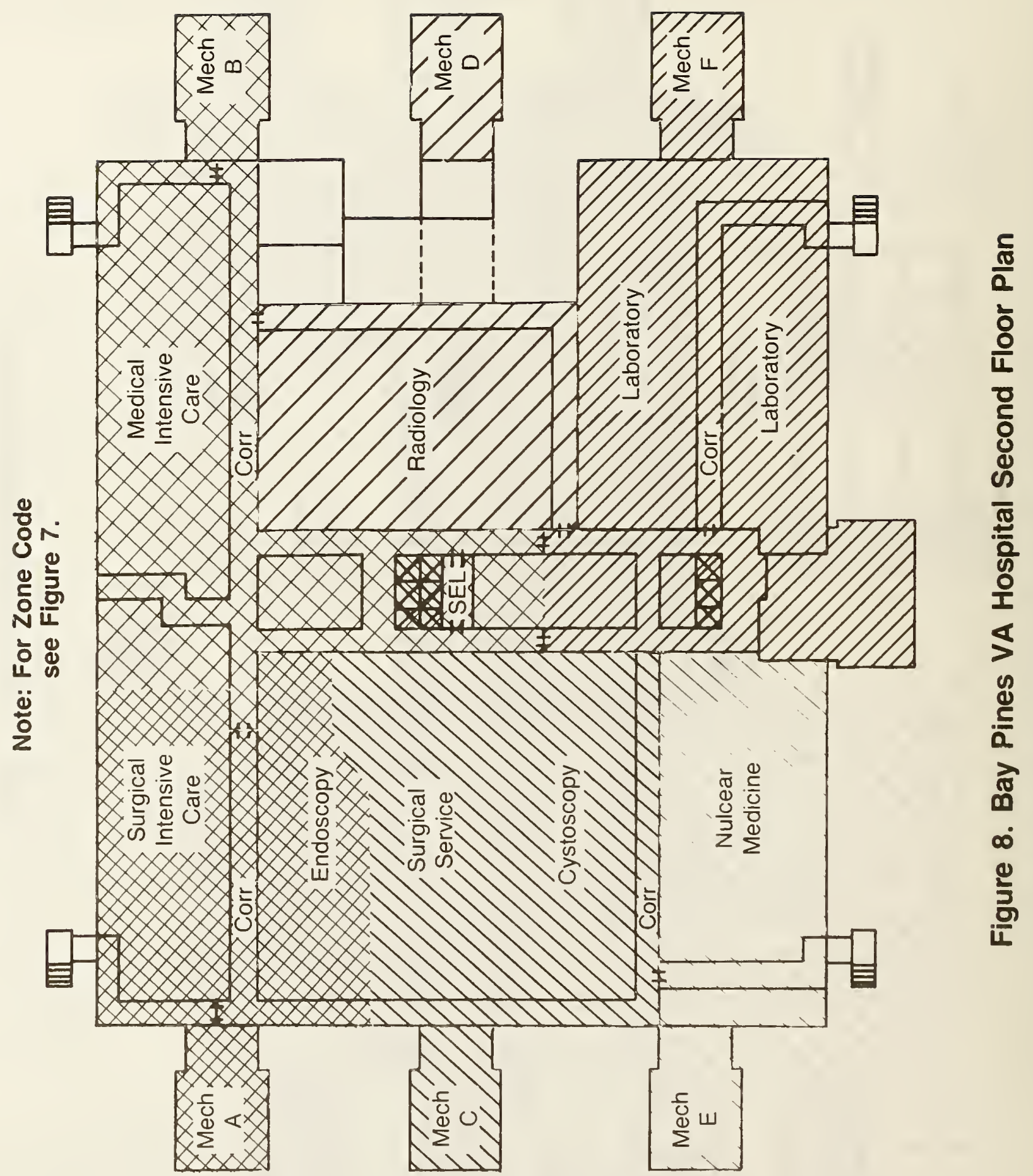




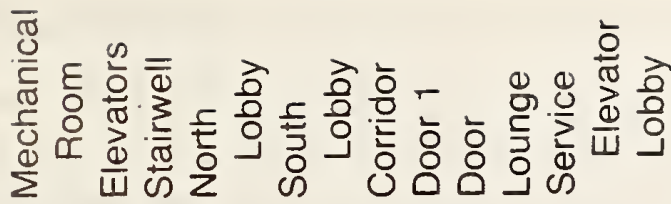

:

ธ

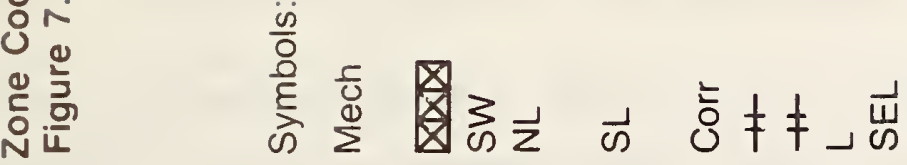

ㅎํ요

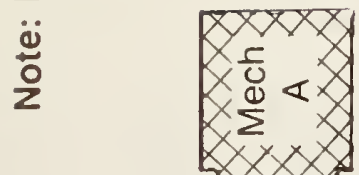

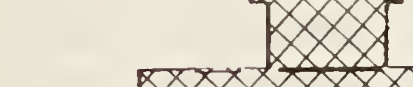

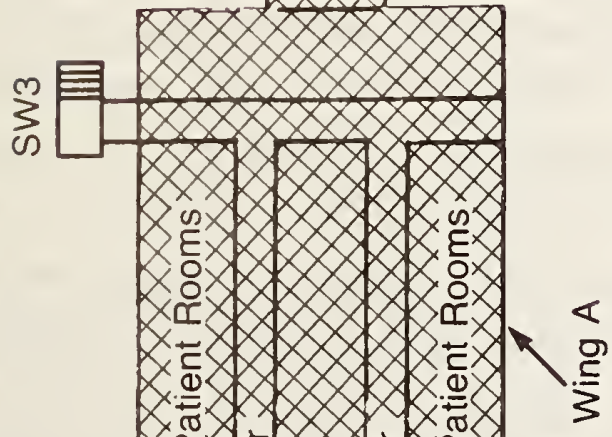

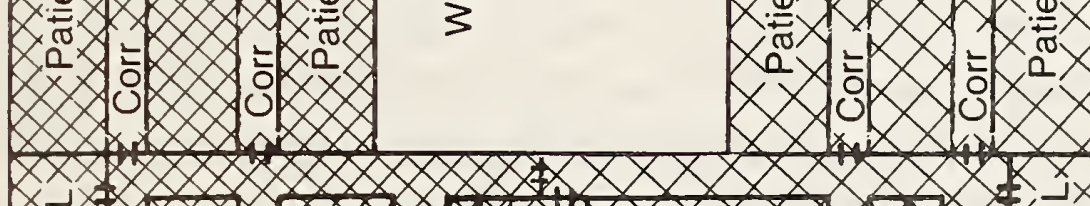

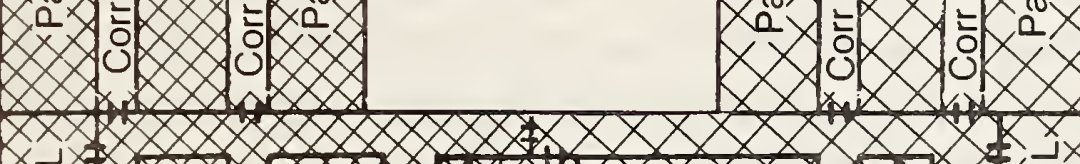

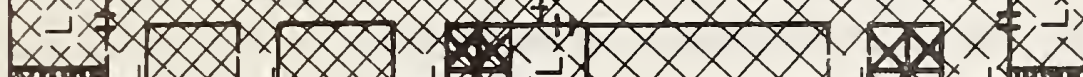

i

Xing की

เก

은

a

ल

๕ั้

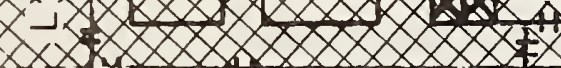
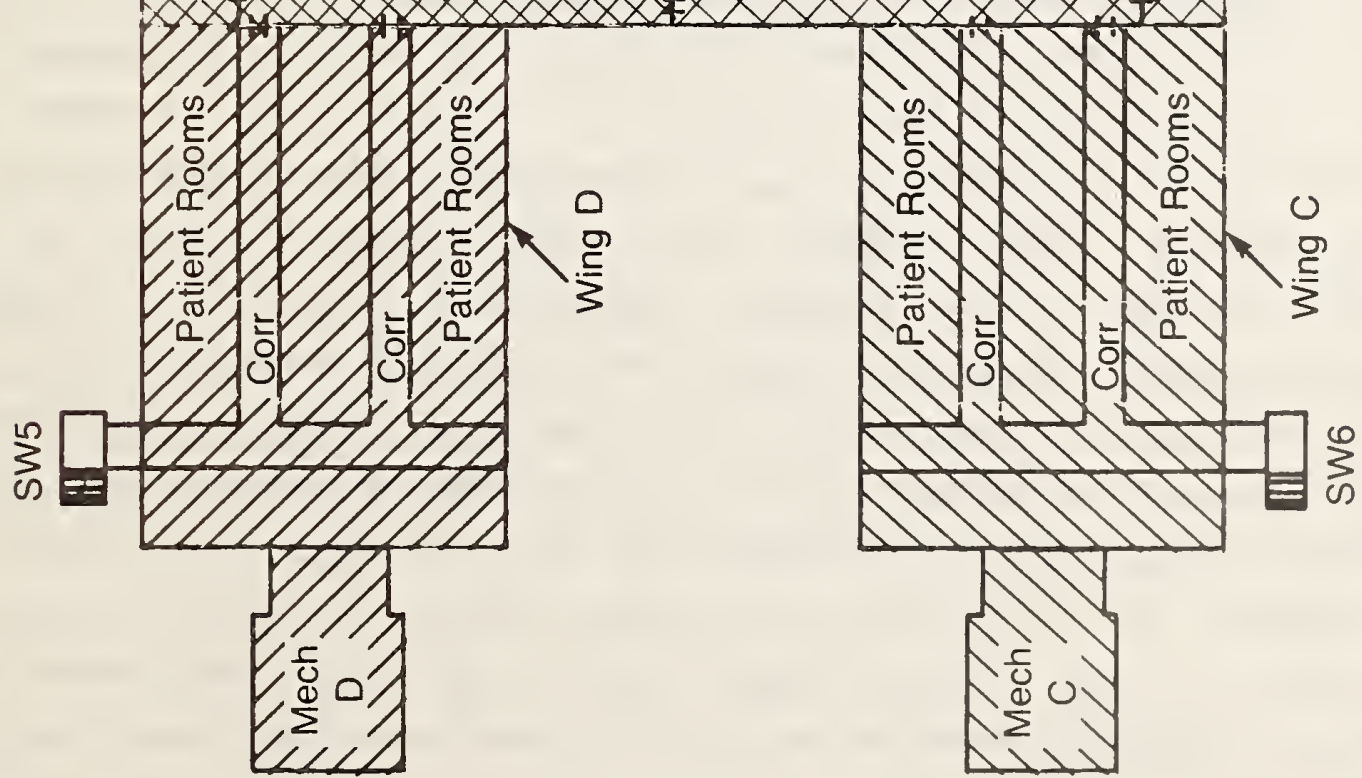

oั

定

$\frac{\infty}{0}$

बृ

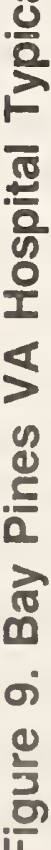


1. The supply fan to the zone in which the fire exists (smoke zone) is shut off.

2. The exhaust fans to the adjacent zones on the fire floor and to zones directly above and below are shut off.

Thus air is being exhausted from the smoke zone and surrounding zones are being pressurized. The intent is that smoke movement will be limited to the smoke zone.

Tests were performed for which individual zones were placed in the smoke control mode and the resulting pressure differences were measured. Data from these tests are listed in tables 1-19. All the pressure differences recorded were on the same floor as the smoke zone. Pressure differences are listed such that positive values represent airflow in the direction of the smoke zone. For example, in the test of zone A of the first floor (figure 7), the smoke control system produced 0.05 in $\mathrm{H}_{2} \mathrm{O}$ (12 $\mathrm{Pa}$ ) (table 1) under normal operation from zone $B$ to zone $A$ at corridor 4. This pressure difference indicates flow to zone $A$, which is the smoke zone. In some cases the flow was away from the smoke zone. Accordingly, the corresponding pressure differences in the tables are negative. This same measurement convention is used for the test data from other tests presented in this paper.

Smoke control systems were tested in every zone on the first, third, fourth, and fifth floors. Tests were omitted on the second floor because of the disruption they would cause to surgery and intensive care. Further, to prevent disruption of the second floor, no second floor exhaust fans were shut off during tests of first or third floor smoke control systems. It is believed that because of the unusually tight construction of the building floor slabs and the interstitial space floor slabs, pressurization of the spaces above and below the smoke zone is not essential. Visual inspection of these slabs impressed the author and the other members of the test team as to the tightness of construction. To confirm the effect of tight construction, a test was conducted on the fourth floor because this was the only floor where it was possible to shut off the exhaust fans on the floors both above and below. Because all the zones on the fourth floor would have been equally 
appropriate, zone B was arbitrarily selected. Zone B on the fourth floor was tested in an increased exhaust, smoke control mode with and without pressurization of the floors above and below. The results of these tests (table 13) indicate that pressurization above and below had no significant effect on the pressure differences produced by the smoke control system for this hospital.

Pressure difference fluctuations did not exceed 0.01 in $\mathrm{H}_{2} \mathrm{O}(2.5 \mathrm{~Pa})$, so only average values are listed in the tables. Also, during all of the tests of the Bay Pines Hospital reported here, the building's windows and doors were closed and the wind was relatively calm; accordingly, wind data are not listed in the tables. In all these tests, the difference between the indoor and outdoor temperature was very small. The implications of these limited test conditions are discussed in section 10.1 .2 .

\subsubsection{Airflow and Doors}

At numerous locations throughout the hospital, there are double-egress doors, as illustrated in figure 10. Upon fire detection, these doors close automatically and low airflow toward the fire through cracks around the doors (and through construction cracks) acts to prevent smoke backflow to the protected spaces. These doors act to prevent excessive pressures in the same manner as a barometric damper. If the airflow increases, the pressure across the door increases. When the pressure difference is sufficient to overcome the force of the automatic door closer, the door opens slightly, the pressure difference drops, and an equilibrium position is achieved with the door 1 to 4 in (25 to $100 \mathrm{~mm}$ ) open. Examination of the test data (tables 1-19) shows that the pressure across such open doors falls within a range of 0.03 to 0.12 in $\mathrm{H}_{2} \mathrm{O}$ ( 7.5 to $30 \mathrm{~Pa}$ ). From this, the airflow equation (ASHRAE smoke control manual, section 2.3.2) indicates that the average velocity through these doorways is 450 to $900 \mathrm{fpm}(2.3$ to $4.5 \mathrm{~m} / \mathrm{s})$. These values are all well above the design velocity range and accordingly would prevent smoke inflltration into the protected zones. 


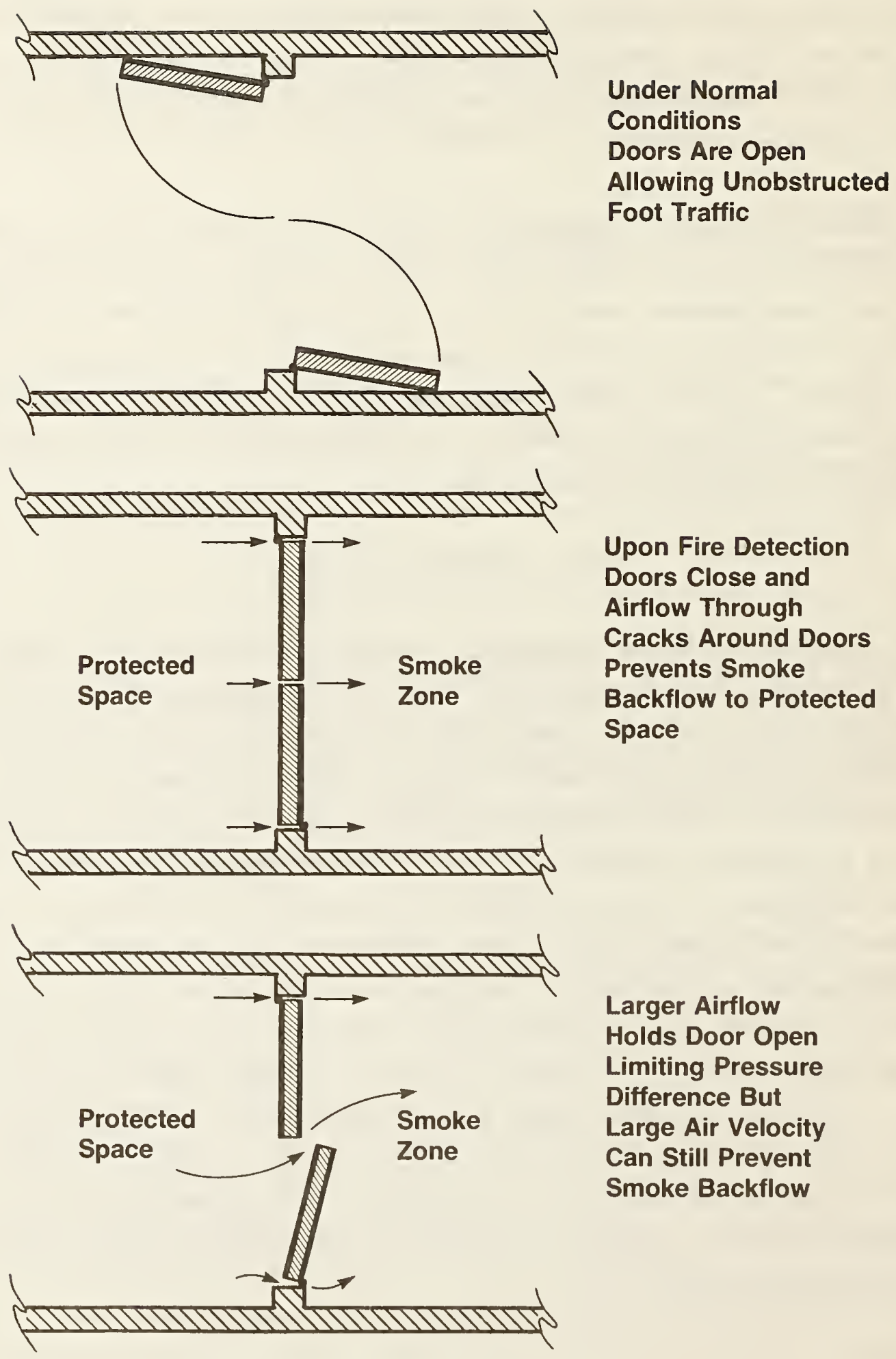

Figure 10. Operations of double egress doors in Smoke Control System 


\subsubsection{Increase Exhaust}

In the smoke control mode, the exhaust fan drew air from the interstitial space as well as the smoke zone. This interstitial space exhaust is required by the Life Safety Code [15] section 12-3.6.1 Exception No. 2(c) for hospitals, where the corridor walls do not extend through the interstitial space to the underside of the roof or floor slab above. It is believed that the intent of the interstitial exhaust was to produce pressure differences such that any smoke within the interstitial space would not flow into nonsmoke zones. However, there was concern that diverting a significant portion of the exhaust air from the smoke zone would adversely affect the performance of the smoke control system.

Most of the tests were performed with normal smoke control operation and with an increased smoke zone exhaust. The smoke zone exhaust was increased by blanking off the large interstitial space exhaust inlet located in the interstitial space near the mechanical room. In the majority of the cases, the pressure differences were significantly increased by increasing the smoke zone exhaust. Additionally, because of the tendency of the bidirectional doors to act like barometric dampers, excessive pressures were never encountered.

One might feel that even without increased exhaust, the pressure differences are generally above the minimum allowable pressure difference and should be acceptable. However, these pressure differences were measured without the influence of stack effect or wind. Such influences could be increased in the case of a broken fire compartment window. Even though this topic is the subject of a another effort of this overall project, it is obvious that increased flows and increased pressure differences due to increased exhaust provide an added margin which will help prevent smoke control system failure due to wind or stack effect.

\subsubsection{Zones $F$ and $G$}

Zones F and G, Ambulatory Care Clinic (see figure 7), on the first floor warrant special attention because they are completely open to each other at several locations. When zone $F$ was placed in the smoke control mode, the air 
velocity from zone $G$ to zone $F$ was almost unnoticeable. This would be no deterent to smoke flow into zone $G$ and then to other areas of the hospital.

For this case, the two HVAC zones should be treated as one zone for smoke control purposes. Tests of the combined zones (table 5) indicate that they maintain pressure differences in the range 0.10 to 0.12 in $\mathrm{H}_{2} \mathrm{O}$ (25 to $30 \mathrm{~Pa}$ ) with respect to zones $A$ and $H$. These pressure differences are many times larger than the minimum pressure differences.

\subsubsection{System Activation}

The smoke control systems are activated by smoke detectors located in the return ducts. When this hospital was designed, this was a common practice. The original intent of smoke detectors in the return ducts is to divert smokeladen air to the outside.* As stated in the ASHRAE smoke control manual, smoke detectors in ducts are not recommended for smoke control system activation because of their long response time and the maintenance problem of clogging with airborne contaminants.

The doors between zones are controlled by smoke detectors located in the vicinity of the door. However, activation of the smoke control system from these detectors would be inappropriate, because it would be impossible to know which zone was the smoke zone based on a signal from a detector located at the boundary between two zones.

Either open area detectors or the sprinkler system or both could be used for smoke zone identification and automatic activation.

\subsubsection{Floors Three, Four, and Five}

In a fire situation on a floor or a hospital with patient rooms, the smoke control system should operate so that it complements the horizontal

\footnotetext{
* The intent of the detector in the supply duct is to shut down the HVAC system and to prevent circulation of smoke from a HVAC fire or from an exterior source.
} 
evacuation discussed in section 9. The two fire scenarios described below evaluate the performance of the smoke control system on the floors with patient rooms. The first fire scenario involves a fire in one of the four wings (figure 9). For example, consider a fire in a patient room or other space on floor four in wing $A$. Due to smoke levels in the corridor, ${ }^{*}$ the wing is evacuated. Evacuation would be first to the north lobby and possibly later to the south lobby. Operation of the smoke control system should be such that the north lobby is pressurized with respect to wing $A$. The test data (table 12) show that this would be the case. Further, the test data (tables 8-19) show that the smoke control systems are capable of maintaining similar pressurization for each wing for the top three floors.

The second scenario consists of a fire in one of the lobbies or in an adjacent room such as a lounge. For example, consider a fire in a lounge opening onto the north lobby of the fourth floor (figure 9). The tests of the smoke control system (Table 12) indicate that the south lobby and wing $D$ would be pressurized relative to the north lobby. These pressures would protect wing $D$ and the south lobby from smoke migration. Unfortunately, the north lobby would be overpressurized with respect to wing A. Thus, the action of the smoke control system would be to force smoke into wing A. This situation is compounded further because the only route for horizontal evacuation of wing $A$ is through the north lobby, which would be smoke logged. The reason these flow patterns occur is that smoke control zone A incorporates both wing $A$ and the north lobby. If the north lobby were exhausted and wings $A$ and $D$ and zone $B$ were pressurized then this problem would be eliminated. This problem is not just limited to the fourth floor north lobby but is common to the north and south lobbies on the third, fourth, and fifth floors (tables 8, 9, 12, 13, 16, and 17 ).

Several negative pressure differences were measured in the tests of zones $C$ and $D$ on the third, fourth, and fifth floors (tables 10, 11, 14, 15, 18, and

\footnotetext{
${ }^{*}$ Closing the burn room door is widely recognized as a method to reduce smoke concentrations in corridors. However, in real fire incidents, patient room doors have been left open due to oversight or because the fire intensity made door closing impossible. Further, some spaces, such as the nurse station, have no doors.
} 
19). In keeping with our sign convention, negative pressure differences indicate an airflow away from the smoke zone. For example, zone $C$ of the third floor (Table 10) has negative pressure differences at three locations. These indicate flow from the south lobby to the south elevator shaft, to stairwel1 2, and to the north lobby. This airflow is to be expected, since zone $B$, which includes the south lobby, was pressurized. The crucial barrier for smoke control is between wing $C$ and the south lobby, where significant pressure differences occur. It can be observed from table 10 that increasing the exhaust of the smoke zone increases this crucial pressure difference. This same reasoning explains the other negative pressure differences encountered in the tests of zones $C$ and $D$ on floors three, four, and five.

\subsubsection{Specific Recommendations}

In general the performance of the smoke control system was quite good; however, to overcome specific problems, five recommendations are made. Recommendation C lists four different alternative solutions that can be considered.

A. It is recommended that smoke control zones $F$ and $G$ on the first floor be combined into one smoke control zone. Because at many locations these zones are completely open to each other, the use of pressurization to achieve smoke control between these zones is impossible. However, when the two zones are combined, pressurization of surrounding areas is readily achieved.

B. It is recommeded that consideration be given to modifying the smoke control systems so that activation of smoke control on the first or third floors will not cause pressurization of any second floor zone. Such pressurization would have essentially no benefit with regard to smoke control; however, it could cause unnecessary disruption to surgery and intensive care.

C. Is is recommended that smoke control zones A and B on floors three, four, and five be modified so that, upon fire detection in the north lobby or the south lobby, air and smoke will not be forced into one of the wings by 
the smoke control system. This can be achieved by going to HVAC shut off for fires detected in these elevator lobbies. Alternatively, the following exhaust modifications that might be considered are:

1. Damper Control. The alternative would consist of installing dampers so that the existing fans could be used. For example, to exhaust the north lobby, the exhaust fans and ducts of smoke zone $A$ would be used. A large number of dampers would be needed to shut off exhaust intakes in wing A. Further, a damper would be needed to shut off the supply to the north lobby.

2. Window Vents. This alternative consists of pressurizing the wings adjacent to the north (south) lobby and the adjacent lobby and venting the north (south) lobby. A damper in the supply duct to the north (south) lobby would prevent supply air from entering this lobby. The vents, which could be located in the windows, would open automatically upon activation of the smoke control system. A damper in the supply duct to the north (south) lobby would be needed. Because this system has vents in vertical walls, performance would be highly dependent on wind conditions, making this the least effective of the systems listed here.

3. Celling Fan. Pressurization of surrounding areas would be the same as alternative $B$, but a ceiling-mounted exhaust fan from the north (south) lobby to the interstitial space would be used. Smoke could be exhausted from the interstitial space by an exhaust fan in mechanical room A (B). This would require additional control dampers in the exhaust system. Even though this system has the same potential for producing reliable pressurization as alternative 1 , it has the disadvantages that it contaminates the interstitial space with smoke and probably subjects the ceiling fan to high temperatures.

4. Ducted Exhaust. An improvement on alternative $C$ is to locate the exhaust fan in one of the mechanical rooms and duct the lobby air to it. A cursory inspection reveals that there should be sufficlent space for such a duct in the interstitial space. This alternative has 
simple controls, eliminates the interstitial space contamination problem of alternative $C$, and has the same potential for producing reliable pressurization as alternatives $A$ and $C$. This alternative also has the advantage over alternative $C$ in that smoke cooled by heat transfer in the duct reduces the concern of temperature endurance of the fan.

D. Activation of the smoke control system depends upon fire detection, which should be by open area smoke detectors, by flow switches in the sprinkler system, or by both. The use of flow indicators would require some logic circuits or reliance on the building's computer control to determine the location of the fire.

E. It is recommended that consideration be given to increasing the smoke zone exhaust by closing the dampers to the interstitial space exhaust. This will provide an increased exhaust flow rate, which will help prevent smoke control system failure due to wind or stack effect. Because of tight construction of the building floor slabs and interstitial space floor slab, it appears that interstitial space exhaust would be of benefit only when smoke would get into the interstitial space. However, interstitial space exhaust can be achieved without use of the smoke zone exhaust fan by using an exhaust fan serving one of the nonsmoke zones.

\subsection{Loma Linda VA Hospital}

The VA hospital at Loma Linda, California, consists of four stories, each with an interstitial space above, with the floor plans shown in figures 11-14. This hospital was designed to the same building system concept as was the Bay Pines VA Hospital. Except for some high risk spaces such as storage areas, the Loma Linda Hospital is not sprinkled.

The smoke control system is designed so that each HVAC zone (see figures 11-14) is a smoke control zone. During a fire situation, the HVAC system, controlled by a computer, is put in the normal smoke mode which consists of shutting off the supply fan to the zone and closing the recirculating air damper to the zone in which the fire exists. This results in exhausting air from the fire zone to the outside but not pressurizing any surrounding zones. 


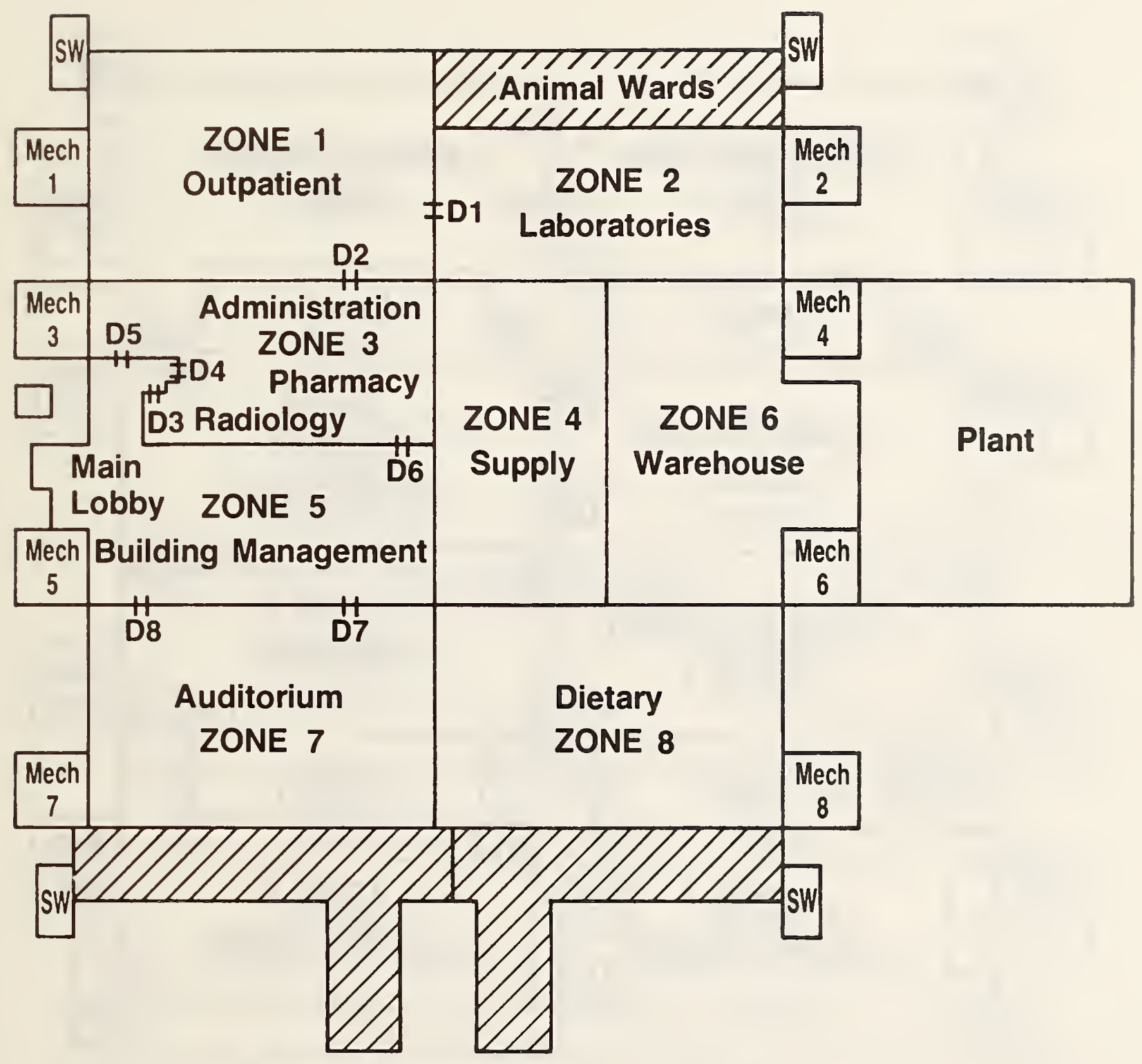

Notes: Spaces served by mechanical rooms of like number. Areas with cross hatching are served by mechanical rooms in the basement.

Figure 11. Loma Linda VA Hospital First Floor Plan 


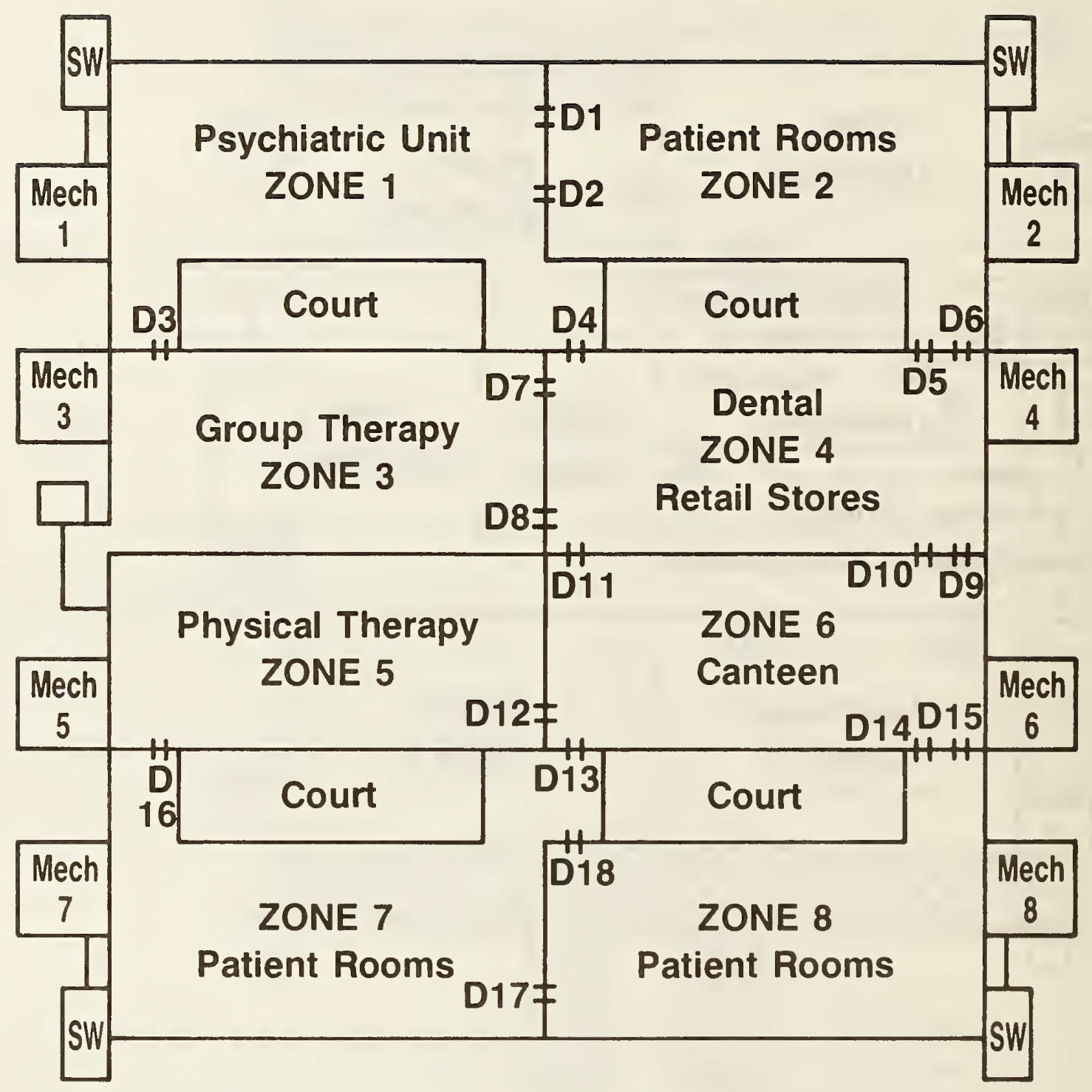

Note: For symbols see Figure 9.

Figure 12. Loma Linda VA Hospital Second Floor Plan 


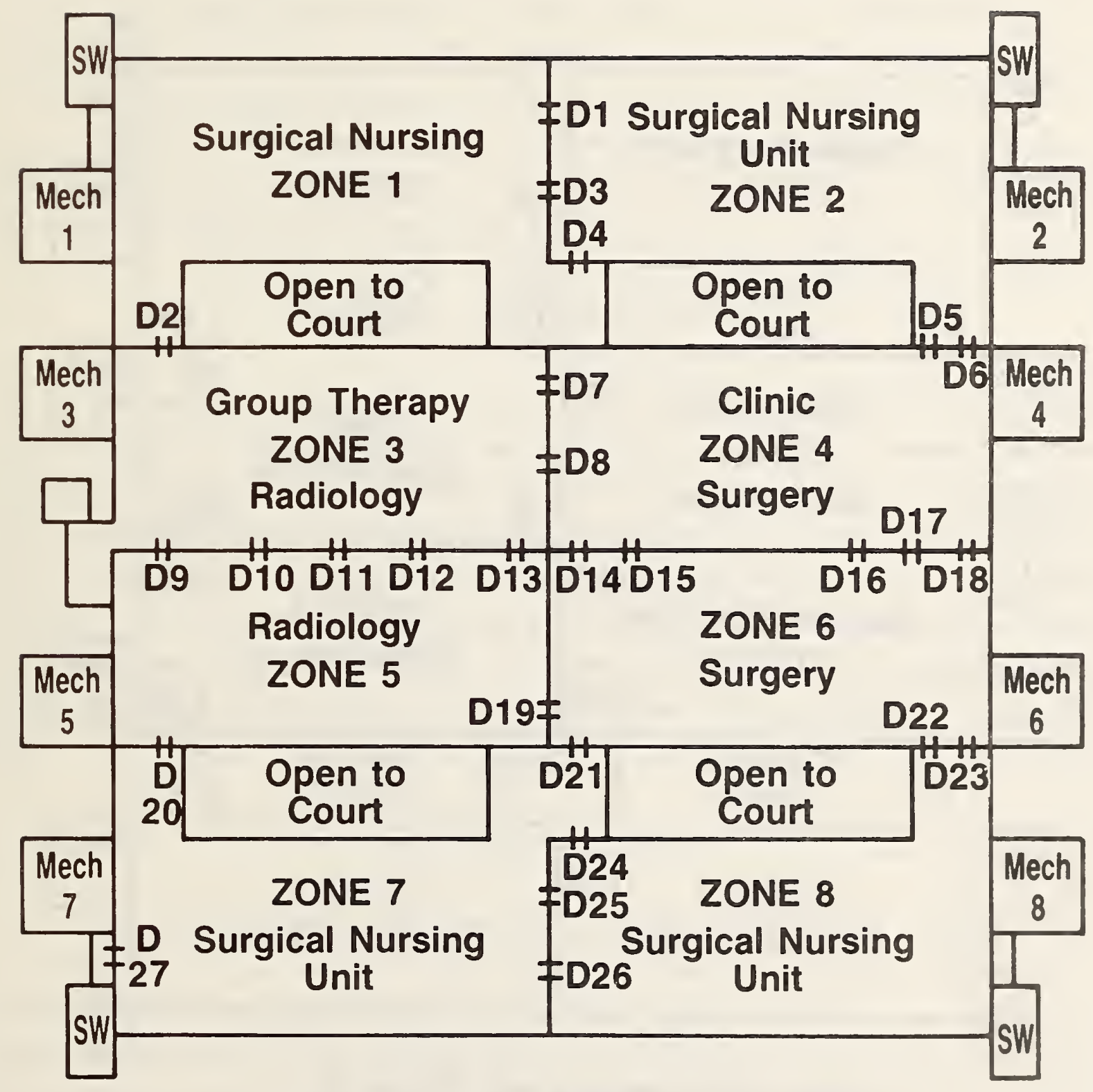

Note: For symbols see Figure 9.

Figure 13. Loma Linda VA Hospital Third Floor Plan 


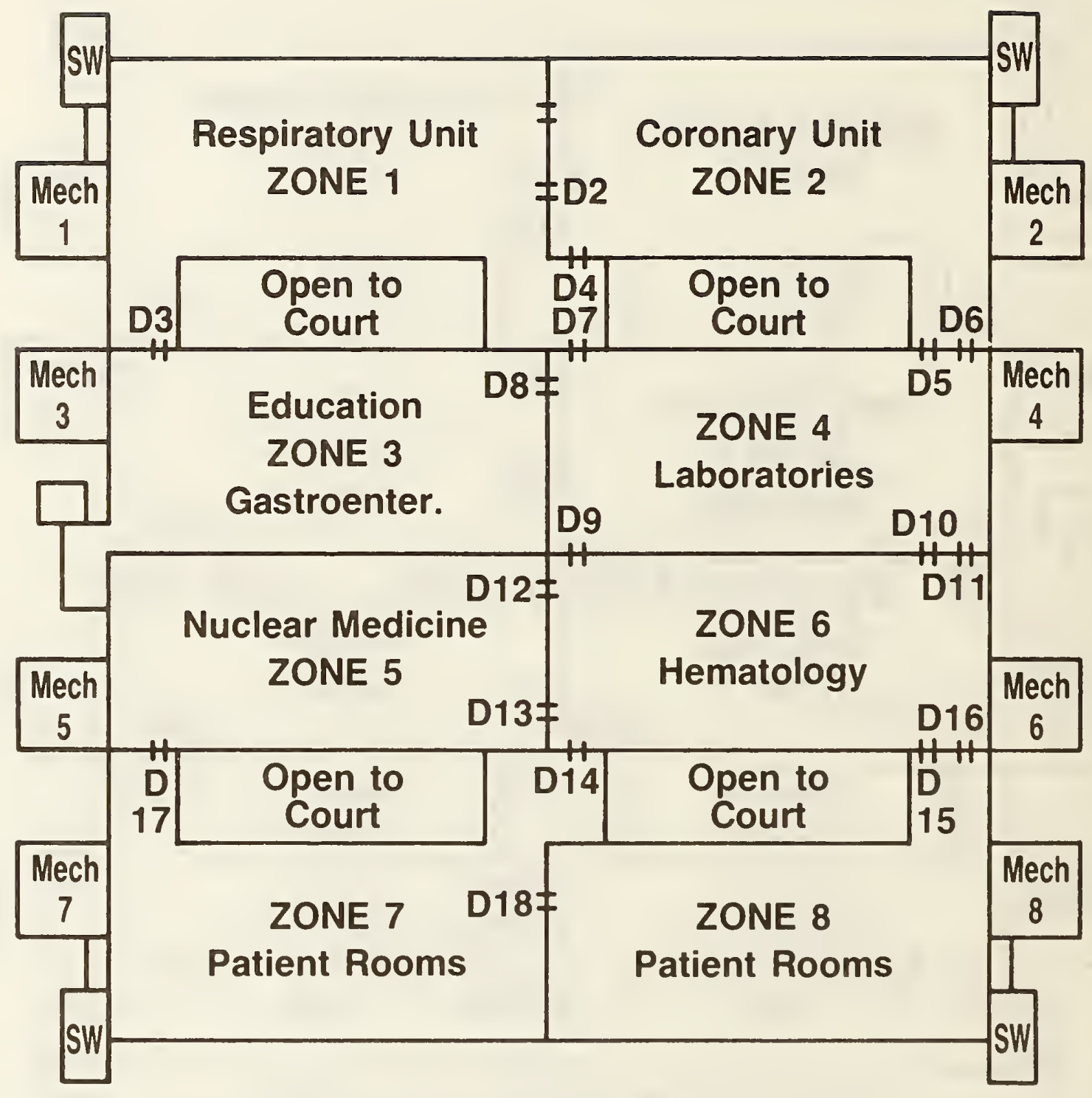

Note: For symbols see Figure 9.

Figure 14. Loma Linda VA Hospital Fourth Floor Plan 
Tests were performed by putting individual zones in smoke control operation and measuring the resulting pressure differences. Data from these tests are listed in tables 20-41. Except as noted otherwise, the selection of the zones to be tested was arbitrary. Also, during all the tests summarized in tables 20-41, the building windows and doors were closed and the wind was relatively calm. The difference between the indoor and outdoor temperature was very small. Accordingly, wind data and temperature data are not listed. An additional test was conducted with an open exterior door and pressure and wind data from this test is presented later.

\subsubsection{Double Egress Doors}

At the Bay Pines Hospital, it was found that double egress doors act to prevent excessive pressures in a manner like a barometric damper (section 10.1.1). Two smoke control tests (table 23 and 36) were arbitrarily selected where measurements were made with doors held open by air flow and doors held shut. These doors perform in the same manner as those at the Bay Pines Hospital. It was evident during the tests that some other smoke zones also had sufficient flows that doors in those zones were held slightly open. Unless otherwise noted the test data was taken without holding such doors shut.

\subsubsection{Elevator Lobbies}

Because of the problem with smoke control for the elevator lobbies on the upper three floors of the Bay Pines VA Hospital (section 10.1.5), the elevator lobbies of the top three floors of the Loma Linda Hospital were evaluated. These lobbies are in the spaces between the courts (figures 12, 13, 14). These lobbies are provided supply air from the main zone they are part of, however, exhaust air is handled by the toilet exhaust system. The southern lobby on the third floor is typical. This lobby is part of zone 7 and $1 \mathrm{~s}$ shown on figure 15. The system maintains pressure differences in the range of 0.14 in $\mathrm{H}_{2} \mathrm{O}(35 \mathrm{~Pa}$ ) for the main part of the zone and lower values of 0.03 in $\mathrm{H}_{2} \mathrm{O}(7 \mathrm{~Pa})$ for the elevator 1obby. Unlike the Bay Pines VA Hospital, smoke from a fire in this elevator lobby (or in a space open to it, such as the toilet or receiving) would not be forced by the smoke control system in 


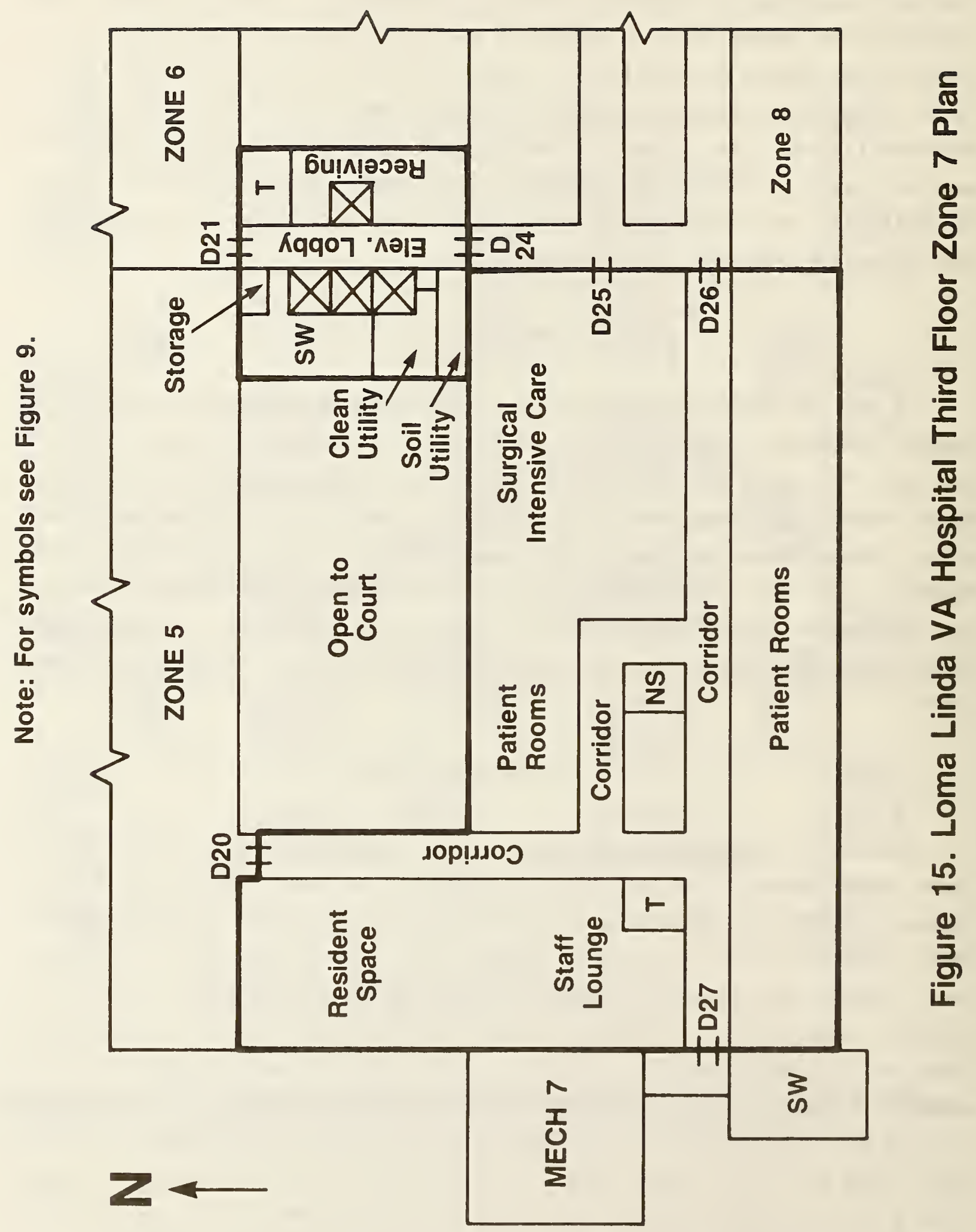


adjacent zones. Considering this and the fact that most of the (utility, receiving, and storage) spaces that open into the elevator lobby are sprinkled, thus there is not the concern here as there was for the elevator lobbies in the top three floors of the Bay Pines Hospital.

\subsubsection{System Activation}

Like the Bay Pines Hospital, the smoke control system at Loma Linda is activated by duct smoke detectors and the same concerns exist about this method. Either open air detectors or sprinkler system or both could be used for smoke zone identification and automatic activation.

\subsubsection{Open Exterior Doors and Windows}

Frequently window glass in the vicinity of a fire breaks and falls out of the window frame. This is believed to be caused by a combination of differential thermal expansion, buoyancy induced pressure difference and stack effect induced pressure difference. Also exterior doors to the smoke zone may be opened by the occupants or fire fighters. For some time, the effect of such openings on the smoke control system performance has been a concern. For this reason, an open door study was conducted at the Loma Linda VA Hospital. Zone 7 on the third floor was arbitrarily selected and instrumented with contact switches on doors and differential pressure transducers. Inside and outside temperature and wind velocity and direction were measured. A microcomputer was used for data acquisition and data reduction.

The data from this test with smoke control plus pressurization of adjacent zones is presented in figure 16. This figure presents the status (opened or closed) of doors 20, 26, and 27. When the exterior door (door 27 in figure 15) was opened, the pressure difference across door 26 dropped from about 0.20 in $\mathrm{H}_{2} \mathrm{O}(50 \mathrm{~Pa})$ to about 0.06 in $\mathrm{H}_{2} \mathrm{O}(15 \mathrm{~Pa})$. Throughout the test, the hospital was in normal operation as evidenced by the opening and closing of doors 20 and 26. Door 25 to surgical intensive care was closed. As might be expected, the opening of either door 20 or 26 resulted in a drop in pressure difference across door 26. The contact switches on the doors only register open or closed, and a door can be almost completely closed and st 111 

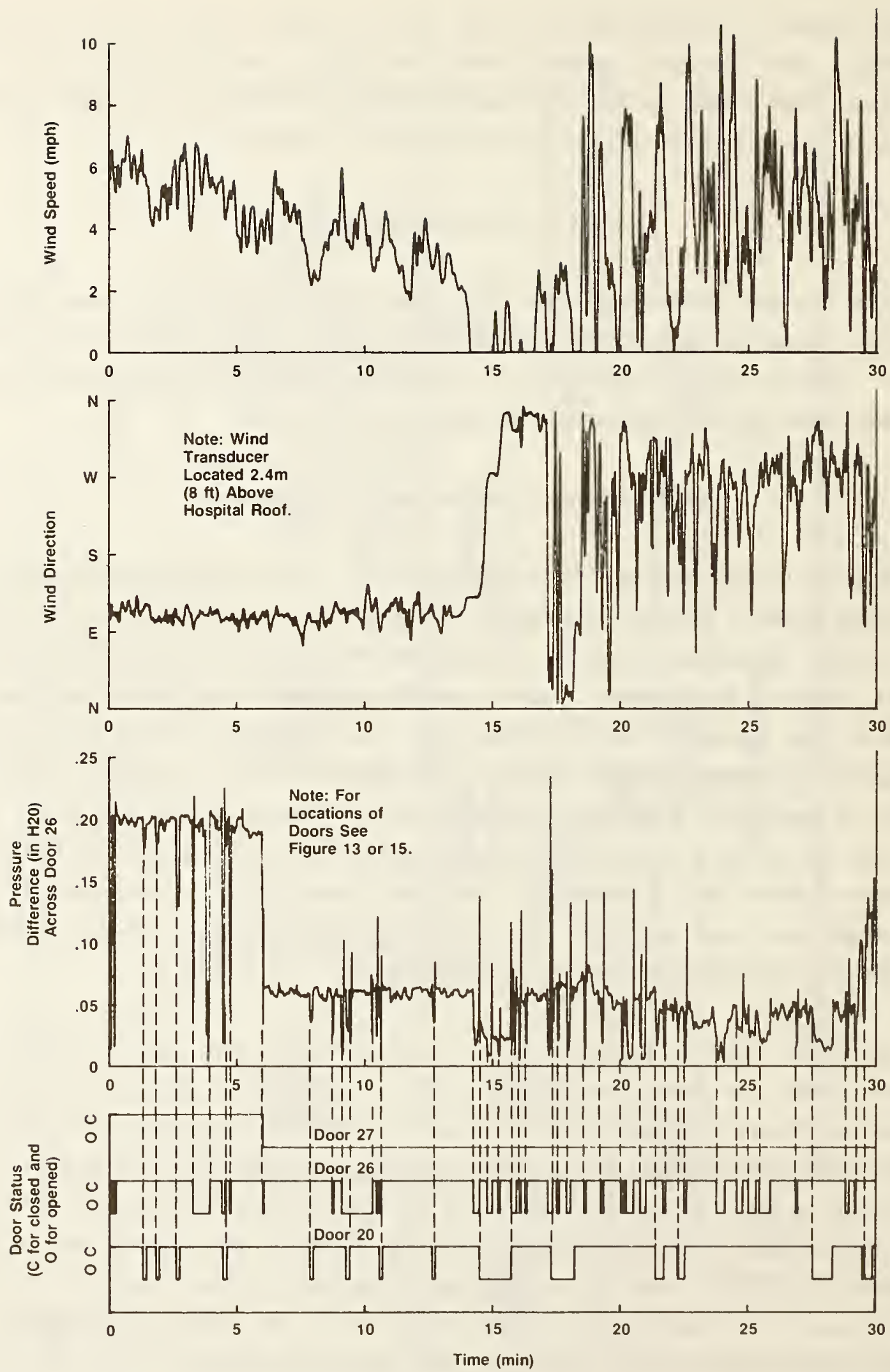

Figure 16. Data from open door study at Loma Linda VA Hospital 
register as opened. At about 9 minutes, door 26 opened and it appears from the pressure curve it closed a few seconds later, but apparently the contact switch falled to make contact and the door registered as opened until a little after 10 minutes when it was opened again. A same thing happened at door 20 at about 17 to 18 minutes. At about 14 minutes and again at 28 minutes door 20 was held open for a minute or a little more. This resulted in a drop of the pressurization to about 0.02 in $\mathrm{H}_{2} \mathrm{O}(5 \mathrm{~Pa})$.

of course, during a real fire considerable traffic can be anticipated to evacuate the smoke zone. However, it seems unlikely that during such an evacuation a person would hold open one of the doors to the smoke zone letting smoke flow out into other zones for several minutes. It seems much more likely that people aiding in the evacuation would open the doors as they went through and let them close automatically behind them. With the exterior door open and neglecting the short lived drops in pressure due to other doors opening, the system maintains pressure differences in the range of 0.05 to 0.06 in $\mathrm{H}_{2} \mathrm{O}(12$ to $15 \mathrm{~Pa})$.

During the first 14 minutes of this test the wind fluctuated between 2 and $7 \mathrm{mph}$ ( 1 and $3 \mathrm{~m} / \mathrm{s}$ ) from east by southeast. At about 15 minutes, the wind direction suddenly changed to a more gusty wind between 0 and $10 \mathrm{mph}$ ( 0 and $4 \mathrm{~m} / \mathrm{s}$ ) coming from what appears to be predominantly the west. It can be concluded that these winds have a very minor effect on the performance of the smoke control system.

\subsubsection{System Performance}

The Loma Linda Hospital achieved pressure levels above the minimum pressure difference (section 9.1) for a sprinklered hospital but not for an unsprinklered hospital throughout. Of the twenty-two tests listed in tables 20-41, seventeen produced pressure differences of 0.06 in $\mathrm{H}_{2} \mathrm{O}$ ( $15 \mathrm{~Pa}$ ) at the barriers of the main smoke zone (not including at elevator lobbies that are part of the zone being tested).

Zones 3 and 5 on the first floor performed poorly for an unsprinklered hospital with pressure differences in the range of 0.03 to 0.06 in $\mathrm{H}_{2} \mathrm{O}$ (7 to 
$15 \mathrm{~Pa})$. These zones were in the vicinity of the main entrance and the leakage areas associated with such an entrance may have contributed to the low level of performance. Examination of the zones ( $A$ and $B$ ) near the main entrance of the Bay Pines VA Hospital (tables 1 and 2) shows a number of locations where such pressures were measured.

The three other cases with pressure differences below 0.06 in $\mathrm{H}_{2} \mathrm{O}(15 \mathrm{~Pa})$ are zone 6 on the second floor (table 26), zone 8 on the third floor (table 36 ) and zone 2 on the fourth floor (table 38). In these zones most of the pressures are above 0.06 in $\mathrm{H}_{2} \mathrm{O}(15 \mathrm{~Pa})$. For zone 8 on the third floor (table 36 ), the system was also tested by pressurizing the adjacent zones (6 and 7 ) by shutting down the return fan and closing the associated damper. This increased all pressure differences significantly so that the lowered value was 0.10 in $\mathrm{H}_{2} \mathrm{O}(25 \mathrm{~Pa})$. The control system could be modified so that for all smoke zones the adjacent zones would be pressurized. This would increase pressurization and help to eliminate situations where pressure differences are less than the minimum design value of 0.06 in $\mathrm{H}_{2} \mathrm{O}(15 \mathrm{~Pa})$ for an unsprinkled hospital. It should be noted that even levels of pressurization below this value provide some reduced measure of protection. They are preferrable to shutting down the HVAC system in that the smoke control mode acts to prevent smoke movement through ducts.

\subsubsection{Specific Recommendations}

If area detectors or sprinklers are added to the hospital, it is recommended that the signals from these be used for activation. It is also recommended that the smoke mode be modified to include pressurization of adjacent zones.

\subsection{San Diego VA Hospital}

Unlike the field tests already discussed, the tests at the San Diego VA Hospital consisted of only one day of testing intended to identify any obvious problems, and, if possible, recommend corrections. The San Diego VA Hospital consists of six stories, each with an interstitial space above for distribution of heating, ventilation, air-conditioning, plumbing and electrical 
systems. Air handling equipment (fans, coils, filters, etc.) is also located within the interstitial space. The interstitial space is approximately $8 \mathrm{ft}$ $(2.4 \mathrm{~m})$ in height and is separated from the floor below by only suspended ceiling system. Except for a few high risk areas, this hospital is unsprinklered.

The top five floors consist of four wings and a central core which contains the elevators as shown in figure 17. Each wing is served by its own HVAC system which is, for the most part, a $100 \%$ outside air system. The central core is supplied with air from all the wings but exhausted by a single fan located in the penthouse. The smoke control system is arranged such that each floor of each wing is a separate smoke control zone. In the event of a fire in one of the wings, the HVAC system, controlled by a computer, is put in the following smoke control mode:

1. The supply fan to the zone in which the fire exists (smoke zone) is shut off.

2. Exhaust fans serving all other wings of the fire floor are shut off, and exhaust fans serving the wings directly above and below are also shut off.

Thus air is being exhausted from the smoke zone and other zones are being pressurized. The intent is that smoke movement will be limited to the zone in which the fire exists. This system is activated by pull boxes, water flow swltches, heat detectors and duct smoke detectors.

When the system was designed no provisions were made for a fire in the central core (see figure 17). However, a core smoke control system is currently being installed which will operate as follows:

1. Dampers in the duct supplying the core close to shut off supply air to the core area on the floor (smoke zone).

2. Dampers in the core exhaust system close on a11 other floors. 


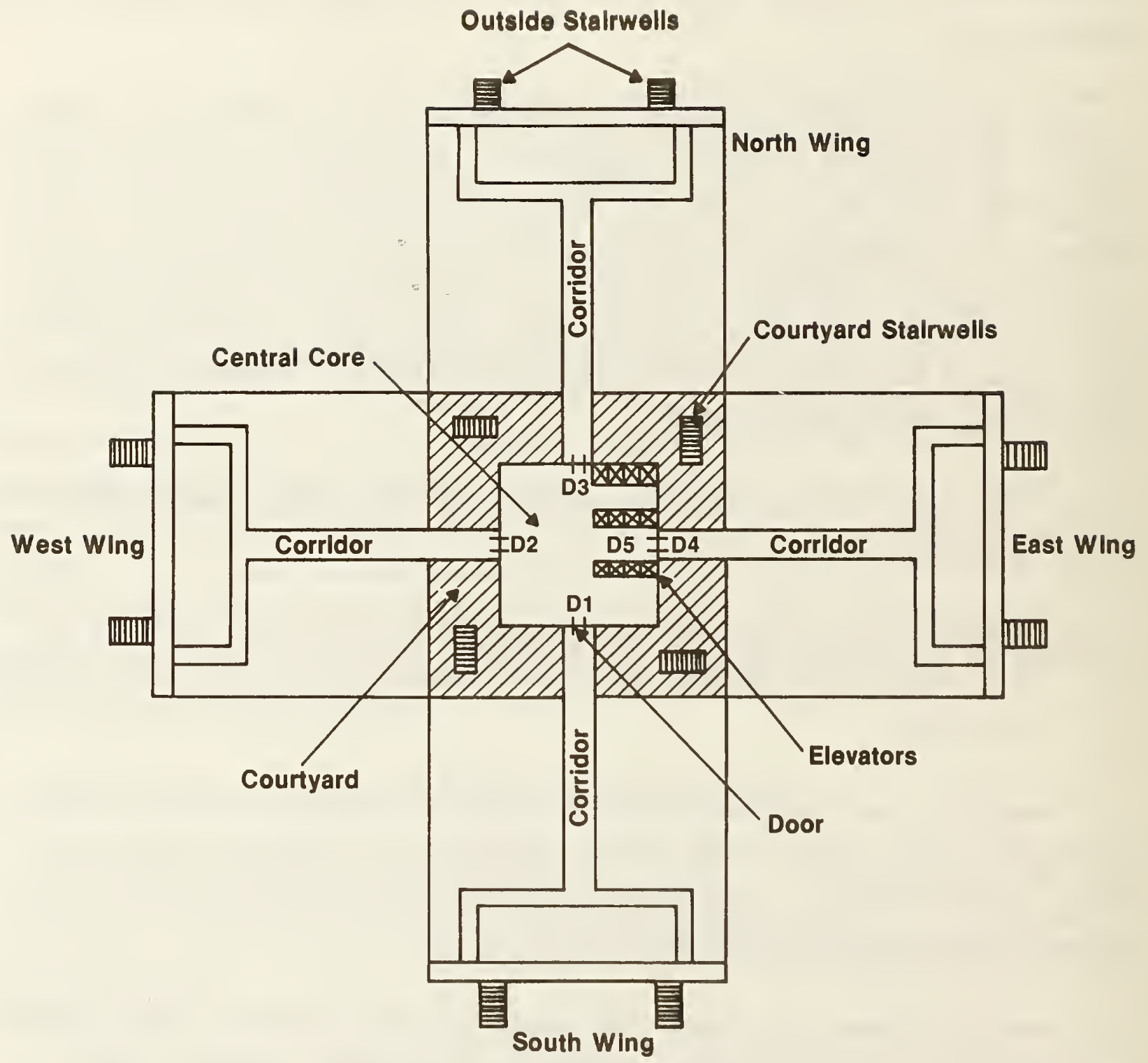

Figure 17. San Diego VA Hospital Typical Floor Plan 
3. Exhaust fans serving the wings of the top five floors are shut off.

This system also is intended to be activated by pull boxes, water flow switches, heat detectors and smoke detectors. The dampers for the system were all Installed so that operation could be simulated by manually controlling the dampers.

\subsubsection{Wing System}

The third floor south wing was tested as the smoke zone in order to compare the system performance with NBS measurements of the same system which were made approximately eight years earlier [17]. The test results from the earlier study for normal smoke control operation and the results from this study are listed in table 17. In the previous study the smoke control system produced only 0.02 in $\mathrm{H}_{2} \mathrm{O}$ ( $5 \mathrm{~Pa}$ ) from the core to the south wing, while the current tests produced 0.04 in $\mathrm{H}_{2} \mathrm{O}(10 \mathrm{~Pa})$. This increase, possibly due to modifications in construction, still results in a pressure difference considerably below the minimum pressure difference for àn unsprinklered space.

It was hypothesized that this poor performance was due to exceptionally high leakage from the outside to the south wing. This would result in exhaust air being pulled directly from the outside rather than through the core. Leakage areas were evident in the gaps around the exterior six doors of this wing to the outside balcony. These door gaps were sealed with tape and the system was retested (table 42). The pressure difference from the core to the south wing had increased to 0.05 in $\mathrm{H}_{2} \mathrm{O}(12 \mathrm{~Pa})$ which was still below the desired minimum pressure difference but which indicated that at least some of the poor performance was due to high leakage from the outside.

The suspended ceiling separating the building space of the south wing and its interstitial space had several obvious openings at poorly fitting tiles and missing tiles in addition to the normal cracks between tiles and suspension system. In addition, the interstitial space had several vents directly to the outside. Because it was suspected that air flow from the outside through these vents and then through the suspended ceiling reduced the smoke control system effectiveness, these vents were blocked of $f$ and the system 
retested. This increased the pressure difference from the core to the south wing to 0.06 in $\mathrm{H}_{2} \mathrm{O}(15 \mathrm{~Pa})$.

\subsubsection{Core System}

The core smoke control system was tested on the third floor and the test results are listed in table 43. In these tests the pressure differences between all the wings and the core are important. The low pressure differences across these boundaries in the normal smoke mode (table 42) was probably due to insufficient exhaust capacity. Inspection of the core indicated that it was relatively air tight to the outside as compared to the south wing. This led the testing team to suspect that if one or more paths for air from the core to the outside existed, then increased flow from the wings would result in increased pressure difference. To test this hypothesis three of the windows in the core were opened and the pressure differences increased from a range of 0.02 to 0.03 in $\mathrm{H}_{2} \mathrm{O}\left(5\right.$ to $7 \mathrm{~Pa}$ ) to a range of 0.05 to $0.08 \mathrm{In}_{2} \mathrm{O}$ (12 to $20 \mathrm{~Pa}$ ).

The system being installed in the core should be reevaluated because of its poor performance. Its capacity can be increased by increasing the exhaust capacity or by the addition of vents from the core directly to the outside. Such vents should be located on at least two opposite outside walls to minimize any adverse effects of the wind.

\subsubsection{Interstitial Space}

Consideration should be given to blanking off the vents from the interstitial space to the outside. This will improve the performance of the smoke control system in the third floor south wing, and probably in all the other wings because of similar construction. Further with the vent open it is questionable whether the interstitial space exhaust is capable of preventing smoke downflow through the suspended ceiling from the interstitial space. Smoke from a fire in a building space can flow up through the ceiling system into the interstitital space, cool and then flow down through the ceiling into a remote space thereby causing hazardous conditions. It has been shown by Klote [18] that this hazard can be prevented by use of an interstitial space 
exhaust at a rate of two air changes per hour, provided that the leakage area between the interstitial space and the outside is relatively small. The exhaust capacity of the interstitial space should be reexamined. If it is below two air changes, it should be increased to, and possibly above this value if improved smoke control system performance is desired.

\subsubsection{System Activation}

Smoke control system activation by pull boxes should be reevaluated. Pull boxes activate the smoke control zone in which they are pulled. However, it is conceivable that they might be pulled in a zone other than the fire zone, resulting in the system aiding smoke spread rather than preventing it. If possible, activation should be by means of open area smoke detectors, sprinkler water flow, or both. Activation only by duct detectors is not recommended because of the long response time and the maintenance problems associated with these units.

\subsection{Martinsburg VA Hospital}

Like the tests of the San Diego Hospital, the test at the VA hospital at Martinsburg, West Virginia, consisted of only one day to identify any obvious problems and, if possible, to recommend corrections. The hospital consists of six stories. Air handlers located above the sixth floor provide the heating and cooling for most of the top five floors of the hospital. Vertical supply and return ducts serve zones on several floors. In an attempt to achieve smoke control, a supply damper is closed to the zone in which a fire exists. A recirculation damper is closed so that $100 \%$ of return air is exhausted to the outside and $100 \%$ of the supply air is from the outside.

The performance of this system was tested in zone 2 on the sixth floor (figure 18 and table 44). The pressure differences produced were from 0.005 to 0.02 in $\mathrm{H}_{2} \mathrm{O}$ ( 1.2 to $5 \mathrm{~Pa}$ ) which is below the minimum design values even for a sprinkled hospital.

When this hospital was built many respected engineers in the HVAC field considered the approach used to be acceptable. However, it is now apparent 
that this type of system does not work well. Determination of what, if anything, should be done about this smoke control system is difficult. Smoke dampers could be placed in the return duct to shut off return from non-smoke zones. This has the potential to produce sufficient levels of pressurization; however, because of high cost and low system reliability, as discussed later, it is not favored. The system could be modified for shut down operation in fire situations. Unfortunately, to achieve this and be in compliance with the codes, a number of fire dampers would probably need to be added.

\subsection{Richmond VA Hospital}

The test at the VA hospital at Richmond, Virginia consisted of only one day with the same intent as the test at San Diego and Martinsburg. This hospital consists of four floors and the tests were limited to the top floor. Figure 19 shows the six smoke zones on this floor. Mechanical room 1 provides heating and cooling for zones 1,2 and 3; and mechanical room 2 provides heating and cooling for zones 4,5 and 6 . In the event of a fire in one of the zones, a damper in the supply to that zone shuts, but no dampers are shut in the return. The recirculation damper is closed so that all exhaust is to the outside and all supply is to the outside. This can be thought of as a horizontal adaptation of the system used at Martinsburg.

The systems on the sixth floor were tested twice (table 45). In the first test pressure differences at the boundary of the smoke zones ranged from -0.01 to 0.03 in $\mathrm{H}_{2} \mathrm{O}(-2$ to $7 \mathrm{~Pa})$. The negative value was due to air flowing from the smoke zone - a complete failure of the system. This poor performance was attributed to errors in the control system and dampers that did not shut properly. After HVAC mechanics spent considerable time adjusting this system it was tested again. The resulting pressure differences range from 0.01 to 0.03 in $\mathrm{H}_{2} \mathrm{O}$ ( 2 to $7 \mathrm{~Pa}$ ). This is an improvement, but performance is still not acceptable. The remarks about what could be done about the Martinsburg hospital apply to the Richmond hospital as well. 

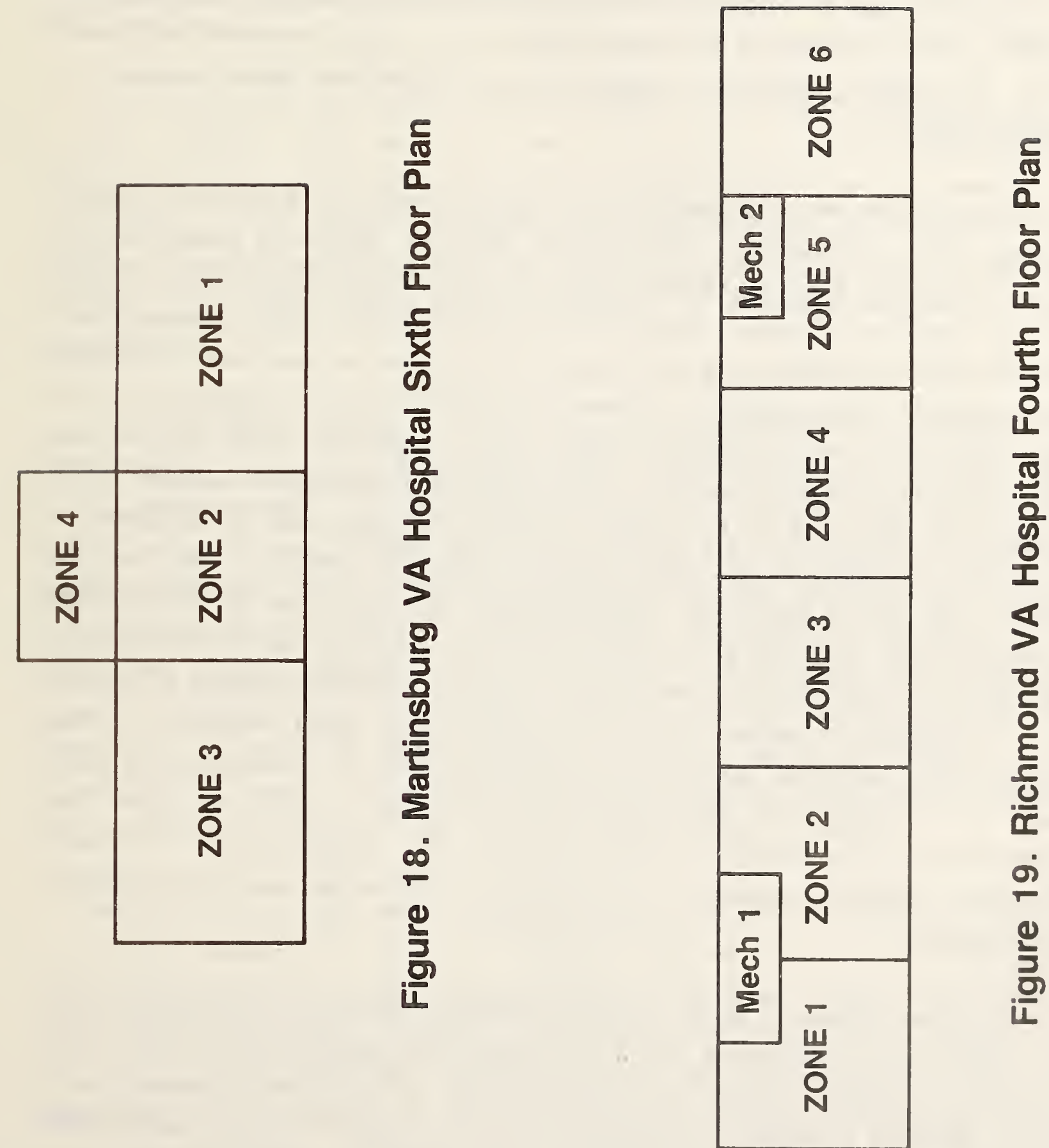


\section{SMOKE CONTROL SYSTEMS}

\subsection{VA Building System Hospitals}

Currently, new VA hospitals are fully sprinkled and designed and bullt in accordance with VA Hospltal Bullding System [16]. These hospitals lend themselves to simple, reliable, inexpensive and effective smoke control as explained below.

These systems would be basically like those tested at Bay Pines, Florida and Loma Linda, California. Smoke control would be limited to exhausting the zone in which the fire is located (the smoke zone) and pressurizing adjacent zones on the same floor. Because of the interstitial space construction, pressurization of zones above and below is not needed as was shown at the Bay Pines hospital. This would be achieved by shutting down the supply fan to the smoke zone and shutting down the return fans to adjacent zones on the same floor. For recirculation systems, the appropriate recirculation dampers would be closed so that $100 \%$ of the return air from the smoke zone is exhausted to the outside and $100 \%$ of the supply air for adjacent zones is taken from the outside. For new VA hospitals, total sprinkler protection and smoke detection at egress doors only are the current VA policy. System activation would be primarily from water flow in the sprinkler system. Secondary means of activation in addition to water flow could include duct smoke detectors. Some engineers have expressed concern that activation based on sprinkler flow would result in a delay over smoke detector activation. It is believed that sprinkler flow has less of a delay and is more reliable than duct smoke detectors. For this approach it is necessary that smoke zones and sprinkler zones coincide.

The above system is simple and the elements used to put the system in the smoke mode are in daily use for such purposes as adjusting ventilation air, operating economizer cycles and load sheding. Thus these components will receive whatever maintenance is given to the HVAC system. This is better than for elements that are needed only for smoke control operation, because there is currently no maintenance program for smoke control systems. 
In general, a system with fewer components will have a lower probability of fallure than a similar system with more components. Thus, the smoke control system described above should be reliable because of its simplicity and because its components will receive the maintenance associated with their HVAC functions.

The majority of the hardware for the system would be there if there were no smoke contro1. The fans and duct work are part of the HVAC system, detection is done by the fire alarm system and HVAC control is by a computer. In addition to some computer software, the only costs for the system are an upgrade of the recirculating damper to a leakage rated damper and a connection from the fire alarm system to the computer. Thus the system is very inexpensive.

As discussed in section 3, it has been experimentally demonstrated in three separate full scale fire tests that pressurization at a barrier can control smoke movement. Based on the field tests at Bay Pines and Loma Linda, it can be stated that if the construction is of similar tightness the smoke control system will produce pressure differences in the range of 0.06 to 0.20 In $\mathrm{H}_{2} \mathrm{O}$ (15 to $50 \mathrm{~Pa}$ ) except at a few locations such as near the main lobby which would be at or above 0.02 in $\mathrm{H}_{2} \mathrm{O}(5 \mathrm{~Pa})$. Provided the construction is of proper tightness, all the zones in the hospital would be capable of producing at or above the minimum design value for a sprinkled hospital. For the majority of zones, the level of pressurization will be considerably above this value, thus resulting in an effective smoke control system.

Design of the zone smoke control system discussed in this section is particularly simple in that no detailed system analysis is required. Pressurized stairwells and elevator smoke control require analysis considering such factors as indoor to outdoor temperature difference and the number of open doors. For a zoned smoke control system, the capacity of the HVAC fans determines the flow rates used for smoke control. No flow rate sizing calculations are needed. However, the configuration and size of zones is important. The VA building system lends itself to zone sizes and configurations that work well as indicated in the field tests at Bay Pines and Loma Linda. It should be cautioned that elevator lobbies will need some attention 
so that conditions like those at the top three floors of the Bay Pines Hospital are not repeated. It is recommended that lounges and other occupied spaces not open directly to elevator lobbies. For fires detected in an elevator lobby or a space open to it any of the approaches discussed for Bay Pines (section $10.1 .5 \mathrm{C}$ ) would work. However, the approach encountered at Loma Linda (section 10.2.2) of exhausting the elevator lobby by the tollet exhaust resulted in the proper air flow direction and adequate pressure differences.

\subsection{Other Hospitals}

The older VA hospitals that were built before the VA Building System was developed have a wide variety of approaches to HVAC systems. Further, a new and even more efficient concept may replace the VA Building System. Thus, smoke control systems for non-VA-Building Systems hospitals need to be addressed.

The system discussed in section 11.1 would be appropriate, provided that:

a. each zone is served by its own HVAC system which serves no other zone; and,

b. each floor has a tightly constructed interstitial space such that pressurization above and below is unnecessary.

Other hospitals could have some other kind of zone smoke control, stairwell pressurization or elevator smoke control.

\subsubsection{Zoned Smoke Contro1}

A common approach is to have each HVAC system serve several zones. In the event of fire in one zone, dampers can be selectively closed and opened so that the smoke zone is exhausted to the outside and the adjacent zones are pressurized with outside air. Where adjacent zones are served by another HVAC system, the other system must be used for pressurization. 
The systems at Martinsburg and Richmond attempted to achieve smoke control primarily by shutting off supply air to the smoke zone. This approach is inadequate, however, if exhaust dampers had been used to shut off return alr from adjacent zones, system performance probably would have been improved. In general, it can be stated that such systems tend to be more complicated and less reliable than the system described in section 11.1. This system has a large number of components which are dampers and controls. Many of these components are dedicated to smoke control and so they don't receive the maintenance associated with HVAC components. If the components fail, the failure goes unnoticed until the smoke control system is tested. Without a routine program of testing, reliability of components is a concern. This was the case at Richmond. The VA may want to consider going to HVAC shut down rather than installing a smoke control system requiring numerous dampers and associated controls.

\subsubsection{Pressurized Stairwe11s}

The method of horizontal evacuation used by the VA hospitals does not lend itself to take advantage of the benefits of pressurized stairwells. Thus, it is believed that pressurized stairwells should not be used at VA hospitals. However, in an unusual condition where a pressurized stairwell would be appropriate for a VA hospital, it is recomended that the design information provided in the ASHRAE smoke control manual be used.

\subsubsection{Elevator Smoke Contro1}

The VA has sponsored another research project at NBS to study the feasibility of using elevators as a means of fire evacuation for the handicapped. Such a system would need an elevator lobby which could serve as a short-term refuge area for the handicapped. It is readily seen how this type of system could be incorporated into the horizontal evacuation approach of the VA.

The many problems associated with the use of elevators as a means of fire evaucation and the results of field tests of pressurized elevators are discussed in the first two reports of the project $[19,20]$. The final report 
of the project [21] deals with the problem of elevator "piston effect" and with evaluation of conceptual systems for elevator smoke control. It is believed that the final report could be of use to a designer considering such a system. Additional research is being conducted in this area, and before undertaking a design 1 is is urged that the latest information be obtained.

\section{ACCEPTANCE TESTING}

Regardless of the care and skill with which a smoke control system is designed, an acceptance test is needed as assurance that the system once built operates as intended. Because those who have been tasked with the responsibility for acceptance testing have various levels of technical skill, the following general discussion of the subject has been written so that a minimum of technical background is necessary. This subject has much in common with testing and balancing of HVAC systems as discussed in chapter 37 of the ASHRAE Handbook, 1984 Systems volume [22] and the testing and balancing manual [23] by the Sheet Metal and Air Conditioning Contractors National Association. In some cases, it may be desirable to have firms specializing in HVAC testing and balancing perform smoke control acceptance tests. A guide specification for testing smoke control systems has been developed by the Smoke Control Association [24].

The treatment of sections 12.1 to 12.7 is of a general nature based on experience gained from field tests of VA hospitals, pressurized stairwells and pressurized elevators and on information from the general literature. This information is applicable to zoned smoke control systems or any other such systems that rely on two principles of smoke control as discussed in section 3. Section 12.8 contains a detailed discussion of testing of a system like the one described In section 11.1 for VA Building Systems Hospitals.

\subsection{Initial Checkout}

This part of an acceptance test consists of activating the smoke control system and determining that fans, dampers, and other components are functioning properly. The importance of such a checkout has become apparent because of the many problems encountered during tests of smoke control systems. These 
problems include fans running backward, fans in which no electrical power is supplied, dampers that do not close properly, and controls that do not operate. Depending on the type of smoke control system, it may be necessary to test several times for changes caused by differing fire locations and corresponding modes of system operation.

Once any problems uncovered in the checkout are corrected, the system performance can be tested by one or more of the methods discussed in the following sections.

\subsection{Pressure Difference Tests}

These tests consist of activating the smoke control system in its various modes and measuring the pressure differences produced at the boundary points of the system. These tests are much like the field tests of the VA hospitals. For zone smoke control, the boundary points most appropriate for measurements are across closed doors that separate the smoke zone from adjacent zones, stalrwells and elevator shafts. Because pressurization is by far the major means of smoke control, pressure difference tests are probably the most meaningful test method for most smoke control systems.

The set-up for measuring pressure difference across a door is illustrated in figure 20. The convention of this set-up is that the instrument is on the low pressure side of the door. Experience has shown that adherence to a particular convention reduces confusion and thus the potential for human error. A hose connected to the high pressure part of the instrument goes through a gap underneath and is terminated with a tee on the high pressure side of the door. The tee is used to minimize any pressure errors due to air velocity. Alternatively, the tube can end without any fitting provided that it is carefully located so that the dynamic pressure component is negligible. Rubber or flexible plastic tube of $6.4 \mathrm{~mm}$ ( $0.25 \mathrm{in})$ outside diameter works well for most cases. If the door gap is too narrow, the tube may be pinched shut thus invalidating any measurement. Small diameter metal tubing can sometimes be used in such cases particularly through the gaps of some gasketed doors. 
The differential pressure instrument should have a sensitivity of at least 0.01 in $\mathrm{H}_{2} \mathrm{O}\left(2.5 \mathrm{~Pa}\right.$ ) and generally a range from 0 to 0.25 in $\mathrm{H}_{2} \mathrm{O}$ ( 0 to $62 \mathrm{~Pa}$ ) is sufficient. Occasionally an instrument with a range of 0 to 0.50 in $\mathrm{H}_{2} \mathrm{O}$ ( 0 to $124 \mathrm{~Pa}$ ) is needed.

\subsubsection{Inclined Manometer}

An inclined manometer with a liquid reservoir is illustrated in figure 21. This device indicates pressure by the height of a column of liquid. Before any measurements the instrument must be adjusted so that it is level. Generally, the scales of inclined manometers are compensated for the liquid rise in the reservoir so that the pressure difference can be read directly. The zero level of these instruments can be adjusted by adding or removing liquid from the reservoir. Because the measurement principle of these devices is so fundamental, it is believed that commercially available inclined manometers are of sufficient accuracy for smoke control acceptance testing without independent calibration.

\subsubsection{Different1a1 Pressure Gages}

A gage without liquid has the advantage of convenience over the inclined manometer. Bourdon-tube gages are the most common type of pressure gages, but the friction of the mechanical linkages of these instruments limits sensitivity. No Bourdon-tube gage is known with sufficient sensitivity for smoke control application. However, a magnetically coupled gage as illustrated in figure 22 is sufficiently sensitive. The gage should have a stand so that it can be set on the floor or other flat surface. Minor deviations of surface level can be accommodated by use of the instrument's zero adjustment. Thus an instrument level adjustment is not necessary for this application. These gages were used for the fleld tests discussed in section 10. A differential pressure gage should be calibrated against a standard such as an inclined manometer. 


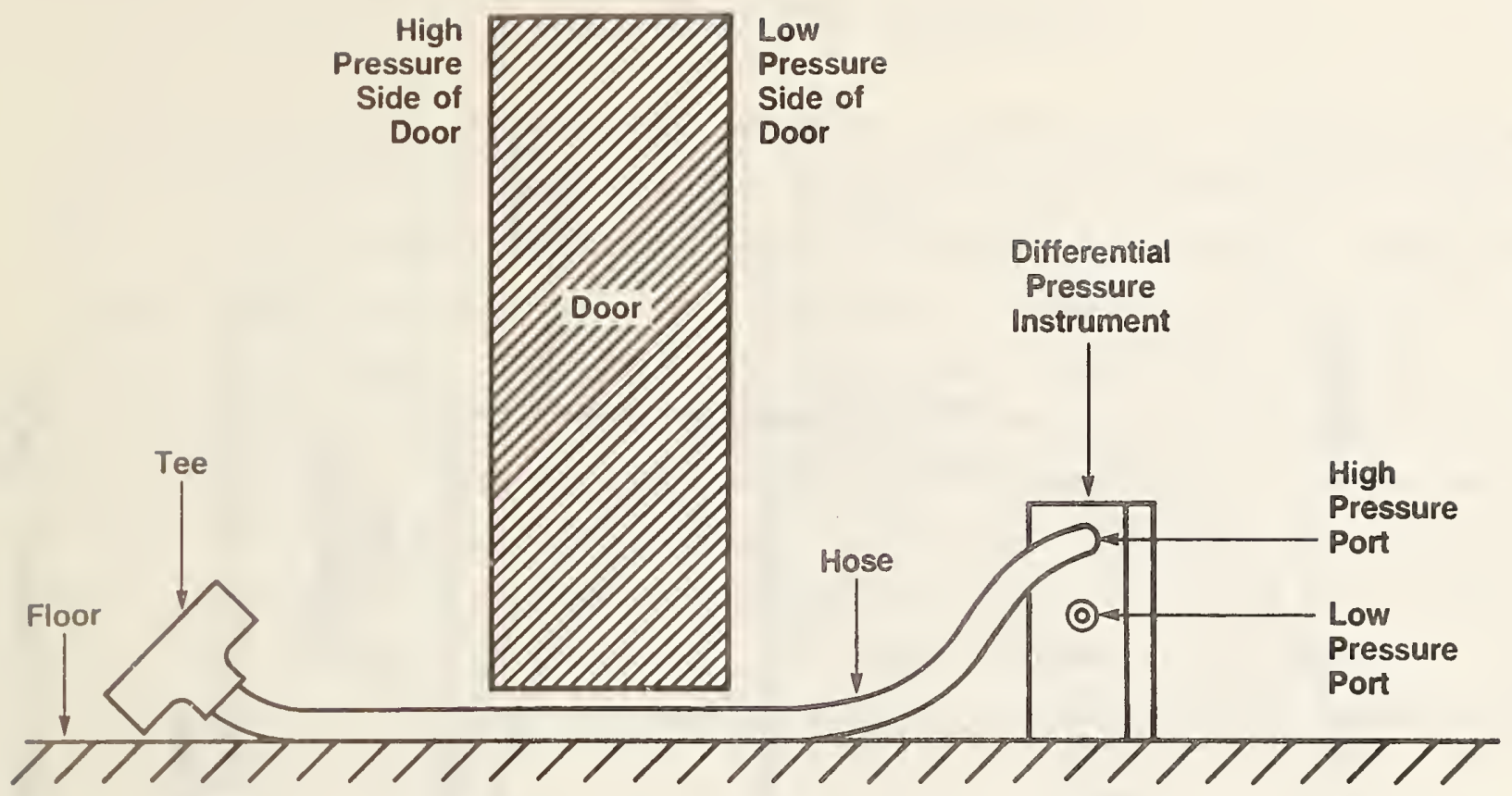

Figure 20. Set-up for measuring pressure difference across a door

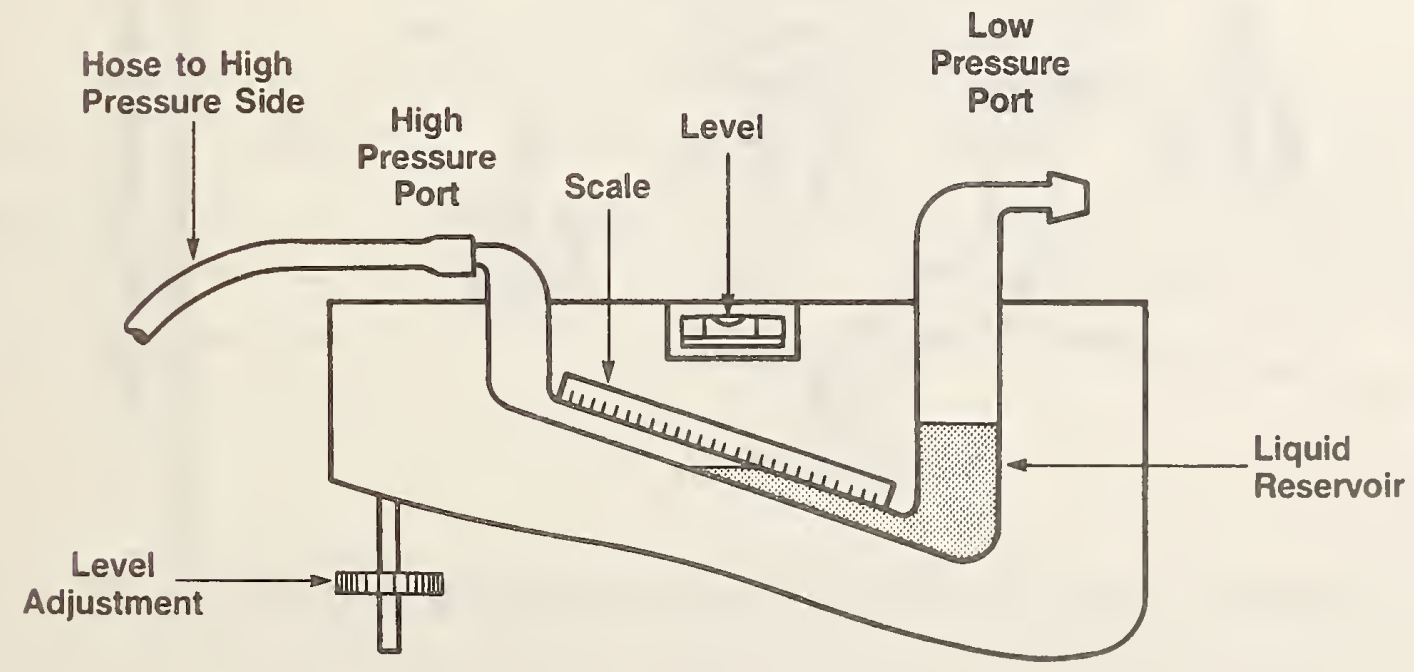

Noie: Scale is compensated for liquid level rise in reservoir so the pressure difference can be read directly.

Figure 21. Inclined manometer with liquid reservoir 


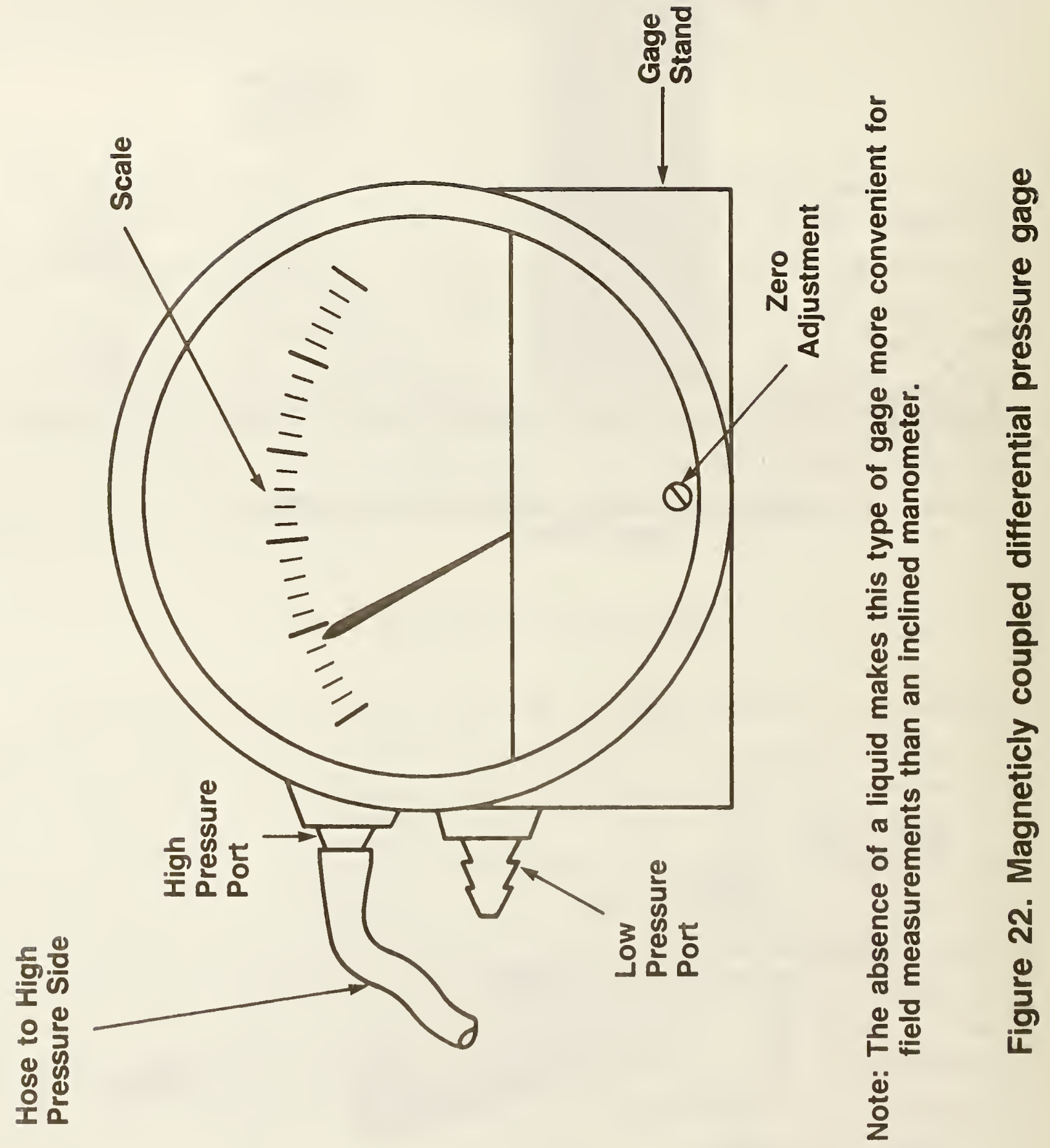




\subsubsection{Electronic Transducers}

Most electronic differential pressure transducers are of the diaphragm type. Changes in pressure across a diaphragm cause diaphragm displacement which can be measured by strain gages, piezoelectric elements, inductance pickups, capacitance pickups, etc. These gages require electrical power and should be calibrated. Many such instruments are commercially available with the necessary sensitivity and in appropriate ranges. For many applications, a major advantage of these instruments is that they have analog voltage output suitable for data acquisition systems. Because of the nature of acceptance tests this feature of electronic transducers is of no benefit. These instruments need periodic calibration. For these reasons and because of the relative expense of these instruments they are not particularly appropriate for acceptance testing.

\subsection{Flow Indication}

Strictly speaking flow indication is not quantitative and thus probably not appropriate as an acceptance test by itself. However, there are many cases where the knowledge of flow direction is desirable. Such cases abound in the initial checkout and to a lesser extent during pressure difference testing.

A piece of paper placed in front of an air grill provides an immediate and simple indication of flow and flow direction. Air flow will cause a hanging strip of tissue paper to noticably deflect diagonally at flow velocities as 1 ow as $0.08 \mathrm{~m} / \mathrm{s}(15 \mathrm{fpm})$. Smoke flow from a punk stick or a cigarette can also be used to detect such low air flows.

\subsection{Flow Measurement}

The air velocity through an open doorway or across a section of corridor is generally far from uniform. Such flow is frequently characterized by the presence of large stationary vortices; especially flow through open stafrwell doors. This makes accurate determination of air flow doubtful even when extreme care is taken. Fortunately, air flow through large openings is not 
the major principle of smoke control for most systems. It follows that for the majority of smoke control systems, flow tests need not be conducted.

Some flows such as that near the mid-length of a long straight corridor are likely to be free of large stationary vortices. The measurement of such flows is appropriate provided that the smoke control system depends on air flow to achieve its goals. Because the velocity in such a flow is seldom uniform across any section, and an anemometer measures velocity at only one location, a traverse should be made to determine the flow. Traversing open doorways or sections of corridor can be done in a manner similar to that for rectangular ducts, as illustrated in figure 23. Velocity readings should be taken in the center of equal areas over the cross section. Chapter 13 of the ASHRAE handbook of fundamentals [13] recommends 16 to 64 such readings for flow in ducts, however because of the likely variations of velocity in doorways and corridors it might be appropriate to make at least 30 readings. The volumetric flow rate is calculated from the formula

$$
\mathrm{Q}=\mathrm{HWV}
$$

where: $Q=$ volumetric flow rate, $\operatorname{cfm}\left(\mathrm{m}^{3} / \mathrm{s}\right)$

$$
\begin{aligned}
& \mathrm{H}=\text { height of the doorway or corridor, ft (m) } \\
& \mathrm{W}=\text { width of the doorway or corridor, ft (m) } \\
& \mathrm{V}=\text { average velocity, } \mathrm{fpm}(\mathrm{m} / \mathrm{s})
\end{aligned}
$$

In the air conditioning industry, pitot tubes, deflecting-vane anemometers and thermal anemometers are used to measure air velocity. These instruments are discussed and evaluated for smoke control acceptance testing in the following sections.

\subsubsection{Deflecting Vane Anemometer}

The deflecting vane anemometer consists of a vane hung from a pin such that air velocity will cause a diagonal deflection of the vane as illustrated In figure 24. Manufacturers rate the accuracy of these instruments at $5 \%$ for flows less than $100 \mathrm{fpm}(0.5 \mathrm{~m} / \mathrm{s})$ and $10 \%$ for greater flows. The ASHRAE handbook identifies the limitations of not being well sulted for such readings 

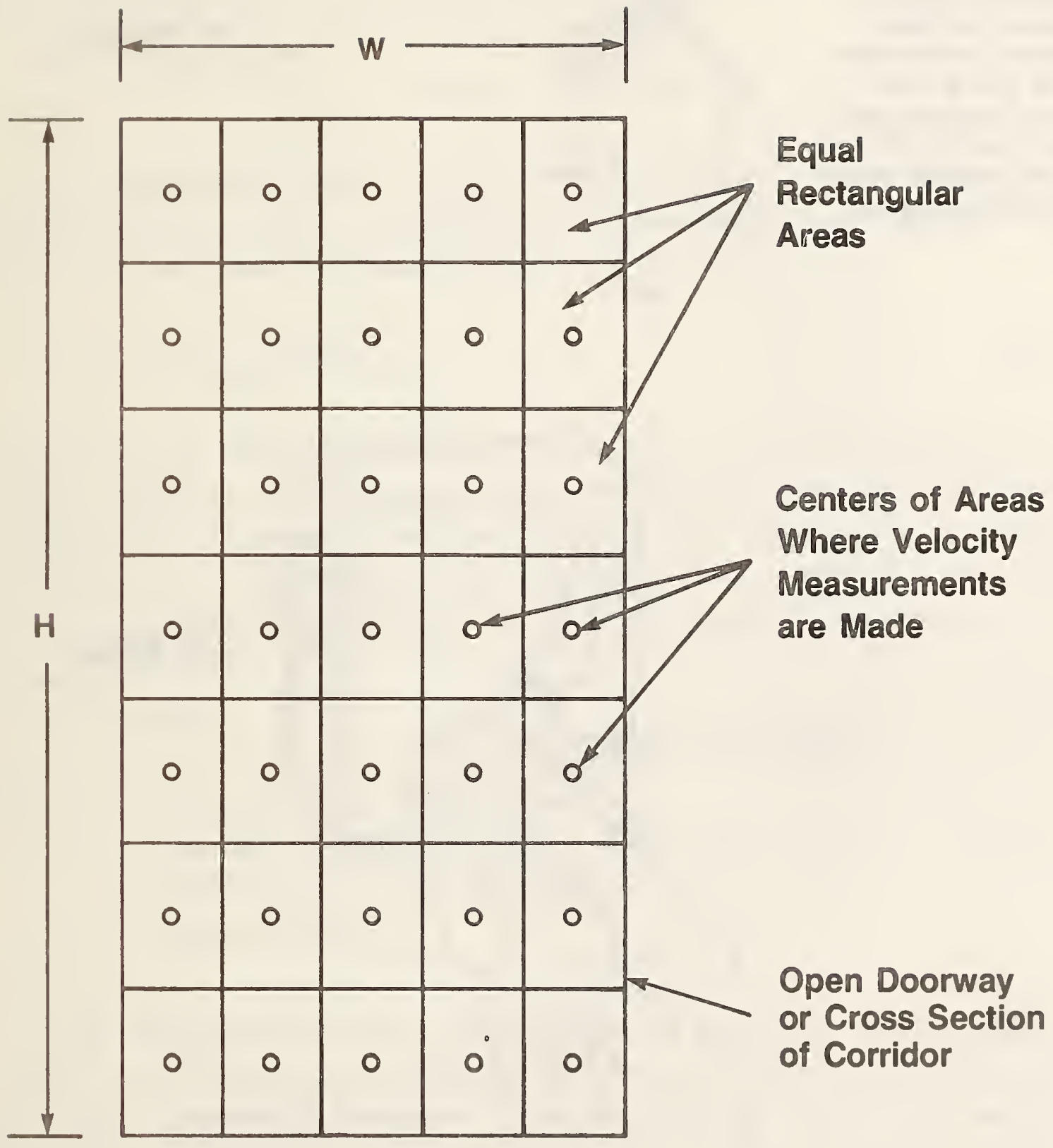

Figure 23. Flow measurement traverse for corridors and open doorways 
Note: The air velocity causes vane to deflect diagonally and the velocity can be read directly from the scale. Because these instruments are low in cost and compact they are popular for spot checks and rough estimates.

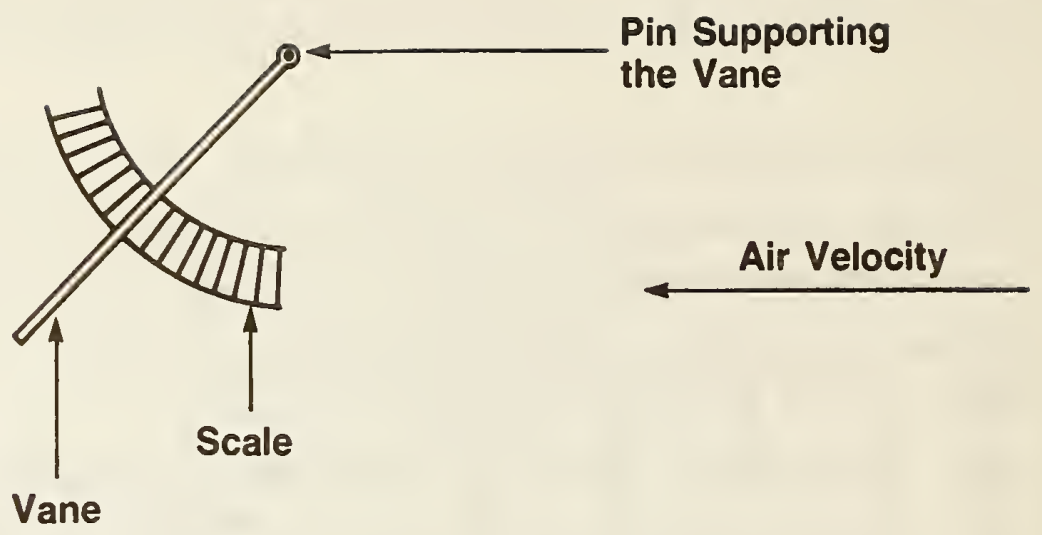

(a)

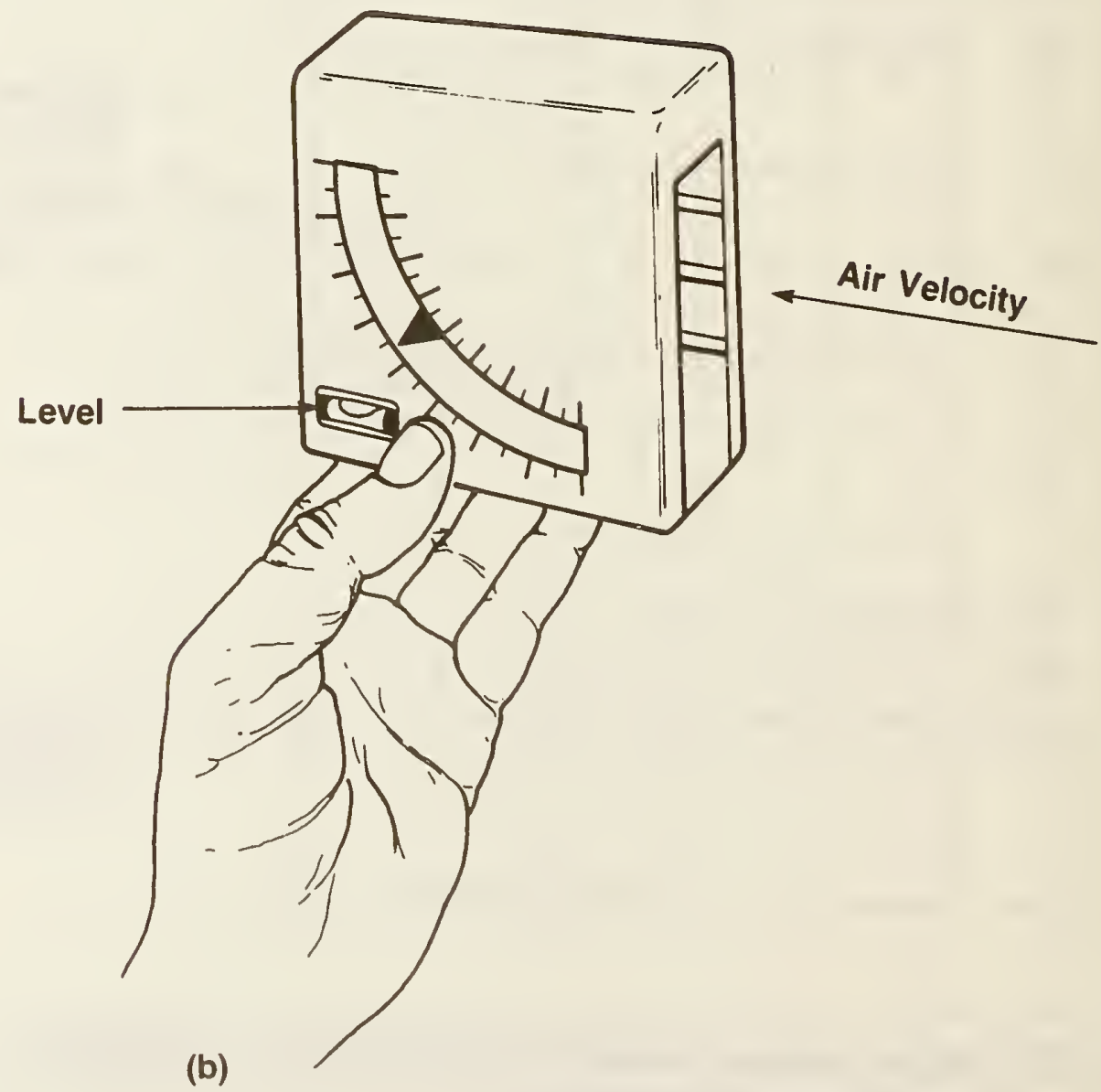

Figure 24. Deflecting vane anemometer: (a) principle of operation and (b) the Instrument in use 
and of needing periodic check calibration. Because of their low cost and compact size these instruments are popular for making spot checks and obtainIng rough estimates of velocity. However, it is not believed that they are appropriate for acceptance testing.

\subsubsection{Pitot Tube}

The stagnation pressure, $P_{\text {stag, is the pressure that would result if a }}$ moving gas were brought to rest. An expression for this pressure can be obtained from Bernoulli's equation

$$
P_{\text {stag }}=P_{\text {stat }}+\frac{1}{2} \rho V^{2}
$$

where $P_{\text {stat }}$ is the static pressure of the gas, $\rho$ is the gas density and $V$ is the gas velocity. Some pitot tubes incorporate static pressure tubes as illustrated in figure 25. Such pitot-static tubes are commercially available in designs to minimize errors. The velocity from eq. (12) can be expressed in terms of the pressure difference, $\Delta \mathrm{P}$, from the pitot tube manometer.

$$
V=C \sqrt{\Delta \mathrm{P} / \rho}
$$

$$
\text { where: } \begin{aligned}
\mathrm{V} & =\text { velocity, } \mathrm{fpm}(\mathrm{m} / \mathrm{s}) \\
\Delta \mathrm{P} & =\text { manometer pressure difference, in } \mathrm{H}_{2} \mathrm{O}\left(\mathrm{mm} \mathrm{H}_{2} \mathrm{O}\right) \\
\rho & =\text { density of air, } 1 \mathrm{~b} / \mathrm{ft}^{3}\left(\mathrm{~kg} / \mathrm{m}^{3}\right) \\
\mathrm{C} & =1096.5(4.426)
\end{aligned}
$$

A pitot static tube can be used to measure velocities in the range of 400 to $2000 \mathrm{fpm}$ ( 2 to $10 \mathrm{~m} / \mathrm{s}$ ) when connected to an inclined manometer. With an electronic differential pressure transducer a pitot tube can be used in the range 200 to $3000 \mathrm{fpm}$ ( 1 to $15 \mathrm{~m} / \mathrm{s}$ ).

\subsubsection{Therma1 Anemometer}

Thermal anemometers (also called hot-wire anemometers and hot-film anemometers) are available in two types: constant-current and constanttemperature. Both types have velocity probes with fine wire. For the 


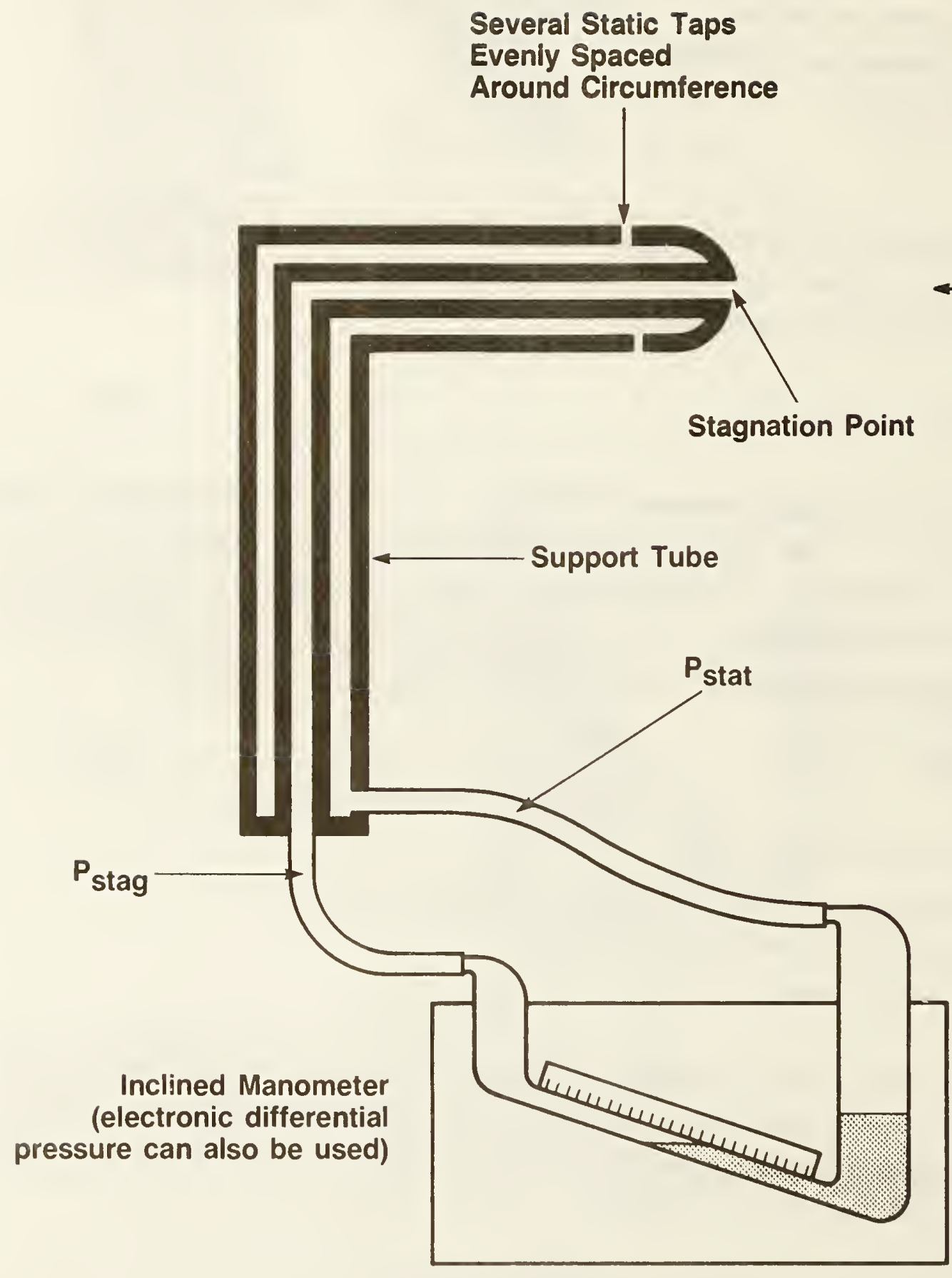

Figure 25. Pilot-static tube 
constant-current type, the wire is subjected to a constant electrical current and the temperature of the wire depends upon the convective cooling of the air flowing past the wire. Thus, temperature is a measure of velocity. The constant-temperature type uses the same principle in a different way. The electrical current through the wire is adjusted so that its temperature remains constant. For this instrument, current is a measurement of velocity. Hand held, battery powered, temperature compensated thermal anemometers are commercially avallable for air at temperatures normally encountered in building heating and cooling systems. Such instruments have ranges of approximately 10 to $5000 \mathrm{fpm}(0.05$ to $25 \mathrm{~m} / \mathrm{s})$ with accuracies of about $5 \%$.

\subsection{Real Fire Tests}

It is an understatement to say that acceptance testing involving a real fire has obvious danger to life and property because of the heat generated and the toxicity of the smoke. Such a fire test was required by the local fire department for a pressurized stairwell system in a eight story office building in Hamburg, Germany [7]. At the time, no pressurized stairwells existed in Germany and the local authorities wanted to be sure the system would work. The test was conducted before the interior finishes were installed. Much of the second floor where the fire was located was "fire hardened" to prevent structural damange. The fire load consisted of wood cribs and expanded polystyrene weighing a total of $1 / 3$ ton $(370 \mathrm{~kg})$. The fire reached a peak temperature of $1300^{\circ} \mathrm{F}\left(700^{\circ} \mathrm{C}\right)$, was above $750^{\circ} \mathrm{F}\left(400^{\circ} \mathrm{C}\right)$ for over 20 minutes, and produced large quantities of dense black smoke. Throughout the test there was no visible smoke within the stairwel1, thus the system passed the acceptance test.

A large real fire like the one described above is the most realistic method of testing the ability of a smoke control system to control smoke movement. Because of the inherent danger, remote instruments should be used and construction and other activities must be suspended in the building during the fire test.

Gas burners could be used in place of solid fuels. Such an approach would reduce the hazard of toxic gases and result in a fire that could be 
simply turned off rather than have to be extinguished with water. To produce visible smoke, smoke candles can be placed on the burners or the gas can contain a small quantity of acetylene.

The fire tests discussed above are obviously not warranted for smoke control system concepts that are well developed. However, it seems reasonable that radically new concepts for smoke control systems should be fire tested either in a research facility or as part of an acceptance test as was done at Hamburg.

Small fires have been used to test open area smoke detection systems usually in computer rooms. The General Services Administration has required fires consisting of two or three sheets of newspaper or computer paper in a metal wastebasket. In Europe [24], two or three slabs of polyurethane foam are used. These techniques could be used to test smoke control systems, however these small fires would give no indication of the smoke control systems ability to deal with smoke from much larger fires.

\subsection{Chemical Smoke Tests}

Chemical smoke tests have achieved a degree of popularity out of proportion to the limited information they are capable of providing. The most common source of chemical smoke is the commercially avallable "smoke candle" (sometimes called a smoke bomb). In this test, the smoke candle is usually placed in a metal container and ignited. The metal container is for protection from heat damage after ignition - it does not inhibit observation of the movement of the chemical smoke. Care must be exercised during observations, because inhalation of chemical smoke can cause nausea.

This type of testing is less realistic than real fire testing because chemical smoke is cold and lacks the buoyancy of smoke from a flaming fire. Such buoyancy forces can be sufficiently large to overpower a smoke control system that was not designed to withstand them. Smoke from a sprinklered fire has little buoyancy, and so it may be expected that such smoke movement is similar to the movement of unheated chemical smoke. This has not yet been confirmed by test data. Chemical smoke testing can identify leakage paths, and such tests are simple and inexpensive to perform. 
The question arises as to what information can be obtained from a cold chemical smoke test. If a smoke control system does not achieve a high enough level of pressurization, the pressures due to hot, buoyant smoke could overcome that system. However, the ability to control cold chemical smoke provides no assurance of the ability to control hot smoke in the event of a real fire.

Chemical smoke is also used to evaluate the effectiveness of smoke purging systems. Even though such systems are not smoke control systems, they are closely related and so they will be briefly addressed here. For example, a system that has six air changes per hour when in the smoke purge mode will be considered. Some testing officials have mistaken this to mean that the air is completely changed every ten minutes, and so ten minutes after the smoke candle is out all the smoke should be gone from the space. of course, this is not what happens. In a purging system, the air entering the space mixes to some extent with the air and smoke in the space. If the purging system is part of the HVAC system, it has been designed to promote a rather complete degree of mixing. If the concentration of smoke is close to uniform within the space, then the method of analysis for purging presented in section 2.3 of the ASHRAE smoke control manual is appropriate. Based on such perfect mixing, after ten minutes $37 \%$ of the original smoke would be remaining in the space.

\subsection{Tracer Gas Tests}

In these tests, a constant flow rate of a tracer gas is released in a building. Samples are collected throughout the building and are analyzed to determine possible paths of smoke movement in the event of a real fire. The tracer gas most commonly used is sulfur hexaflouride ( $\mathrm{SF}_{6}$ ) because it is nonflammable, colorless, odorless, virtually nontoxic*, and chemically stable. These attributes result in tests that do not interfere with the normal operation of the facility being tested. In addition, $\mathrm{SF}_{6}$ is virtually unused industrially, which essentially eliminates the chance of interference from another source.

\footnotetext{
*OSHA concentration limit of $\mathrm{SF}_{6}$ is $1,000 \mathrm{ppm}$ as set forth in the Federal Register, Vol. 36, No. 157, August 13, 1971. However, in smoke control testing, concentrations generally do not exceed 2 ppm.
} 
$\mathrm{SF}_{6}$ is commercially avallable and is stored as a liquid at 320 psi $(2.2 \mathrm{MPa})$ at $70^{\circ} \mathrm{F}\left(21^{\circ} \mathrm{C}\right)$. A constant flow rate of gaseous $\mathrm{SF}_{6}$ can be maintalned by using a pressure regulator and a flowmeter such as a rotameter. The flowmeter should be specifically calibrated for $\mathrm{SF}_{6}$. Flow rates in the ranges of 2 to $10 \mathrm{~mL} / \mathrm{mln}$ have been used.

Traditionally, alr samples have been collected in hypodermic syringes and analyzed in a batch mode on a gas chromatograph fitted with an electron capture cell and an appropriate column for separation of $\mathrm{SF}_{6}$ from other gases. Continuous sampling using a gas chromatograph is also possible. Samples of standard concentrations of $\mathrm{SF}_{6}$ in air or nitrogen are commercially avallable for calibration of the gas chromatograph. Gas chromatographs can analyze $\mathrm{SF}_{6}$ in the range of 0 to $180 \mathrm{ppb}$, and samples of higher concentration should be diluted for analysis. Caution should be exercised because, at high concentrations, $\mathrm{SF}_{6}$ can permeate some materials and thus contaminate any air samples that might contact these materials. Because of the many possibilities of error, the tester must adhere rigorously to good testing methods.

Tracer gas testing has the advantage of 1dentifying leakage paths and determining if a smoke control system can control the movement of a nonbuoyant gas. Because gaseous $\mathrm{SF}_{6}$ is invisible, careful selection of the locations to be sampled is 1mportant.

A major drawback to the use of tracer gas testing is, again, the lack of buoyancy in the gas, $1 . e .$, the gas is typically at an ambient temperature when released. To overcome this deficiency, the air and $\mathrm{SF}_{6}$ mixture can be heated, but caution should be exercised, because at high temperatures $\mathrm{SF}_{6}$ can degenerate into toxic components. As with chemical smoke, unheated $\mathrm{SF}_{6}$ movement is likely to be similar to that of smoke from a sprinklered fire, but, this has not yet been confirmed by test data.

Because of the many possibilities of error and the limitations discussed above, tracer gas tests should be conducted and evaluated with a high level of professional competance. It is not believed that tracer gas testing will become a routine method of acceptance testing smoke control systems. 


\subsection{Zone Smoke Control}

This section $1 \mathrm{~s}$ intended particularly for acceptance testing of VA Bullding System Hospitals. The information may be useful for those interested in testing other buildings with zone smoke control. The goal of such testing 1s to assure that the system is capable of maintaining the required levels of performance. In order to meet the performance requirements used in section 7 for discussion purposes a system would need to produce at least 0.02 in $\mathrm{H}_{2} \mathrm{O}$ ( $5 \mathrm{~Pa}$ ) but not more than 0.25 in $\mathrm{H}_{2} \mathrm{O}(62 \mathrm{~Pa})$ across the doors in the boundaries of an operating smoke zone. An initial checkout (section 12.1) should be conducted to assure that all components of the system are functioning properly at the time of the pressure difference test. Then pressure difference tests (section 12.2) on each zone in the smoke mode are conducted to assure that pressure differences are in the range above. It is belleved that for VA Building System Hospitals, the other tests discussed earlier would be inappropriate.

In the event that a pressure difference at a system boundary does not meet the lower level, the most likely possibilities to be checked are that some system component is not functioning properly or large leakage areas to the outside exist. The double egress doors should prevent pressure differences from exceeding the upper level. Any values exceeding this level may be an indication that the door closer or the door frame need adjustment.

In a few of the zones tested in the field tests, it was difficult to determine exactly what some of the zone boundaries were. It is urged that the designers be encouraged to clearly define zones and make them the same for HVAC and fire protection and other utilities.

\section{SUMMARY AND RECOMMENDATIONS}

This report presents general background information about smoke management, the principles of smoke control, purging, door opening forces, building air flow analysis, flow areas and weather data that is belleved to be useful to those who are tasked with the design, construction and acceptance testing of smoke control systems. The performance requirements of smoke 
control systems for VA hospitals was discussed. For a sprinkled hospital the performance requirements used for discussion in this paper are that the system be capable of producing at least 0.02 in $\mathrm{H}_{2} \mathrm{O}(5 \mathrm{~Pa})$ but not more than 0.25 in $\mathrm{H}_{2} \mathrm{O}(62 \mathrm{~Pa})$ across the doors in the boundaries of an operating smoke zone.

The results of fleld tests of five VA hospltals were presented, and where appropriate, specific recommendations regarding those hospitals were presented. Based on information from field tests and the basic information presented in the early sections of this paper, different approaches to smoke control at VA hospitals and methods of acceptance testing were evaluated. The following recommendations are made:

1. For new sprinkled VA Building System Hospitals, zone smoke control, as described in section 11.1 , is recommended because these hospitals lend themselves to simple, reliable, inexpensive smoke control, as discussed in section 11.1 For this approach it is necessary that smoke zones and sprinkler zones coincide.

2. The same type of zoned smoke control is recommended for other hospitals provided that each zone is served by its own HVAC system which serves no other zone, and that each floor has a tightly constructed interstitial space such that pressurization above and below are not necessary.

3. It is recommended that zone smoke control not be used for systems that would require numerous dampers and controls only needed for smoke control. These systems when compared to the system recommended above tend to be more complicated and less reliable, as discussed in section 12.2 .1 .

4. It is recommended that pressurized stairwells not be used for VA hospitals because these systems do not lend themselves to the horizontal evacuation used at VA hospitals.

5. For hospitals where zone smoke control is inappropriate and where some smoke control is desired it is recommened that elevator smoke control 
be considered. Elevator smoke control is a new concept and can be designed to enhance horizontal evacuation. Section 11.2 .3 references recent research funded by the VA to study the feasibility of fire evacuation of the handicapped by elevators.

6. It is recommended that acceptance tests of zoned smoke control systems recommended in 1 . above be by pressure difference test, as discussed in section 12.8 .

\section{REFERENCES}

[1] Klote, J.H., Field Tests of the Smoke Control System at the Bay Pines VA Hospital, Nat. Bur. Stand. (U.S.), NBSIR 84-2868, May 1984.

[2] Klote, J.H., Fleld Tests of the Smoke Control System at the San Diego VA Hospital, Nat. Bur. Stand. (U.S.), NBSIR 84-2948, November 1984.

[3] Annual Book of ASTM Standards, Part 18, ASTM E176-80, American Society for Testing and Materials, Philadelphia, PA, 1980.

[4] Standard for the Installation of Air Conditioning and Ventilating Systems, NFPA 90A-1981, National Fire Protection Association, Inc., Quincy, MA, 1981.

[5] De Cicco, P.R., Smoke and Fire Control in High-Rise Office Buildings Part I: Full-Scale Tests for Establishing Standards, Symposium on Experience and Applications on Smoke and Fire Control at the ASHRAE Annual Meeting, June 1973, Louisville, KY, Atlanta, GA, pp. 9-15, 1973.

[6] Koplon, N.A., Report of the Henry Grachy Fire Tests, City of Atlanta Building Department, Atlanta, GA, January 1973.

[7] Butcher, E.G., Parnell, A.C. and Easthan, G., Smoke Control by Pressurization, Fire Engineers' Journal, VoI. 36, No. 103, pp. 16-19, September 1976.

[8] Thomas, P.H., Movement of Smoke in Horizontal Corridors Against an Air Flow, Institution of Fire Engineers, Quarterly, 30 (77), pp. 45-53, 1970 .

[9] Shaw, B.H. and Whyte, W., Air Movement Through Doorways--The Influence of Temperature and its Control by Forced Air Flow, Bullding Services Engineer, Vol. 42, pp. 210-218, December 1974.

[10] McGuire, J.H., Tamura, G.T. and Wilson, A.G., Factors in Controlling Smoke in High Buildings, Symposium on Fire Hazards in Buildings, ASHRAE Semiannual Meeting, January 1970 (San Francisco, CA). 
[11] Klote, J.H. and Fothergill, J.W., Design of Smoke Control Systems for Buildings, American Soclety of Heating, Refrigerating, and AirConditioning Engineers, Atlanta, GA, 1983.

[12] Cresci, R.J., Smoke and Fire Control in High-Rise office Buildings-Part II: Analysis of Stair Pressurization Systems, Symposium on Experience and Applications on Smoke and Fire Control, ASHRAE Annual Meeting, June 24-28, 1973, Atlanta, GA.

[13] ASHRAE Handbook-1981 Fundamentals, American Society of Heating, Refrigerating and Air-Conditioning Engineers, Atlanta, GA, 1981.

[14] Temperature Extremes in the United States, National Oceanic and Atmospheric Administration, (U.S.) National Climatic Center, Ashville, NC, 1979.

[15] Code for Safety to Life from Fire in Buildings and Structures, NFPA 101-1985, Quincy, MA, National Fire Protection Assn., 1985.

[16] Development Study - VA Hospita1 Building Syste, U.S. Government Printing Office, Washington, DC, August 1977.

[17] Fung, F.C.W. and Zile, R.H., Test and Evaluation of the Smoke Control Capabilities of the San Diego Veterans Administration Hospital, Nat. Bur. Stand. (U.S.), NBSIR 77-1225, Apri1 1977.

[18] Klote, J.H., Smoke Movement Through a Suspended Celling System, Nat. Bur. Stand. (U.S.), NBSIR 81-2444, Feb. 1982.

[19] Klote, J.H., Elevators as a Means of Fire Escape, ASHRAE Trans., Vo1. 89, Part 1, 1983.

[20] Klote, J.H., Smoke Control for Elevators, ASHRAE Journal, Vo1. 26, No. 4, pp. 23-33, Apr11 1984.

[21] Klote, J.H. and Tamura, G., Smoke Control and Fire Evacuation by Elevators, ASHRAE Transactions, Vo1. 92, Part 1, to be published 1986.

[22] ASHRAE Handbook - 1984 Systems Volume, American Society of Heating, Refrigerating and Air-Conditioning Engineers, Atlanta, GA, 1984.

[23] HVAC Systems Testing, Adjusting and Balancing, Sheet Metal and Air Conditioning Contractors Nationa1 Association, Vienna, VA, 1983.

[24] Guide Specification for Smoke Control Systems, Smoke Control Association, Buckingham, PA, 1985. 
Construction

Element

Exterior Building Walls

(includes construction

cracks, cracks around windows and doors)

Stalrwell Walls

(includes construction cracks but not cracks around windows or doors)

Elevator Shaft Walls

(includes construction cracks but not cracks around doors)

Floors

(includes construction cracks and cracks around penetrations)

$A=$ leakage area

$\mathrm{Aw}=$ wall area

$A_{F}=$ floor area
Wa 11

Tightness

Tight [1]

Average [1]

Loose [1]

Very Loose [2]

Tight [3]

Average [3]

Loose [3]

Tight [3]

Average [3]

Loose [3]

Average [4]
Area Ratio

A/Aw

$0.70 \times 10^{-4}$

$0.21 \times 10^{-3}$

$0.42 \times 10^{-3}$

$0.13 \times 10^{-2}$

$0.14 \times 10^{-4}$

$0.11 \times 10^{-3}$

$0.35 \times 10^{-3}$

$0.18 \times 10^{-3}$

$0.84 \times 10^{-3}$

$0.18 \times 10^{-2}$

$\mathrm{A} / \mathrm{A}_{\mathrm{F}}$

$0.52 \times 10^{-4}$

A11 of the above area ratios are based on a relatively small number of tests and actual values may vary considerably from the range indicated. Leakage areas are highly dependent upon the quality of construction. Area ratios are evaluated at typical air flows at 0.30 in $\mathrm{H}_{2} \mathrm{O}(75 \mathrm{~Pa}$ ) for walls, and 0.10 in $\mathrm{H}_{2} \mathrm{O}(25 \mathrm{~Pa})$ for floors based on field tests of buildings described in the following references.

[1] Tamura, G.T. and Shaw, C.Y., Studies on Exterior Wall Air Tightness and Air Infiltration of Tall Buildings, ASHRAE Transactions 1976, Vol. 82, Part I, pp. 122-134, 1976.

[2] Tamura, G.T. and Wilson, A.G., Pressure Differences for a 9-Story Building as a Result of Chimney Effect and Ventilation System Operation, ASHRAE Transaction 1966, Vo1. 72, Part I, pp. 180-189, 1966.

[3] Tamura, G.T. and Shaw, C.Y., Air Leakage Data for the Design of Elevator and Stair Shaft Pressurization Systems, ASHRAE Transaction 1976, Vol. 83, Part 2, pp. 179-190, 1976.

[4] Tamura, G.T. and Shaw, C.Y., Experimental Studies of Mechanical Venting for Smoke Control in Tall office Buildings, ASHRAE Transaction 1978, Part 1, Vol. 86, pp. 54-71, 1978. 
Table 1. Smoke control test of VA Bay Pines Hospital, first floor, zone $A$

\begin{tabular}{|c|c|c|c|c|}
\hline \multirow[b]{2}{*}{ Location } & \multicolumn{2}{|c|}{$\begin{array}{c}\text { Normal Smoke } \\
\text { Control Operation }\end{array}$} & \multicolumn{2}{|c|}{$\begin{array}{c}\text { Increased Smoke } \\
\text { Zone Exhaust }\end{array}$} \\
\hline & $(\mathrm{Pa})$ & $\left(\right.$ in $\left.\mathrm{H}_{2} \mathrm{O}\right)$ & $(\mathrm{Pa})$ & $\left(\right.$ in $\left.\mathrm{H}_{2} \mathrm{O}\right)$ \\
\hline Zone $B$ to Zone $A$ at corridor 4 & 12 & 0.05 & 27 & 0.11 \\
\hline Zone $\mathrm{B}$ to Zone $\mathrm{A}$ at corridor 3 & 5 & 0.02 & 12 & 0.05 \\
\hline Zone $\mathrm{B}$ to Zone $\mathrm{A}$ at door $\mathrm{Dl}$ & 17 & 0.07 & 40 & 0.16 \\
\hline Zone $\mathrm{H}$ to Zone $\mathrm{A}$ at corridor 2 & 15 & 0.06 & 17 & 0.07 \\
\hline Zone $\mathrm{H}$ to Zone $\mathrm{A}$ at corridor 1 & 10 & 0.04 & 12 & 0.05 \\
\hline Zone $\mathrm{E}$ to Zone $\mathrm{A}$ at corridor 8 & 5 & 0.05 & 0 & 0 \\
\hline Zone $\mathrm{E}$ to Zone $\mathrm{A}$ at $\mathrm{D} 3$ & 0 & 0 & 5 & 0.02 \\
\hline Zone $\mathrm{G}$ to Zone $\mathrm{A}$ at $\mathrm{D} 4$ & 0 & 0 & 5 & 0.02 \\
\hline $\begin{array}{l}\text { Corridor } 5 \text { to Interior of Zone B } \\
\text { at door D2 }\end{array}$ & 15 & 0.06 & 37 & 0.15 \\
\hline Corridor 5 to corridor 3 & 10 & 0.04 & 12 & 0.05 \\
\hline
\end{tabular}

For notes see table 19.

Table 2. Smoke control test of VA Bay Pines Hospital, first floor, zone $B$

Location
Norma1 Smoke

Increased Smoke

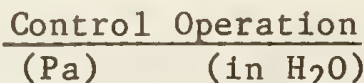

Zone Exhaust ${ }^{a}$

$(\mathrm{Pa}) \quad\left(\right.$ in $\left.\mathrm{H}_{2} \mathrm{O}\right)$

Main lobby to director's suite

at door D5

Main lobby to corridor 9 (DO) b

Main lobby to corridor $9(D C)^{b}$
12

12

27
0.05

0.05

0.11
7

0.03

7

0.03

20

0.08

For notes see table 19. 
Table 3. Smoke control test of VA Bay Pines Hospital, first floor, zone $\mathrm{C}$

\begin{tabular}{|c|c|c|c|c|}
\hline \multirow[b]{2}{*}{ Location } & \multicolumn{2}{|c|}{$\begin{array}{c}\text { Normal Smoke } \\
\text { Control Operation }\end{array}$} & \multicolumn{2}{|c|}{$\begin{array}{c}\text { Increased Smoke } \\
\text { Zone Exhaust }\end{array}$} \\
\hline & $(\mathrm{Pa})$ & $\left(\right.$ in $\left.\mathrm{H}_{2} \mathrm{O}\right)$ & $(\mathrm{Pa})$ & $\left(\right.$ in $\left.\mathrm{H}_{2} \mathrm{O}\right)$ \\
\hline Zone $B$ to Zone $C$ at door D6 & 15 & 0.06 & 42 & 0.17 \\
\hline Zone D to Zone C & 22 & 0.09 & 32 & 0.13 \\
\hline $\begin{array}{l}\text { Corridor } 7 \text { to Dietetic Services } \\
\text { at door D7 }\end{array}$ & 2 & 0.01 & 27 & 0.11 \\
\hline
\end{tabular}

For notes see table 19.

Table 4. Smoke control test of VA Bay Pines Hospital, first floor, zone $\mathrm{E}$

\begin{tabular}{lcccc} 
& & $c$ & Normal Smoke \\
Location & $\frac{\text { Control Operation }}{(\mathrm{Pa})}$ & $\left(\right.$ in $\left.\mathrm{H}_{2} \mathrm{O}\right)$ & \multicolumn{2}{c}{$\begin{array}{c}\text { Increased Smoke } \\
\text { Zone Exhausta }\end{array}$} \\
\hline Zone A to Zone E at corridor 8 & 25 & 0.10 & 40 & 0.16 \\
Zone B to Zone E at corridor 7 & 20 & 0.08 & 20 & 0.08 \\
Corridor 7 to Pharmacy & 7 & 0.03 & 32 & 0.13
\end{tabular}

For notes see table 19.

Table 5. Smoke control test of VA Bay Pines Hospital, first floor, zones $F$ \& $G$

\begin{tabular}{|c|c|c|c|c|}
\hline \multirow[b]{2}{*}{ Location } & \multicolumn{2}{|c|}{$\begin{array}{c}\text { Normal Smoke } \\
\text { Control Operation }\end{array}$} & \multicolumn{2}{|c|}{$\begin{array}{c}\text { Increased Smoke } \\
\text { Zone Exhaust }\end{array}$} \\
\hline & $(\mathrm{Pa})$ & $\left(\right.$ in $\left.\mathrm{H}_{2} \mathrm{O}\right)$ & $(\mathrm{Pa})$ & $\left(\right.$ in $\left.\mathrm{H}_{2} \mathrm{O}\right)$ \\
\hline Zone $\mathrm{H}$ to Zones $\mathrm{F} \& \mathrm{G}$ at door $\mathrm{D9}$ & 25 & 0.10 & 27 & 0.11 \\
\hline Zone A to Zones $F \& G$ at door D4 & 30 & 0.12 & 30 & 0.12 \\
\hline
\end{tabular}

For notes see table 19. 
Table 6. Smoke control test of VA Bay Pines Hospital, first floor, zone $\mathrm{H}$

\begin{tabular}{|c|c|c|c|c|}
\hline \multirow[b]{2}{*}{ Location } & \multicolumn{2}{|c|}{$\begin{array}{c}\text { Normal Smoke } \\
\text { Control Operation }\end{array}$} & \multicolumn{2}{|c|}{$\begin{array}{c}\text { Increased Smoke } \\
\text { Zone Exhaust }\end{array}$} \\
\hline & $(\mathrm{Pa})$ & $\left(\right.$ In $\left.\mathrm{H}_{2} \mathrm{O}\right)$ & $(\mathrm{Pa})$ & $\left(\right.$ In $\left.\mathrm{H}_{2} \mathrm{O}\right)$ \\
\hline Zone $\mathrm{G}$ to Zone $\mathrm{H}$ at door $\mathrm{D} 9$ & 15 & 0.06 & 25 & 0.10 \\
\hline Zone $\mathrm{G}$ to Zone $\mathrm{H}$ at door $\mathrm{D} 10$ & 17 & 0.07 & 20 & 0.08 \\
\hline Zone $\mathrm{A}$ to Zone $\mathrm{H}$ at corridor 1 & 7 & 0.03 & 17 & 0.07 \\
\hline Zone $\mathrm{A}$ to Zone $\mathrm{H}$ at corridor 2 & 17 & 0.07 & 17 & 0.07 \\
\hline Zone $\mathrm{G}$ to corridor 5 & 0 & 0 & 10 & 0.04 \\
\hline Corridor 3 to corridor 5 & 10 & 0.04 & 7 & 0.03 \\
\hline Corridor 4 to corridor 5 & 22 & 0.09 & 10 & 0.04 \\
\hline Corridor 8 to corridor 5 & 0 & 0 & 0 & 0 \\
\hline
\end{tabular}

For notes see table 19.

Table 7. Smoke control test of VA Bay Pines Hospital, first floor, zone J

Normal Smoke Contro1 Operation

Location

Zone $\mathrm{E}$ to Zone $\mathrm{J}$ at corridor 8

Outside to Zone $E$
12

5

Increased Smoke Zone Exhaust ${ }^{\mathrm{a}}$

For notes see table 19. 
Table 8. Smoke control test of VA Bay Pines Hospital, third floor, zone A

Location

Normal Smoke Increased Smoke Control Operation Zone Exhaust ${ }^{\mathrm{a}}$ $(\mathrm{Pa}) \quad\left(\right.$ in $\left.\mathrm{H}_{2} \mathrm{O}\right)$

( $\mathrm{Pa}) \quad\left(\mathrm{In} \mathrm{H}_{2} \mathrm{O}\right)$

Wing $D$ to north lobby (DO)b 12

0.05

20

0.08

Wing $D$ to north lobby $(D C)^{b}$

32

0.13

55

0.22

North elevator shaft to north lobby

0.01

15

0.06

South lobby to north lobby

12

0.05

25

0.10

North lobby to wing A (DO)b

15

0.06

15

0.06

North lobby to wing $A(D C)^{b}$

22

0.09

60

0.24

For notes see table 19.

Table 9. Smoke control test of VA Bay Pines Hospital, third floor, zone $B$

\begin{tabular}{|c|c|c|c|c|}
\hline \multirow[b]{2}{*}{ Location } & \multicolumn{2}{|c|}{$\begin{array}{c}\text { Normal Smoke } \\
\text { Control Operation }\end{array}$} & \multicolumn{2}{|c|}{$\begin{array}{c}\text { Increased Smoke } \\
\text { Zone Exhaust }\end{array}$} \\
\hline & $(\mathrm{Pa})$ & $\left(\right.$ In $\left.\mathrm{H}_{2} \mathrm{O}\right)$ & $(\mathrm{Pa})$ & $\left(\mathrm{In} \mathrm{H}_{2} \mathrm{O}\right)$ \\
\hline Wing $C$ to south lobby (DO) b & 20 & 0.08 & 17 & 0.07 \\
\hline Wing $C$ to south lobby $(D C)^{b}$ & 40 & 0.16 & 62 & 0.25 \\
\hline South elevator shaft to south lobby & 0 & 0 & 5 & 0.02 \\
\hline Stairwe11 2 to south lobby & -2 & -0.01 & 2 & 0.01 \\
\hline North lobby to south lobby & 15 & 0.06 & 20 & 0.08 \\
\hline South lobby to wing $B(D O)^{b}$ & 12 & 0.05 & 12 & 0.05 \\
\hline South lobby to wing $B(D C)^{b}$ & 22 & 0.09 & 42 & 0.17 \\
\hline
\end{tabular}

For notes see table 19. 
Table 10. Smoke control test of VA Bay Pines Hospital, third floor, zone C

\begin{tabular}{|c|c|c|c|c|}
\hline \multirow[b]{2}{*}{ Location } & \multicolumn{2}{|c|}{$\begin{array}{c}\text { Normal Smoke } \\
\text { Control Operation }\end{array}$} & \multicolumn{2}{|c|}{$\begin{array}{c}\text { Increased Smoke } \\
\text { Zone Exhaust }{ }^{a} \\
\end{array}$} \\
\hline & $(\mathrm{Pa})$ & $\left(\right.$ in $\left.\mathrm{H}_{2} \mathrm{O}\right)$ & $(P a)$ & $\left(\right.$ In $\left.\mathrm{H}_{2} \mathrm{O}\right)$ \\
\hline Wing $B$ to south lobby $(\mathrm{DO})^{\mathrm{b}}$ & 12 & 0.05 & 12 & 0.05 \\
\hline Wing $B$ to south lobby $(D C)^{b}$ & 17 & 0.07 & 27 & 0.11 \\
\hline South elevator shaft to south lobby & -10 & -0.04 & -5 & -0.02 \\
\hline Stairwel1 2 to south lobby & -10 & -0.04 & -2 & -0.01 \\
\hline North lobby to south lobby & -5 & -0.02 & -5 & -0.02 \\
\hline South lobby to wing $C(\mathrm{DO})^{\mathrm{b}}$ & 15 & 0.06 & 17 & 0.07 \\
\hline South lobby to wing $C(D C)^{b}$ & 25 & 0.10 & 57 & 0.23 \\
\hline
\end{tabular}

For notes see table 19.

Table 11. Smoke control test of VA Bay Pines Hospital, third floor, zone D

\begin{tabular}{|c|c|c|c|c|}
\hline \multirow[b]{2}{*}{ Location } & \multicolumn{2}{|c|}{$\begin{array}{c}\text { Normal Smoke } \\
\text { Control Operation }\end{array}$} & \multicolumn{2}{|c|}{$\begin{array}{c}\text { Increased Smoke } \\
\text { Zone Exhaust } \\
\end{array}$} \\
\hline & $(\mathrm{Pa})$ & $\left(\right.$ In $\left.\mathrm{H}_{2} \mathrm{O}\right)$ & $(\mathrm{Pa})$ & $\left(\mathrm{In} \mathrm{H}_{2} \mathrm{O}\right)$ \\
\hline Wing $A$ to north lobby $(D 0)^{b}$ & 10 & 0.04 & 22 & 0.09 \\
\hline Wing $A$ to north lobby $(D C)^{b}$ & 17 & 0.07 & 27 & 0.11 \\
\hline North elevator to north lobby & -7 & -0.03 & 0 & 0 \\
\hline South lobby to north lobby & -2 & -0.01 & 0 & 0 \\
\hline North lobby to wing A (DO) ${ }^{b}$ & 22 & 0.09 & 15 & 0.06 \\
\hline North lobby to wing $A(D C)^{b}$ & 22 & 0.09 & 60 & 0.24 \\
\hline
\end{tabular}

For notes see table 19. 
Table 12. Smoke control test of VA Bay Pines Hospital, fourth floor, zone A

\begin{tabular}{|c|c|c|c|c|}
\hline \multirow[b]{2}{*}{ Location } & \multicolumn{2}{|c|}{$\begin{array}{c}\text { Normal Smoke } \\
\text { Control Operation }\end{array}$} & \multicolumn{2}{|c|}{$\begin{array}{c}\text { Increased Smoke } \\
\text { Zone Exhaust }\end{array}$} \\
\hline & $(\mathrm{Pa})$ & (in $\left.\mathrm{H}_{2} \mathrm{O}\right)$ & $(\mathrm{Pa})$ & $\left(\right.$ in $\left.\mathrm{H}_{2} \mathrm{O}\right)$ \\
\hline Wing $D$ to north lobby $(\mathrm{DO})^{\mathrm{b}}$ & 12 & 0.05 & 22 & 0.09 \\
\hline Wing $D$ to north lobby $(D C)^{b}$ & 30 & 0.12 & 50 & 0.20 \\
\hline North elevator shaft to north lobby & 0 & 0 & 10 & 0.04 \\
\hline Stairwe 111 to north lobby & 0 & 0 & 10 & 0.04 \\
\hline South lobby to north lobby & 10 & 0.04 & 25 & 0.10 \\
\hline North lobby to wing $D(D O)^{b}$ & 10 & 0.04 & 10 & 0.04 \\
\hline North lobby to wing $D(D C)^{b}$ & 15 & 0.06 & 45 & 0.18 \\
\hline
\end{tabular}

For notes see table 19.

Table 13. Smoke control test of VA Bay Pines Hospital, fourth floor, zone B

Increased Smoke

Increased Exhaust Zone Exhaust ${ }^{a}$ with without Pressurization

Normal Smoke Pressurization of Floors Control Opertion Above and Below

Location $(\mathrm{Pa}) \quad\left(\right.$ in $\left.\mathrm{H}_{2} \mathrm{O}\right)$ $(\mathrm{Pa})$ (in $\mathrm{H}_{2} \mathrm{O}$ ) Above and Below $\mathrm{c}$

\begin{tabular}{|c|c|c|c|c|c|c|}
\hline Wing $C$ to south lobby (DO $)^{b}$ & 15 & 0.06 & 15 & 0.06 & 15 & 0.06 \\
\hline Wing $C$ to south lobby $(D C)^{b}$ & 47 & 0.19 & 62 & 0.25 & 60 & 0.24 \\
\hline $\begin{array}{l}\text { South elevator shaft to } \\
\text { south lobby }\end{array}$ & 0 & 0 & 7 & 0.03 & 7 & 0.03 \\
\hline North lobby to south lobby & 12 & 0.05 & 17 & 0.07 & 25 & 0.10 \\
\hline South lobby to wing $B(D O)^{b}$ & - & -- & 22 & 0.09 & 17 & 0.07 \\
\hline South lobby to wing $B(D C)^{b}$ & $15^{d}$ & $0.06^{d}$ & 45 & 0.18 & 47 & 0.19 \\
\hline
\end{tabular}

For notes see table 19. 
Table 14. Smoke control test of VA Bay Pines Hospital, fourth floor, zone $C$

\begin{tabular}{lcccc} 
Locat1on & $\begin{array}{c}\text { Normal Smoke } \\
\text { Contro1 Operation }\end{array}$ & $\begin{array}{c}\text { Increased Smoke } \\
\text { Zone Exhaust }\end{array}$ \\
\hline Wing B to south lobby (DO)b & 15 & 0.06 & 20 & 0.08 \\
Wing B to south lobby (DC) & 30 & 0.12 & 30 & 0.12 \\
South elevator shaft to south lobby & -10 & -0.04 & -2 & -0.01 \\
North lobby to south lobby & -15 & -0.06 & -7 & -0.03 \\
South lobby to wing C (DO) & 10 & 0.04 & 30 & 0.12 \\
South lobby to wing C (DC) & 37 & 0.15 & 70 & 0.28 \\
\hline
\end{tabular}

For notes see table 19.

Table 15. Smoke control test of VA Bay Pines Hospital, fourth floor, zone $D$

\begin{tabular}{|c|c|c|c|c|}
\hline \multirow[b]{2}{*}{ Location } & \multicolumn{2}{|c|}{$\begin{array}{c}\text { Normal Smoke } \\
\text { Control Operation } \\
\end{array}$} & \multicolumn{2}{|c|}{$\begin{array}{c}\text { Increased Smoke } \\
\text { Zone Exhaust }\end{array}$} \\
\hline & $(\mathrm{Pa})$ & $\left(\right.$ in $\left.\mathrm{H}_{2} \mathrm{O}\right)$ & $(\mathrm{Pa})$ & $\left(\right.$ in $\left.\mathrm{H}_{2} \mathrm{O}\right)$ \\
\hline Wing $A$ to north lobby (DO)b & 15 & 0.06 & 17 & 0.07 \\
\hline Wing $A$ to north lobby $(D C)^{b}$ & 20 & 0.08 & 30 & 0.12 \\
\hline North elevator shaft to north lobby & -7 & -0.03 & 0 & 0 \\
\hline Stairwe11 1 to north lobby & -7 & -0.03 & 0 & 0 \\
\hline South lobby to north lobby & 0 & 0 & 0 & 0 \\
\hline North lobby to wing $D(D O)^{b}$ & 20 & 0.08 & 22 & 0.09 \\
\hline North lobby to wing $D(D C)^{b}$ & 27 & 0.11 & 65 & 0.26 \\
\hline
\end{tabular}

For notes see table 19. 
Table 16. Smoke control test of VA Bay Pines Hospital, fifth floor, zone A

\begin{tabular}{|c|c|c|c|c|}
\hline \multirow[b]{2}{*}{ Location } & \multicolumn{2}{|c|}{$\begin{array}{c}\text { Normal Smoke } \\
\text { Control Operation } \\
\end{array}$} & \multicolumn{2}{|c|}{$\begin{array}{c}\text { Increased Smoke } \\
\text { Zone Exhaust }{ }^{a} \\
\end{array}$} \\
\hline & $(\mathrm{Pa})$ & $\left(\right.$ in $\left.\mathrm{H}_{2} \mathrm{O}\right)$ & $(\mathrm{Pa})$ & $\left(\right.$ in $\left.\mathrm{H}_{2} \mathrm{O}\right)$ \\
\hline Wing $D$ to north lobby $(\mathrm{DO})^{\mathrm{b}}$ & 25 & 0.10 & 25 & 0.10 \\
\hline Wing $D$ to north lobby $(D C)^{b}$ & 32 & 0.13 & 50 & 0.20 \\
\hline North elevator shaft to north lobby & 2 & 0.01 & 5 & 0.02 \\
\hline Stairwell 1 to north lobby & 0 & 0 & 7 & 0.03 \\
\hline South lobby to north lobby & 12 & 0.05 & 17 & 0.07 \\
\hline North lobby to wing A (DO) ${ }^{b}$ & 12 & 0.05 & 7 & 0.03 \\
\hline North lobby to wing $A(D C)^{b}$ & 15 & 0.06 & 40 & 0.16 \\
\hline
\end{tabular}

For notes see table 19.

Table 17. Smoke control test of VA Bay Pines Hospital, fifth floor, zone B

Location

Normal Smoke $\frac{\text { Control Operation }}{(\mathrm{Pa})\left(\text { in } \mathrm{H}_{2} \mathrm{O}\right)}$

Increased Smoke

Zone Exhaust ${ }^{\mathrm{a}}$

Location

Wing $C$ to south lobby (DO) ${ }^{b}$

17

0.07

17

0.07

Wing $c$ to south lobby $(D C)^{b}$

27

0.11

47

0.19

South elevator shaft to south lobby

0.01

7

0.03

Stairwe11 2 to south lobby

2

0.01

0

0

North lobby to south lobby

22

0.09

40

0.16

South lobby to wing $B(D O)^{b}$

20

0.08

20

0.08

South lobby to wing $B(D C)^{b}$

25

0.10

57

0.23

For notes see table 19. 
Table 18. Smoke control test of VA Bay Pines Hospital, fifth floor, zone $C$

\begin{tabular}{|c|c|c|c|c|}
\hline \multirow[b]{2}{*}{ Location } & \multicolumn{2}{|c|}{$\begin{array}{c}\text { Normal Smoke } \\
\text { Control Operation }\end{array}$} & \multicolumn{2}{|c|}{$\begin{array}{c}\text { Increased Smoke } \\
\text { Zone Exhaust }{ }^{a} \\
\end{array}$} \\
\hline & $(\mathrm{Pa})$ & $\left(\right.$ In $\left.\mathrm{H}_{2} \mathrm{O}\right)$ & $(\mathrm{Pa})$ & $\left(\right.$ In $\left.\mathrm{H}_{2} \mathrm{O}\right)$ \\
\hline Wing $B$ to south lobby & 20 & 0.08 & 22 & 0.09 \\
\hline South elevator shaft to south lobby & -7 & -0.03 & 0 & 0 \\
\hline Stairwell to south lobby & 2 & 0.01 & 50 & 0.20 \\
\hline North lobby to south lobby & -5 & -0.02 & 0 & 0 \\
\hline South lobby to wing $C(D O)^{b}$ & 20 & 0.08 & 15 & 0.06 \\
\hline South lobby to wing $C(D C)^{b}$ & 22 & 0.09 & 75 & 0.30 \\
\hline
\end{tabular}

For notes see table 19. 
Table 19. Smoke control test of VA Bay Pines Hospital, fifth floor, zone D

\begin{tabular}{|c|c|c|c|c|}
\hline \multirow[b]{2}{*}{ Location } & \multicolumn{2}{|c|}{$\begin{array}{c}\text { Normal Smoke } \\
\text { Control Operation }\end{array}$} & \multicolumn{2}{|c|}{$\begin{array}{c}\text { Increased Smoke } \\
\text { Zone Exhaust } \\
\end{array}$} \\
\hline & $(\mathrm{Pa})$ & $\left(\right.$ in $\left.\mathrm{H}_{2} \mathrm{O}\right)$ & $(\mathrm{Pa})$ & $\left(\right.$ in $\left.\mathrm{H}_{2} \mathrm{O}\right)$ \\
\hline Wing $A$ to north lobby $(D O)^{b}$ & 25 & 0.10 & 25 & 0.10 \\
\hline Wing $A$ to north lobby (DC $)^{b}$ & 30 & 0.12 & 45 & 0.18 \\
\hline South elevator to north lobby & -17 & -0.07 & -7 & -0.03 \\
\hline Stairwe 111 to north lobby & -15 & -0.06 & 2 & 0.01 \\
\hline South lobby to north lobby & -27 & -0.11 & -12 & -0.05 \\
\hline North lobby to wing $\mathrm{D}(\mathrm{DO})^{\mathrm{b}}$ & 17 & 0.07 & 27 & 0.11 \\
\hline North lobby to wing $D(D C)^{b}$ & 27 & 0.11 & 57 & 0.23 \\
\hline
\end{tabular}

Notes:

a. Exhaust air 1ncreased from the smoke zone by blocking an exhaust inlet located inside the interstitial space.

b. Frequently, the airflow was sufficient to hold doors open a few inches. Pressure difference measurements made under this condition are denoted (DO). Additional measurements were made where the doors were held closed $(\mathrm{DC})$.

c. Operation of smoke control system was without pressurization of zones on floors above and below and with increased smoke zone exhaust due to blocking of interstitial space exhaust.

d. Insufficient airflow to hold door open. 
Table 20. Smoke control test of Loma Linda VA Hospital, first floor, zone 1

Normal Smoke Control Operat1on

Location
$(\mathrm{Pa})$ $\left(\right.$ In $\left.\mathrm{H}_{2} \mathrm{O}\right)$

Zone 2 to Zone 1 at door 2 22 .09

30 .12

Table 21. Smoke control test of Loma Linda VA Hospital, first floor, zone 3

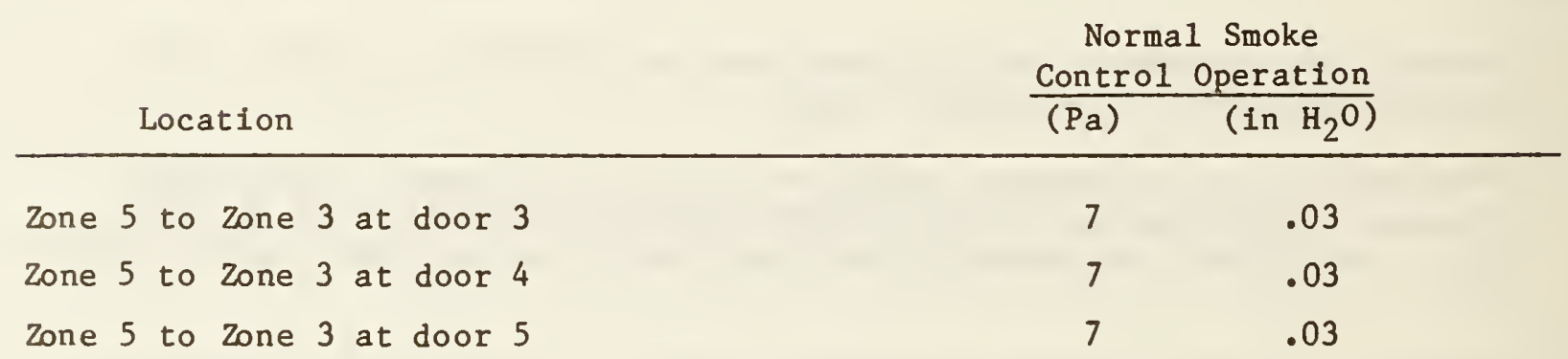

Table 22. Smoke control test of Loma Linda VA Hospital, first floor, zone 5

\begin{tabular}{ccc} 
Location & $\begin{array}{c}\text { Normal Smoke } \\
\text { Control Operation }\end{array}$ \\
\hline Zone 3 to Zone 5 at door 6 & 12 & .05 \\
Zone 7 to Zone 5 at door 7 & 15 & .06 \\
Zone 7 to Zone 5 at door 8 & 12 & .05
\end{tabular}


Table 23. Smoke control test of Loma Linda VA Hospital, second floor, zone 1

\begin{tabular}{|c|c|c|c|c|}
\hline \multirow[b]{2}{*}{ Location } & \multicolumn{2}{|c|}{$\begin{array}{c}\text { Normal Smoke } \\
\text { Control Operation } \\
\end{array}$} & \multicolumn{2}{|c|}{$\begin{array}{l}\text { Smoke Operation } \\
\text { with Pressurization } \\
\text { of Adjacent Zones }\end{array}$} \\
\hline & $(\mathrm{Pa})$ & $\left(\right.$ in $\left.\mathrm{H}_{2} \mathrm{O}\right)$ & $(\mathrm{Pa})$ & $\left(\right.$ in $\left.\mathrm{H}_{2} \mathrm{O}\right)$ \\
\hline Zone 2 to Zone 1 at door 1 & 37 & .15 & 42 & .17 \\
\hline Zone 2 to Zone 1 at door 2 (DO) ${ }^{b}$ & 17 & .07 & 20 & .08 \\
\hline Zone 2 to Zone 1 at door $2(D C)^{b}$ & 40 & .16 & 40 & .16 \\
\hline Zone 3 to Zone 1 at door $3(\mathrm{DO})^{\mathrm{b}}$ & 20 & .08 & 17 & .07 \\
\hline Zone 3 to Zone 1 at door $3(D C)^{b}$ & 37 & .15 & 52 & .21 \\
\hline Zone 4 to Zone 1 at door 4 & 7 & .03 & 7 & .03 \\
\hline
\end{tabular}

Table 24. Smoke control test of Loma Linda VA Hospital second floor, zone 2

Norma1 Smoke

Location

Contro1 Operation

Zone 1 to Zone 2 at door 1

$50 \quad .20$

Zone 1 to Zone 2 at door 2

$52 \quad .21$

Zone 4 to Zone 2 at door 5

25

.10

Zone 4 to Zone 2 at door 6

35

.14 
Table 25. Smoke control test of Loma Linda VA Hospital, second floor, zone 4

Location $\quad \begin{gathered}\text { Normal Smoke } \\ \text { Control Operat1on }\end{gathered}$

Zone 1 to Zone 4 at door 4

$30 \quad .12$

Zone 3 to Zone 4 at door 7

$25 \quad .10$

Zone 3 to Zone 4 at door 8

$22 \quad .09$

Zone 6 to Zone 4 at door 9

$15 \quad .06$

Zone 6 to Zone 4 at door 10

25

.10

Zone 6 to Zone 4 at door 11

17

.07

Table 26. Smoke control test of Loma Linda VA Hospital, second floor, zone 6

\begin{tabular}{llll} 
Location & \multicolumn{1}{c}{$\begin{array}{c}\text { Normal Smoke } \\
\text { Control Operation }\end{array}$} \\
\hline Zone 4 to Zone 6 at door 9 & 5 & .02 \\
Zone 4 to Zone 6 at door 10 & 22 & .09 \\
Zone 4 to Zone 6 at door 11 & 45 & .18 \\
Zone 5 to Zone 6 at door 12 & 20 & .08 \\
Zone 7 to Zone 6 at door 13 & 22 & .09 \\
Zone 8 to Zone 6 at door 14 & 22 & .09 \\
Zone 8 to Zone 6 at door 15 & 12 & .05
\end{tabular}


Table 27. Smoke control test of Loma Linda VA Hospital, second floor, zone 7

Normal Smoke

Location

Control Operation

$(\mathrm{Pa}) \quad\left(\right.$ in $\left.\mathrm{H}_{2} \mathrm{O}\right)$

Zone 5 to Zone 7 at door $16(D C)^{b}$

$<62<.25$

Zone 8 to Zone 7 at door $17(D C)^{\text {b }}$

$<62<.25$

For notes see table 19.

Table 28. Smoke control test of Loma Linda VA Hospital, second floor, zone 8

Normal Smoke

Location

Control Operation

$(\mathrm{Pa})\left(\right.$ in $\left.\mathrm{H}_{2} \mathrm{O}\right)$

$\begin{array}{ll}\text { Zone } 6 \text { to Zone } 8 \text { at door } 14 \\ \text { Zone } 6 \text { to Zone } 8 \text { at door } 15 \\ \text { Zone } 7 \text { to Zone } 8 \text { at door } 17(D C)^{\text {b }} & .25 \\ \text { Zone } 7 \text { to Zone } 8 \text { at door } 18 & .25\end{array}$

For notes see table 19.

Table 29. Smoke control test of Loma Linda VA Hospital, third floor, zone 1

Normal Smoke Control Operation

Location (Pa) (In $\left.\mathrm{H}_{2} \mathrm{O}\right)$

Zone 2 to Zone 1 at door 1 (DC) b

$<62$

$<.25$

Zone 3 to Zone 1 at door 1 (DC) $)^{b}$

62

.25

For notes see table 19. 
Table 30. Smoke control test of Loma Linda VA Hospital, third floor, zone 2

\begin{tabular}{|c|c|c|}
\hline Location & \multicolumn{2}{|c|}{$\begin{array}{c}\text { Normal Smoke } \\
\text { Control Operation }\end{array}$} \\
\hline Zone 1 to Zone 2 at door 1 & 50 & .20 \\
\hline Zone 1 to Zone 2 at door 3 & 40 & .16 \\
\hline Zone 1 to Zone 2 at door 4 & 42 & .17 \\
\hline Zone 3 to Zone 2 at door $5(D C)^{b}$ & 62 & .25 \\
\hline Zone 3 to Zone 2 at door 6 (DC) b & $<62$ & $<.25$ \\
\hline
\end{tabular}

For notes see table 19.

Table 31. Smoke control test of Loma Linda VA Hospital, third floor, zone 3

$\begin{array}{llll}\text { Location } & \begin{array}{c}\text { Normal Smoke } \\ \text { Control Operation } \\ \text { (Pa) }\end{array} & 15 & .06 \\ \text { Zone } 1 \text { to Zone } 3 \text { at door } 2 & 15 & .06 \\ \text { Zone } 4 \text { to Zone } 3 \text { at door } 7 & 22 & .09 \\ \text { Zone } 4 \text { to Zone } 3 \text { at door } 8 & 15 & .06 \\ \text { Zone } 5 \text { to Zone } 3 \text { at door } 9 & 15 & .06 \\ \text { Zone } 5 \text { to Zone } 3 \text { at door } 10 & 15 & .06 \\ \text { Zone } 5 \text { to Zone } 3 \text { at door } 11 & 15 & .06 \\ \text { Zone } 5 \text { to Zone } 3 \text { at door } 12 & 22 & .09 \\ \text { Zone } 5 \text { to Zone } 3 \text { at door } 13 & \end{array}$


Table 32. Smoke control test of Loma Linda VA Hospita1, third floor, zone 4

Norma1 Smoke

Location

$\frac{\text { Contro1 Operation }}{(\mathrm{Pa}) \quad\left(\text { in } \mathrm{H}_{2} \mathrm{O}\right)}$

Zone 1 to Zone 4 at door 13
Zone 2 to Zone 4 at door 5
Zone 2 to Zone 4 at door 6
Zone 3 to Zone 4 at door 7
Zone 3 to Zone 4 at door 8
Zone 6 to Zone 4 at door 14
Zone 6 to Zone 4 at door 15
Zone 6 to Zone 4 at door 16
Zone 6 to Zone 4 at door 17
Zone 6 to Zone 4 at door 18

22

.09

17

.07

22

.09

20

.08

$20 \quad .08$

$22 \quad .09$

$27 \quad .11$

$25 \quad .10$

$17 \quad .07$

15.06

Table 33. Smoke control test of Loma Linda VA Hospital, third floor, zone 5

Location

Zone 3 to Zone 5 at door 9
Zone 3 to Zone 5 at door 10
Zone 3 to Zone 5 at door 11
Zone 3 to Zone 5 at door 12
Zone 3 to Zone 5 at door 13
Zone 6 to Zone 5 at door 19
Zone 7 to Zone 5 at door 20
Normal Smoke

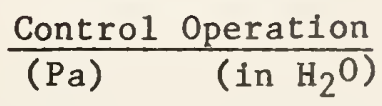


Table 34. Smoke control test of Loma Linda VA Hospital, third floor, zone 6

\begin{tabular}{llll} 
Location & $\begin{array}{c}\text { Normal Smoke } \\
\text { Control Operat 1on } \\
(\mathrm{Pa})\end{array}$ & 20 & .08 \\
\hline Zone 4 to Zone 6 at door 14 & 37 & .15 \\
Zone 4 to Zone 6 at door 15 & 37 & .15 \\
Zone 4 to Zone 6 at door 16 & 17 & .07 \\
Zone 4 to Zone 6 at door 17 & 7 & .03 \\
Zone 4 to Zone 6 at door 18 & 17 & .07 \\
Zone 5 to Zone 6 at door 19 & 17 & .07 \\
Zone 7 to Zone 6 at door 21 & 17 & .07 \\
Zone 8 to Zone 6 at door 22 & 17 & .07 \\
Zone 8 to Zone 6 at door 23 &
\end{tabular}

Table 35. Smoke control test of Loma Linda VA Hospital, third floor, zone 7

\begin{tabular}{llcc} 
Location & $\begin{array}{c}\text { Normal Smoke } \\
\text { Control Operation } \\
(\mathrm{Pa})\end{array}$ \\
\hline Zone 5 to Zone 7 at door 20 & 35 & .14 \\
Zone 6 to Zone 7 at door 21 & 7 & .03 \\
Zone 8 to Zone 7 at door 24 & 7 & .03 \\
Zone 8 to Zone 7 at door 25 & 32 & .13 \\
Zone 8 to Zone 7 at door 26 & 35 & .14
\end{tabular}


Table 36. Smoke control test of Loma Linda VA Hospital, third floor, zone 8

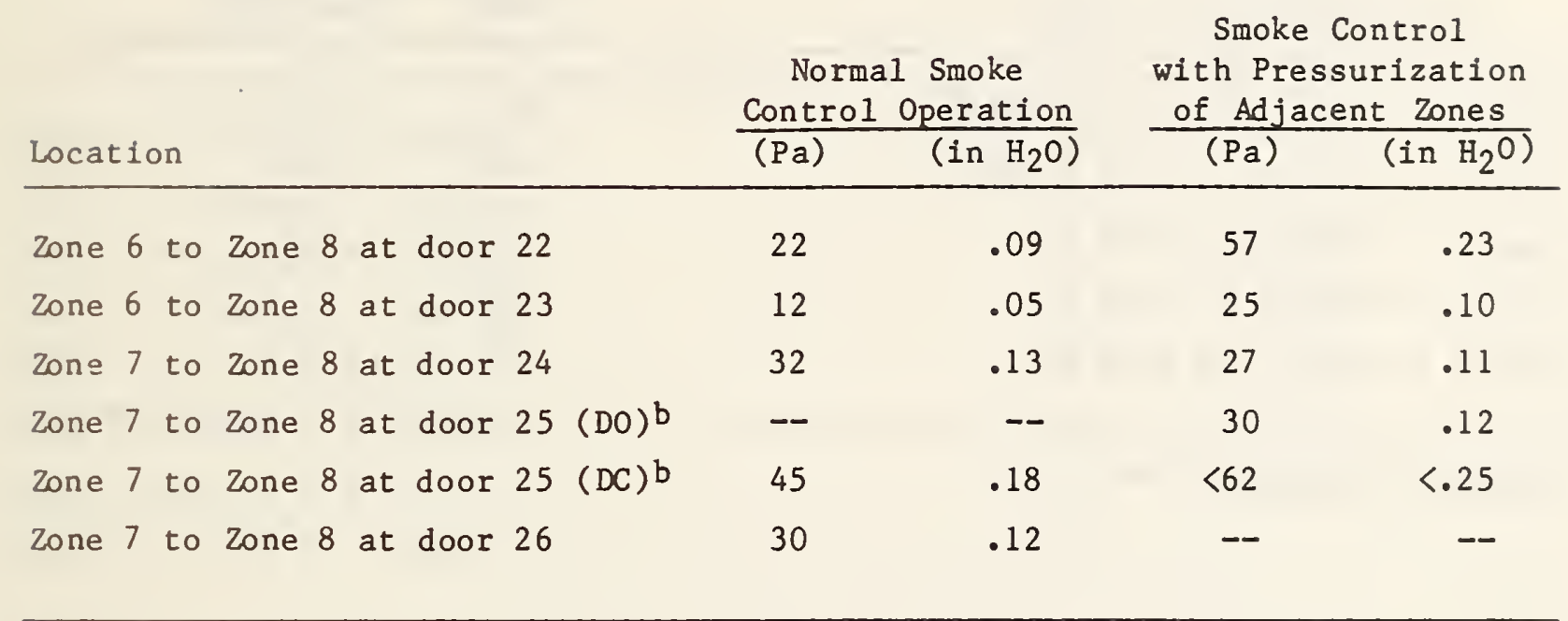

For notes see table 19.

Table 37. Smoke control test of Loma Linda VA Hospital, fourth floor, zone 1

Normal Smoke

Location $\frac{\text { Control Operation }}{(\mathrm{Pa})}$

Zone 2 to Zone 1 at door 1 47

.19

Zone 2 to Zone 1 at door 2

60

.24

Zone 3 to Zone 1 at door 3

62

.25 
Table 38. Smoke control test of Loma Linda VA Hospital, fourth floor, zone 2

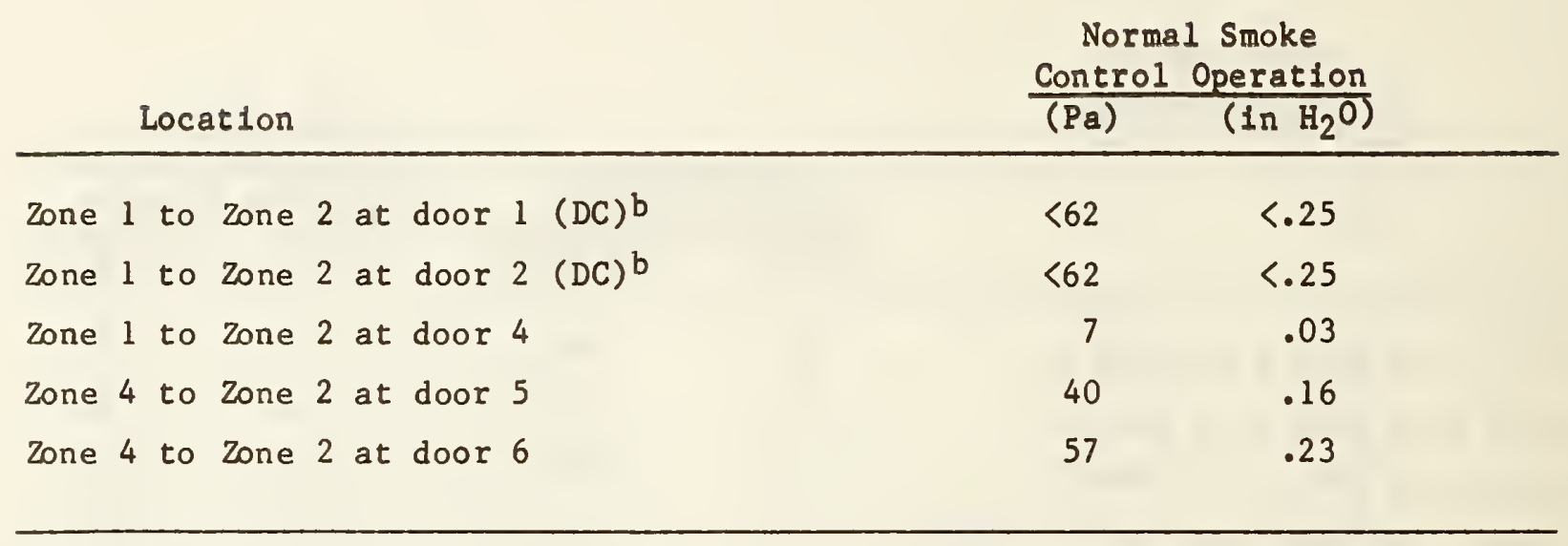

For notes see table 19.

Table 39. Smoke control test of Loma Linda VA Hospital, fourth floor, zone 4

Normal Smoke

Location $\frac{\text { Control Operation }}{(\mathrm{Pa})}$

Zone 1 to Zone 4 at door 7
Zone 2 to Zone 4 at door 5
Zone 2 to Zone 4 at door 6
Zone 3 to Zone 4 at door 8
Zone 6 to Zone 4 at door 9
Zone 6 to Zone 4 at door 10
Zone 6 to Zone 4 at door 11

40

.16

40

.16 
Table 40. Smoke control test of Loma Linda VA Hospital, fourth floor, zone 6

Normal Smoke

Control Operation

Location

$(\mathrm{Pa})$ (in $\mathrm{H}_{2} \mathrm{O}$ )

Zone 4 to Zone 6 at door 9

$25 \quad .10$

Zone 4 to Zone 6 at door 10

25

.10

Zone 4 to Zone 6 at door 11

30

.12

Zone 5 to Zone 6 at door 12

25

.10

Zone 5 to Zone 6 at door 13

27

.11

Zone 8 to Zone 6 at door 14

25

.10

Zone 8 to Zone 6 at door 15

27

.11

Zone 8 to Zone 6 at door 16

25

.10

Table 41. Smoke control test of Loma Linda Va Hospital, fourth floor, zone 7

Norma1 Smoke

Location

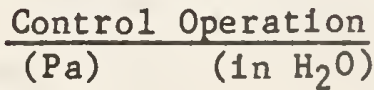

Zone 5 to Zone 7 at door 17

$45 \quad \cdot 18$

Zone 8 to Zone 7 at door 18

$52 \quad .21$




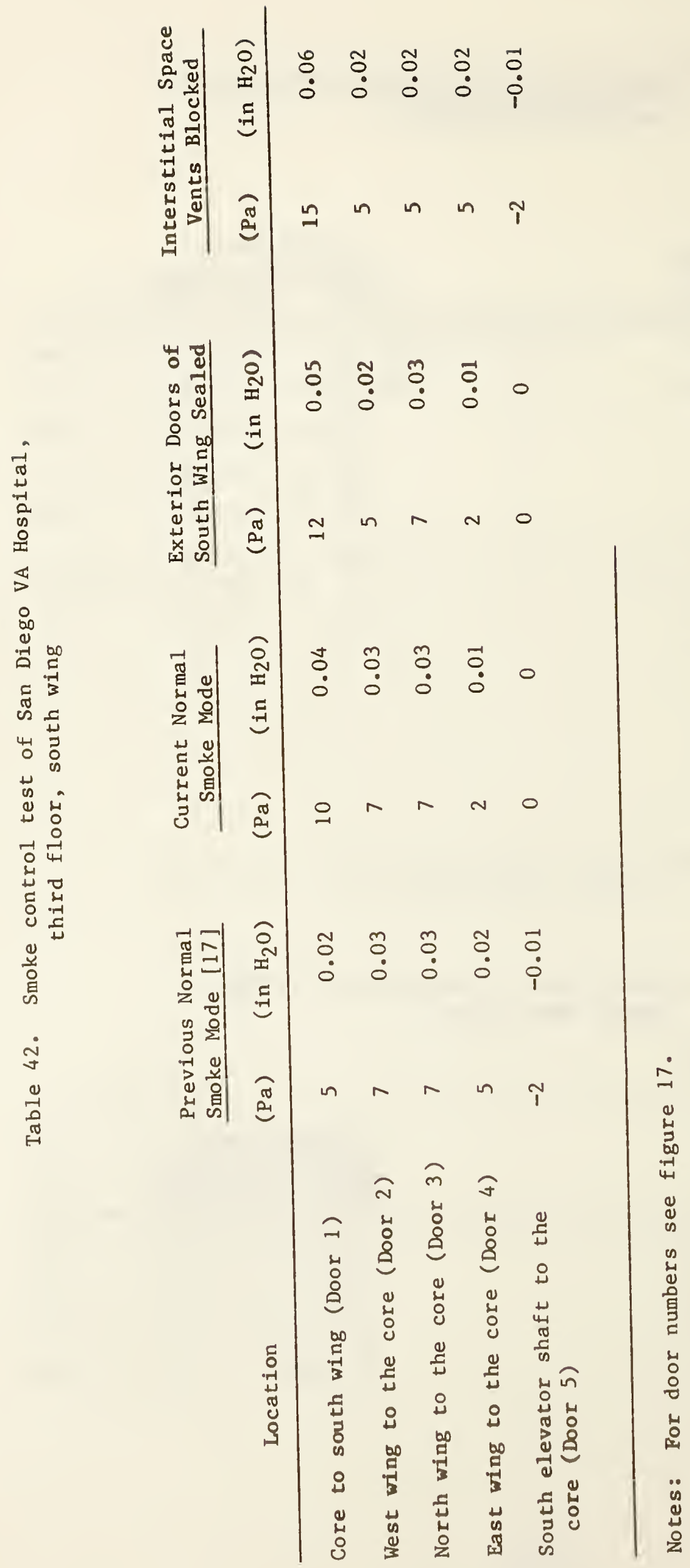


Table 43. Smoke control tests of the San Diego VA Hospital, third floor, core area

\begin{tabular}{lcccc} 
& \multicolumn{2}{c}{$\begin{array}{c}\text { Normal Smoke } \\
\text { Location }\end{array}$} & $\begin{array}{c}\text { Three Open } \\
\text { Core Windows }\end{array}$ & \multicolumn{2}{c}{$\begin{array}{c}\text { Core } \\
\text { South wing to the core (Door 1) }\end{array}$} & 5 & 0.02 & 12 & 0.05 \\
Sest wing to the core (Door 2) & 7 & 0.03 & 20 & 0.08 \\
North wing to the core (Door 3) & 7 & 0.03 & 12 & 0.05 \\
East wing to the core (Door 4) & 7 & 0.03 & 12 & 0.05 \\
South elevator (Door 5) & 0 & 0 & 7 & 0.03
\end{tabular}

Table 44. Smoke control test of Martinsburg VA Hospital, sixth floor, zone 2

Location

Zone 1 to Zone 2

Zone 3 to Zone 2

Zone 4 to Zone 2

Stairwe 11 to Zone 2 $\frac{\text { Pressure Difference }}{(\mathrm{Pa})}$

$\begin{array}{rl}1.2 & .005 \\ 5 & .02 \\ 1.2 & .005 \\ 2.5 & .01\end{array}$


Table 45. Smoke control test of Richmond VA Hospital, fourth floor

\begin{tabular}{|c|c|c|c|c|c|}
\hline \multirow{2}{*}{$\begin{array}{c}\text { Zone in } \\
\text { Smoke Mode }\end{array}$} & \multirow[b]{2}{*}{ Location } & \multirow{2}{*}{\multicolumn{2}{|c|}{$\begin{array}{l}\text { First Test with } \\
\text { Smoke Control } \\
(\mathrm{Pa})\left(\mathrm{in} \mathrm{H}_{2} \mathrm{O}\right)\end{array}$}} & \multicolumn{2}{|c|}{$\begin{array}{l}\text { Smoke Control } \\
\text { after System } \\
\text { Adjustment }\end{array}$} \\
\hline & & & & $(\mathrm{Pa})$ & $\left(\mathrm{In} \mathrm{H}_{2} \mathrm{O}\right)$ \\
\hline 1 & Zone 2 to Zone 1 & - & -- & 7 & .03 \\
\hline \multirow[t]{2}{*}{2} & Zone 1 to Zone 2 & $-\infty$ & - & 2 & .01 \\
\hline & Zone 3 to Zone 2 & $-\infty$ & - & 4 & .015 \\
\hline \multirow[t]{2}{*}{3} & Zone 2 to Zone 3 & $-\infty$ & - & 5 & .02 \\
\hline & Zone 4 to Zone 3 & -- & $-\infty$ & 2 & .01 \\
\hline \multirow[t]{2}{*}{4} & Zone 3 to Zone 4 & 4 & .015 & 5 & .02 \\
\hline & Zone 5 to Zone 4 & 2 & .01 & 4 & .015 \\
\hline \multirow[t]{2}{*}{5} & Zone 4 to Zone 5 & 2 & .01 & 5 & .02 \\
\hline & Zone 6 to Zone 5 & -2 & -.01 & 5 & .02 \\
\hline 6 & Zone 5 to Zone 6 & 7 & .03 & 7 & .03 \\
\hline
\end{tabular}


BIBLIOGRAPHIC DATA

SHEET (see instructions) 1. PUBLICATION OR
REPORT NO.

NBSIR 85-3297
2. Performing Organ. Report Nod 3. Publication Date

Jamuary 1986

4. TITLE AND SUBTITLE

Smoke Control at Veterans Administration Hospitals

5. AUTHOR(S)

John H. Klote

6. PERFORMING ORGANIZATION (If joint or other than NBS, see instructions)

7. Contract/Grant No.

NATIONAL BUREAU OF STANDARDS

DEPARTMENT OF COMMERCE

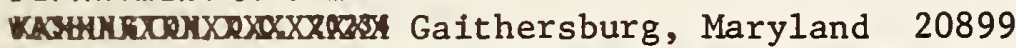

9. SPONSORING ORGANIZATION NAME AND COMPLETE ADDRESS (Street, CIty, StOte, ZIF)

8. Type of Report \& Period Covered

10. SUPPLEMENTARY NOTES

Document describes a computer program; SF-185, FIPS Software Summary, is attached.

11. ABSTRACT (A 200-word or less foctual summory of most significont information. If document includes a significant bibliography or literoture survey. mention it here)

The Veterans Administration (VA) has sponsored a project at the Center for Fire Research of the National Bureau of Standards to study smoke control in VA hospitals and evaluate design system approaches and methods of acceptance testing. This report presents general background information that is believed to be of interest to those tasked with design, construction and acceptance testing of smoke control systems. The performance requirements of smoke control systems for VA hospitals are discussed. The results of field tests at five VA hospitals is presented and discussed. Based on the information gained from the field tests and the background information, different approaches to smoke control at VA hospitals and methods of acceptance testing are evaluated. General recommendations concerning smoke control at VA hospitals are made.

12. KEY WORDS (Six to twelve entries; alphabetical order: copitallze only proper names; and seporate key words by semicolons) acceptability; acceptance tests; air movement; doors; field tests; hosp1tals; pressurization; smoke control

13. AVAILABILITY

Unlimited

For Official Distribution. Do Not Release to NTIS

Order From Superintendent of Documents, U.S. Government Printing Office, Washington, D.C. 20402.

14. NO. OF

PRINTED PAGES

108

15. Price

[X] Order From National Technical Information Service (NTIS), Springfield, VA. 2216I

$\$ 16.95$ 





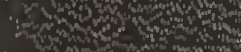

A

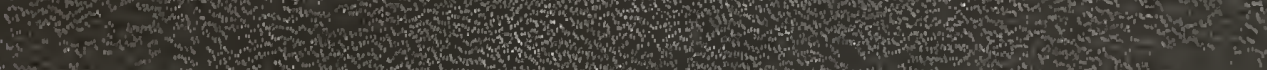

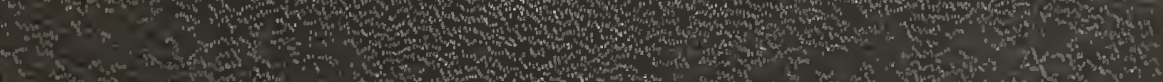

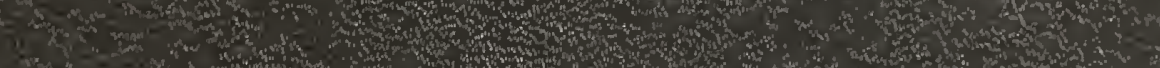

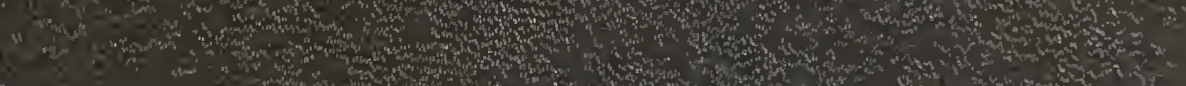

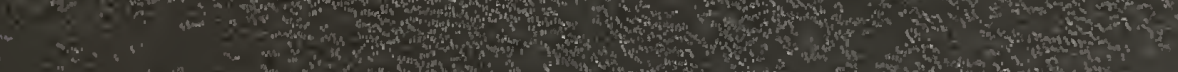

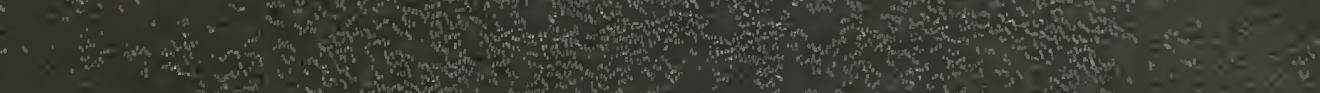

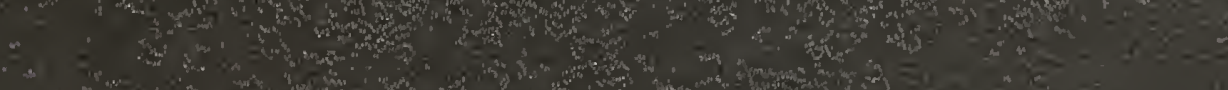

"we
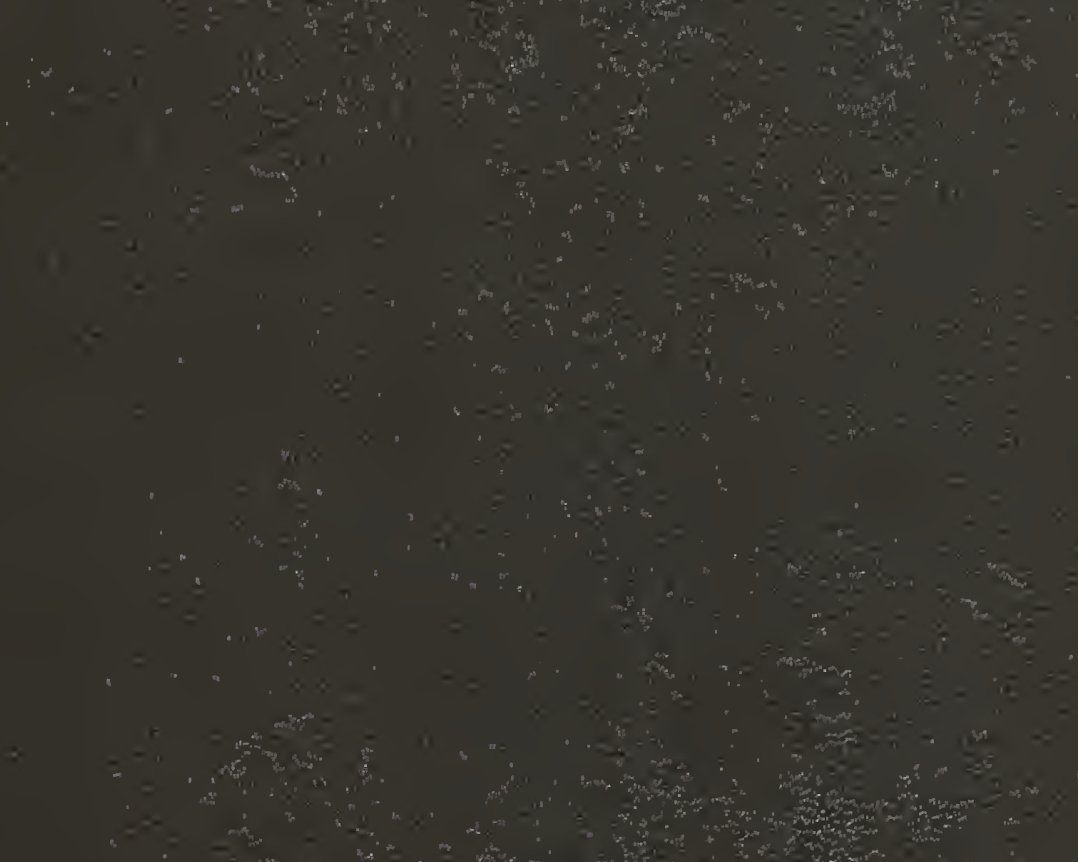

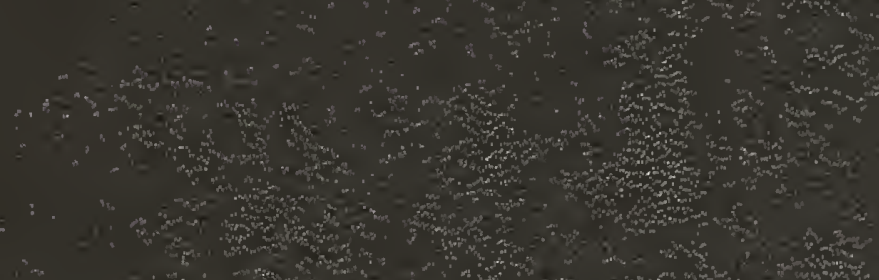

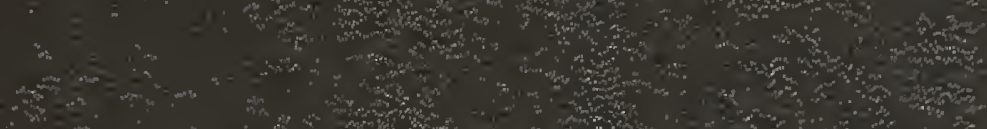
$\therefore$ (

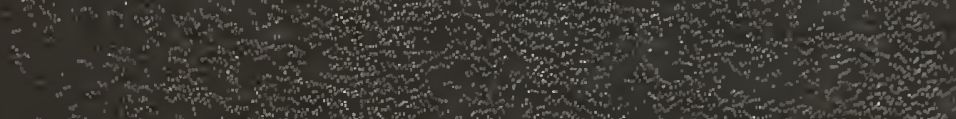

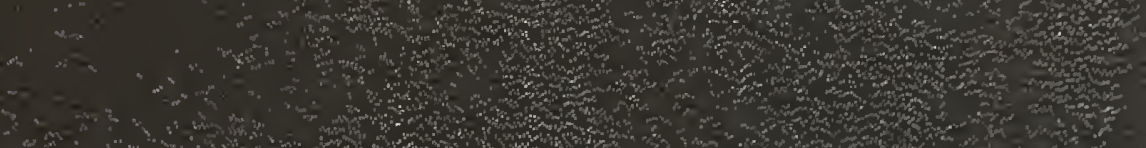

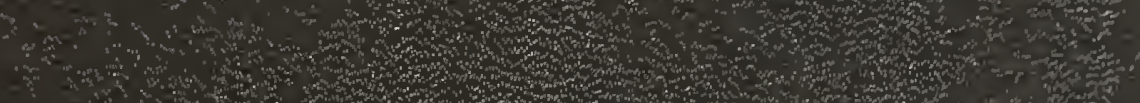
(1) $\therefore$ (1)

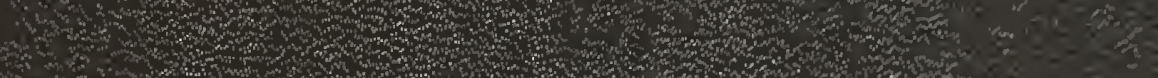

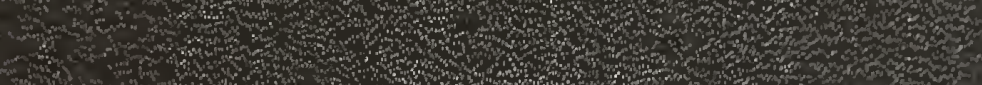
(1)

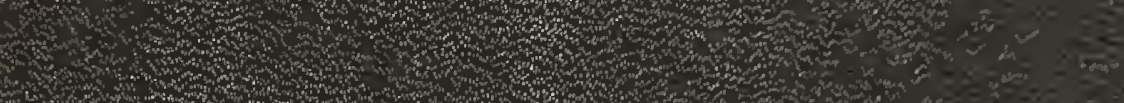

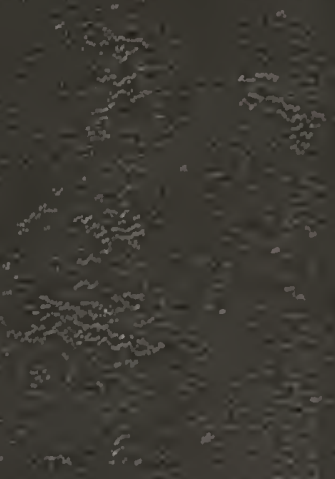

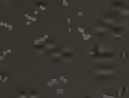

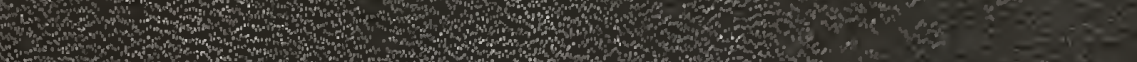


